UNIVERSIDADE DE SÃO PAULO

INSTITUTO DE GEOCIÊNCIAS

\title{
OTIMIZAÇÃO DO INFILL PARA REDUÇÃO DAS INCERTEZAS EM UM DEPÓSITO SINTÉTICO DE COBRE
}

\author{
Gustavo Zanco Ramos
}

Orientador: Prof. Dr. Marcelo Monteiro da Rocha

DISSERTAÇÃO DE MESTRADO

Programa de Pós-Graduação em Geociências: Recursos Minerais e Hidrogeologia

Versão Corrigida

SÃO PAULO

2016 
Autorizo a reprodução e divulgação total ou parcial deste trabalho, por qualquer meio convencional ou eletrônico, para fins de estudo e pesquisa, desde que citada a fonte.

\footnotetext{
Ficha catalográfica preparada pelo Serviço de Biblioteca e Documentação do Instituto de Geociências da Universidade de São Paulo
}

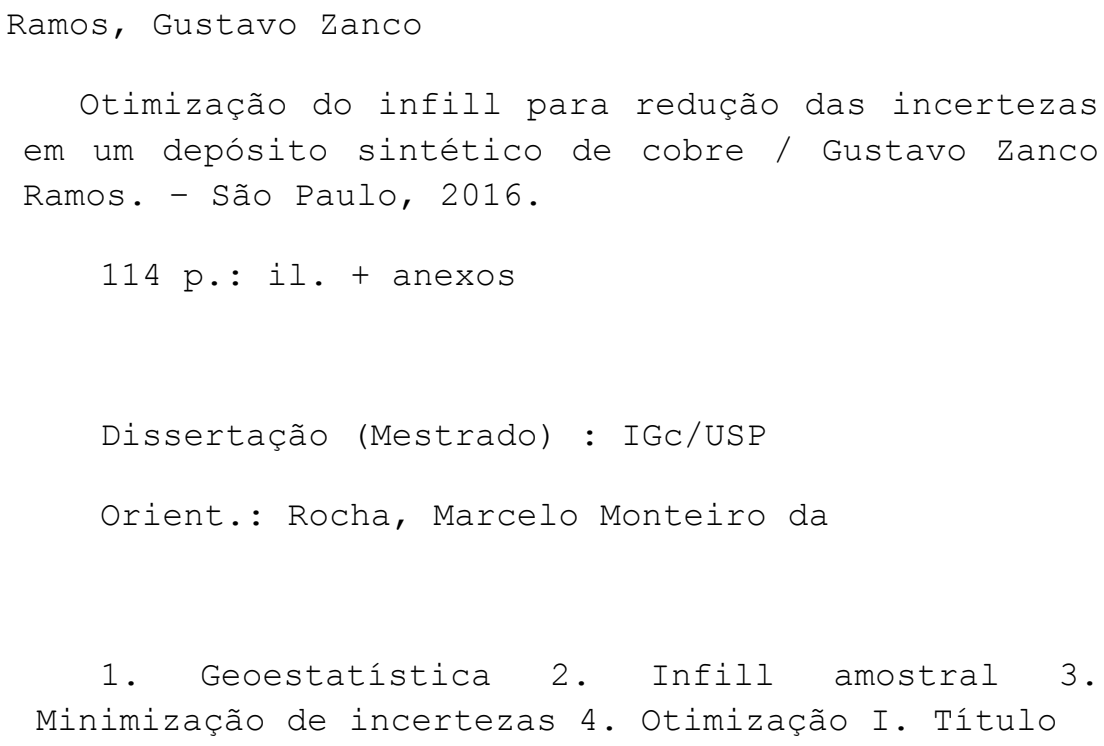




\section{AGRADECIMENTOS}

Agradeço: meu orientador, Marcelo, pela paciência, apoio, ideias, apontamentos e inúmeras discussões e observações pertinentes ao trabalho; Eduardo H. pelo apoio, observações e apontamentos que ajudaram o desenvolvimento do trabalho; Arthur pela inestimável ajuda em escrever e implementar os algoritmos deste trabalho e entendimento sobre o que é e como se faz otimização; Eduardo R. por me forçar a trabalhar diversas vezes; João pelas histórias hilárias; CAPES pelo apoio financeiro; E a CAE por disponibilizar o programa Datamine@. 


\section{RESUMO}

RAMOS, G. Z., Otimização do infill para redução das incertezas em um depósito sintético de cobre. São Paulo: Instituto de Geociências, Universidade de São Paulo, 2016. 114 p. Dissertação de Mestrado em Recursos Minerais.

A aquisição de novas informações de sondagem é realizada por intermédio do infill de furos de sonda e esta é uma prática utilizada em diversas etapas da exploração mineral. Métodos de otimização são largamente utilizados em várias fases e processos na vida da mina, por exemplo na otimização de cavas, na otimização do sequenciamento de lavra, entre outros. Contudo a utilização de métodos de otimização aplicados à locação de furos de inifill não é usual. Neste trabalho propõem-se utilizar a otimização matemática para melhorar a distribuição espacial dos novos furos, bem como para definir a quantidade adequada de furos a serem realizados.

Métodos de otimização meta-heurísticos foram testados com o objetivo de minimizar duas funções objetivo que tratam das incertezas associadas à simulação dos dados, que são a soma da variância e a soma dos coeficientes de variação dos blocos simulados. O método que apresentou melhores resultados na otimização da função objetivo no menor tempo e custo computacional foi o método simulated annealing com resfriamento rápido e memória.

Com base neste método de otimização comparou-se as funções objetivo propostas. Para efetuar a comparação amostraram-se os 11 furos definidos pela otimização para ambas as funções objetivo. O infill amostral foi realizado no corpo sintético e as comparações realizadas foram: a estatística descritiva - dos dados de infill comparados à população - e o gráfico $Q-Q$ entre o e-type das simulações realizadas na base com infill e a população. A estatística descritiva do infill permitiu interpretar que a amostragem atualizada (soma das amostragens inicial e a nova) apresentou-se mais representativa do que a amostragem incial. Baseado no resultado dos gráficos $Q-Q$, a simulação calculada com o infill otimizando a minimização da soma dos coeficientes de variação apresentou maior aderência à população.

Palavras-chave: Geoestatística; Infill Amostral; Minimização de Incertezas; Otimização. 


\begin{abstract}
RAMOS, G. Z., Infill optimization to reduce uncertainty in a copper ore synthetic deposit. São Paulo: Institute of Geosciences, University de São Paulo, 2016. 114 p. Dissertation in Mineral Resources.

The acquisition of new drillhole information can be accomplished by the drill hole infill, a practice used in several steps of the mineral exploration. Optimization methods are widely used in several stages and processes of the mine life cycle, for example, mine pit optimization, mine scheduling optimization among others. However the optimization of drill hole infill locations are unusual. This work proposes the use of mathematical optimization to improve the spatial distribution and the number of the new drill holes to be made.

Metaheuristics optimization methods were tested to minimize two objective functions that deal with the uncertainty associated to simulated data, the sum of the simulated blocks variance and the sum of the simulated blocks coefficient of variation. The best processing cost, processing time and results were obtained by simulated annealing method with fast cooling and memory for both objective functions.

Based on this optimization method both proposed objective functions were compared. In order to perform the comparison 11 optimized drill holes locations by both objective functions were sampled. Sampling infill were done in the synthetic ore body and the made comparisons were: statistics - comparison between the infill data and population - and the QQ plot of the e-type statistics computed for simulation based on infill and population. Statistics for infill allowed to interpret that updated sample (the addition of new sampling in the initial data) was more representative than the initial sampling. Based on Q-Q plot the simulation computed for optimized infill location by the sum of the coefficient of variation minimization has more adherence to population.
\end{abstract}

Keywords: Geoestatistics; Drill hole Infill; Uncertainty Minimization; Optimization. 


\section{ÍNDICE DE FIGURAS}

Figura 01 - Representação dos parâmetros de cálculo de variogramas experimentais (Pannatier 1994)

Figura 02 - Variograma típico e suas propriedades (Yamamoto 2001).

Figura 03 - Representação dos tipos de anisotropia. A) Geométrica; B) Zonal; C) Mista

(Yamamoto 2001).

Figura 04 - Representação gráfica dos principais modelos de variograma; A) Efeito Pepita

Puro ; B) Esférico; C) Exponencial; D) Gaussiano. Modificado de Rocha (1999).

Figura 05 - Exemplo de pesquisa por dados em uma vizinhança por quadrantes, com os raios de busca por amostras diferentes pela ocorrência de anisotropia. Pontos que estejam fora da elipse não são considerados na estimativa (fonte: Autor).

Figura 06 - Exemplo em 2D da vizinhança utilizada para o cálculo dos pesos da krigagem ordinária. $\mathrm{X}_{0}$ é o ponto a ser estimado e os pontos numerados de 1 a 4 são amostras utilizadas no cálculo da estimativa (fonte: Autor).

Figura 07 - Exemplo de espaço de parâmetros de uma dimensão relacionado a uma função objetivo. Os picos ímpares são os máximos da função, com o pico 3 sendo o máximo global (no intervalo estudado) e os demais os máximos locais. Os vales pares representam os mínimos da função, com o vale 2 sendo o mínimo global (no intervalo estudado) e os demais vales os mínimos locais (fonte: Autor).

Figura 08 - Esquema de funcionamento do algoritmo de simulated annealing em espaço de parâmetros 2D. A locação inicial será aleatória, no ponto 1, que será movido inicialmente na variável i até o local do ponto 2. Havendo melhora no resultado da função objetivo, a locação em 2 é aceita, do contrário pode ser aceito, ou não, considerando o cooling schedule utilizado. Esse processo se repete de 2 para 3, modificando apenas a variável i+1 e em 3 o teste da função objetivo será realizado novamente. De 3 para 4 o processo e o teste são realizados de forma análoga (fonte: Autor).

Figura 09 - Particle swarm optimization representada esquematicamente. São utilizadas 3 partículas, sendo 1 e 2 as partículas que pesquisam melhores soluções no espaço amostral e a partícula $g$ que representa a melhor posição já obtida por uma partícula até a presente iteração. O ponto com o índice $l$ indica a melhor posição que a referida partícula já encontrou no espaço de parâmetros. As áreas A e B representam a região onde cada partícula pode se movimentar na referida iteração, entre seu melhor local até o momento e a partícula melhor locada (fonte: Autor).

Figura 10 - Perfil geológico do depósito sintético mostrando as camadas dobradas de metarenito e folhelhos e a zona de falha com quartzito remobilizado mineralizado.

Figura 11 - Mapa geológico da área, baseado no corpo confeccionado, e as 32 sondagens iniciais que foram usadas no presente trabalho. (fonte: Autor)

Figura 12 - Fluxograma da otimização por pesquisa aleatória. Só apresenta um nó decisório, que representa a comparação entre o valor ótimo e a resposta da iteração..............................46

Figura 13 - Fluxograma da otimização por simulated annealing ............................................48

Figura 14 - Fluxograma da otimização por particle swarm optimization ...............................52

Figura 15 - Mapa base com a distribuição espacial das amostras..........................................53

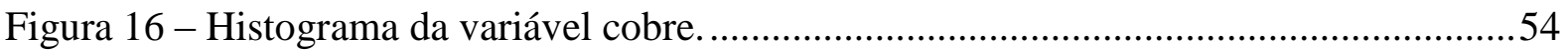


Figura 17 - Histograma da variável cobre regularizada. A linha azulada representa a distribuição acumulada (cdf) e as barras representam a densidade de probabilidade (pdf).....54

Figura 18 - Modelo teórico de variograma ajustado ao variograma experimental. ...............57

Figura 19 - Variograma experimental com modelo teórico ajustado....................................60

Figura 20 - Diagrama de dispersão entre valores amostrados e valores estimados na validação

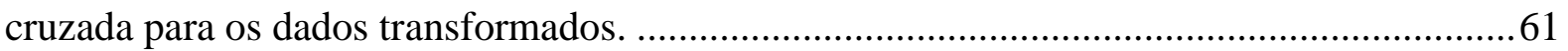

Figura 21- Representação de uma simulação tomada ao acaso. ............................................62

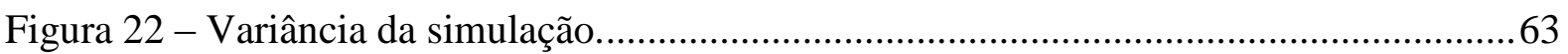

Figura 23 - Gráfico apresentando o resultado da otimização de 1 a 15 novos furos de sonda com a minimização da soma da variância de simulação como função objetivo.......................65

Figura 24 - Gráfico apresentando o resultado da otimização de 5 a 50 novos furos com a minimização da soma da variância da simulação como função objetivo. O número de furos zero representa o valor da função objetivo com base na amostragem inicial.

Figura 25 - Resultado da otimização de 1 a 15 novos furos de sonda com a minimização da soma dos coeficientes de variação como função objetivo.

Figura 26 - Gráfico apresentando o resultado da otimização de 5 a 50 novos furos de sonda com a minimização da soma dos coeficientes de variação como função objetivo. $\mathrm{O}$ número de furos zero representa o valor da função objetivo com base na amostragem inicial.

Figura 27 - Configuração da boca de furo obtida pela otimização simulated annealing com resfriamento rápido. Os pontos em azul representam a amostragem original. Em (A) os pontos ótimos em verde foram obtidos pela função objetivo que visava minimizar o coeficiente de variação. Em (B) os pontos vermelhos representam o resultado otimizado para a função objetivo que minimizou a variância.

Figura 28 - Variograma experimental calculado para as direções $0^{\circ}, 90^{\circ}$ e vertical e respectivo modelo teórico ajustado.

Figura 29 - Diagrama de dispersão entre valor amostral e estimado na validação cruzada para os dados atualizados transformados em distribuição gaussiana. .75

Figura 30 - Variograma experimental calculado para as direções $0^{\circ}, 90^{\circ}$ e vertical e seus respectivos modelos teóricos ajustados

Figura 31 - Diagrama de dispersão entre valor amostral e estimado na validação cruzada para os dados atualizados transformados em distribuição gaussiana. .79

Figura 32 - Q-Q plot entre o dado populacional e o infill obtido pela minimização da variância de bloco. O intervalo considerado para a população se limitou ao máximo obtido pelo e-type. A segunda imagem apresenta o comportamento no intervalo até o valor 1 , de modo a eliminar possíveis outiliers e poder observar a curva detalhadamente.

Figura 33 - Q-Q plot entre o dado populacional e o infill obtido pela minimização do coeficiente de variação dos blocos. O intervalo considerado para a população se limitou ao máximo obtido pelo e-type. A segunda imagem apresenta o comportamento no intervalo até o valor 1, para eliminar possíveis outliers e se pode observar a curva de modo detalhado........ 82 Figura A1 - Variograma experimental da análise exploratória na direção $0^{\circ}$ de azimute......... 1 Figura A2 - Variograma experimental da análise exploratória na direção $45^{\circ}$ de azimute....... 2 Figura A3 - Variograma experimental da análise exploratória na direção $90^{\circ}$ de azimute........ 3 Figura A4 - Variograma experimental da análise exploratória na direção $135^{\circ}$ de azimute.....4 
Figura A5 - Variograma experimental da análise exploratória na direção $0^{\circ}$ de azimute e mergulho $90^{\circ}$.

Figura A6 - Variograma experimental da análise exploratória dos dados transformados na direção $0^{\circ}$ de azimute.

Figura A7 - Variograma experimental da análise exploratória dos dados transformados na direção $45^{\circ}$ de azimute.

Figura A8 - Variograma experimental da análise exploratória dos dados transformados na direção $90^{\circ}$ de azimute.

Figura A9 - Variograma experimental da análise exploratória dos dados transformados na direção $135^{\circ}$ de azimute.

Figura A10 - Variograma experimental da análise exploratória dos dados transformados na direção $0^{\circ}$ de azimute e $90^{\circ}$ de mergulho.

Figura A11 - Histograma e distribuição acumulada da amostragem otimizada não regularizada, locada utilizando a variância como função objetivo.

Figura A12 - Histograma e distribuição acumulada da amostragem otimizada regularizada, locada utilizando a variância como função objetivo.

Figura A13 - Histograma e distribuição acumulada da amostragem otimizada não

regularizada, locada utilizando o coeficiente de variação como função objetivo.

Figura A14 - Histograma e distribuição acumulada da amostragem otimizada regularizada, locada utilizando o coeficiente de variação como função objetivo.

Figura A15 - Histograma e distribuição acumulada da amostragem otimizada não regularizada, locada aleatoriamente.

Figura A16 - Histograma e distribuição acumulada da amostragem otimizada regularizada, locada aleatoriamente.

Figura A17 - Variograma experimental da análise exploratória dos dados atualizados com a amostragem baseada na otimização da soma da variância de blocos transformados em distribuição gaussiana. Cálculo realizado na direção $0^{\circ}$ de azimute.

Figura A18 - Variograma experimental da análise exploratória dos dados atualizados com a amostragem baseada na otimização da soma da variância de blocos transformados em distribuição gaussiana. Cálculo realizado na direção $45^{\circ}$ de azimute.

Figura A19 - Variograma experimental da análise exploratória dos dados atualizados com a amostragem baseada na otimização da soma da variância de blocos transformados em distribuição gaussiana. Cálculo realizado na direção $90^{\circ}$ de azimute.

Figura A20 - Variograma experimental da análise exploratória dos dados atualizados com a amostragem baseada na otimização da soma da variância de blocos transformados em distribuição gaussiana. Cálculo realizado na direção $135^{\circ}$ de azimute.

Figura A21 - Variograma experimental da análise exploratória dos dados atualizados com a amostragem baseada na otimização da soma da variância de blocos transformados em distribuição gaussiana. Cálculo realizado na direção $0^{\circ}$ de azimute com $90^{\circ}$ de mergulho. ...21 Figura A22 - Variograma experimental da análise exploratória dos dados atualizados com a amostragem baseada na otimização da soma dos coeficientes de variação dos blocos transformados em distribuição gaussiana. Cálculo realizado na direção $0^{\circ}$ de azimute. 
Figura A23 - Variograma experimental da análise exploratória dos dados atualizados com a amostragem baseada na otimização da soma dos coeficientes de variação dos blocos transformados em distribuição gaussiana. Cálculo realizado na direção $45^{\circ}$ de azimute. ........23 Figura A24 - Variograma experimental da análise exploratória dos dados atualizados com a amostragem baseada na otimização da soma dos coeficientes de variação dos blocos transformados em distribuição gaussiana. Cálculo realizado na direção $90^{\circ}$ de azimute. 24 Figura A25 - Variograma experimental da análise exploratória dos dados atualizados com a amostragem baseada na otimização da soma dos coeficientes de variação dos blocos transformados em distribuição gaussiana. Cálculo realizado na direção $90^{\circ}$ de azimute........25 Figura A26 - Variograma experimental da análise exploratória dos dados atualizados com a amostragem baseada na otimização da soma dos coeficientes de variação dos blocos transformados em distribuição gaussiana. Cálculo realizado na direção $135^{\circ}$ de azimute. .....26 Figura A27- Variograma experimental da análise exploratória dos dados atualizados com a amostragem baseada na otimização da soma dos coeficientes de variação dos blocos transformados em distribuição gaussiana. Cálculo realizado na direção $0^{\circ}$ de azimute e $90^{\circ}$ de mergulho. 


\section{ÍNDICE DE TABELAS}

Tabela 01 - Estatísticas descritivas da variável cobre da base de dados original, considerada a população.

Tabela 02 - Estatísticas descritivas da variável cobre antes e depois da regularização das amostras.

Tabela 03 - Parâmetros de cálculo do variograma experimental na análise exploratória........56

Tabela 04 - Parâmetros de cálculo do variograma considerando as três direções principais..56

Tabela 05 - Parâmetros do modelo teórico de variograma utilizado no ajuste. .......................56

Tabela 06 - Estatística descritiva da amostragem transformada. ........................................58

Tabela 07 - Parametrização da modelagem do variograma dos dados transformado. .............59

Tabela 08 - Parâmetros de vizinhança utilizados na simulação estocástica............................61

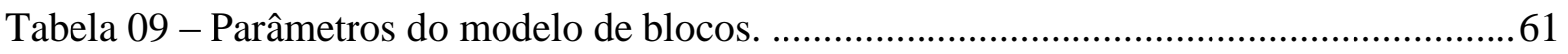

Tabela 10 - Estatísticas descritivas da variável cobre da amostragem atualizada pelo infill, baseado na otimização da variância e do coeficiente de variação. ...........................................70

Tabela 11 - Estatísticas descritivas da variável cobre com furos de infill locados aleatoriamente.

Tabela 12 - Parâmetros de cálculo do variograma experimental na análise exploratória dos dados atualizados com base na variância de blocos, transformados em uma distribuição gaussiana.

Tabela 13 - Parâmetros de cálculo do variograma experimental a ser modelado dos dados atualizados com base na variância de blocos, transformados em uma distribuição gaussiana.

Tabela 14 - Parâmetros da modelagem ajustado para o variograma calculado da nova amostragem

Tabela 15 - Parâmetros da vizinhança utilizados na simulação estocástica da amostragem atualizada.

Tabela 16 - Parâmetros de cálculo do variograma experimental na análise exploratória dos dados transformados em uma distribuição gaussiana.

Tabela 17 - Parâmetros de cálculo do variograma experimental a ser modelado dos dados atualizados com base no coeficiente de variação de blocos, transformados em uma distribuição gaussiana.

Tabela 18 - Parâmetros do modelo teórico de variograma ajustado ao variograma experimental.

Tabela 19 - Parâmetros da modelagem ajustados para o variograma calculado da nova amostragem. 


\section{SUMÁRIO}

1. INTRODUÇÃ

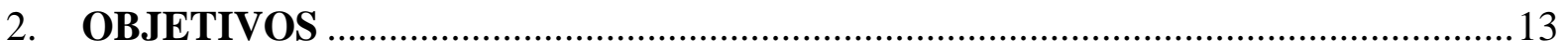

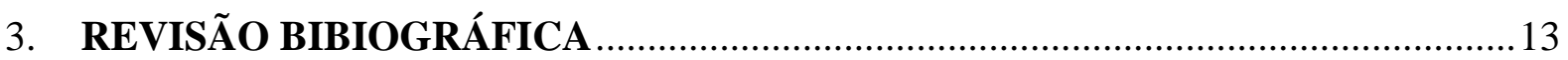

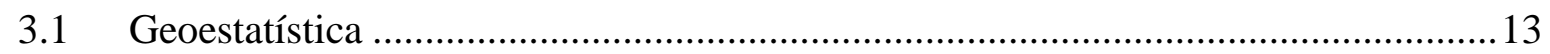

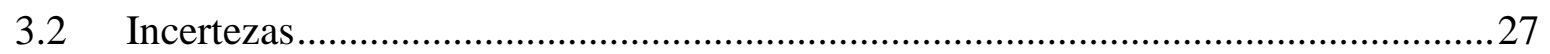

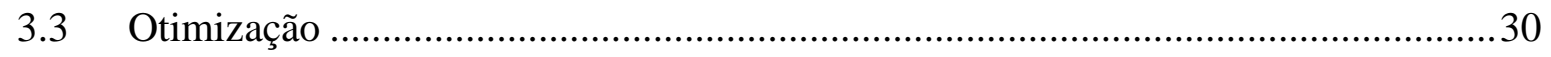

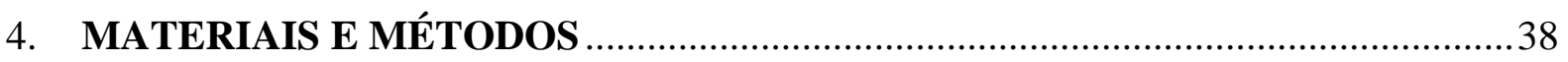

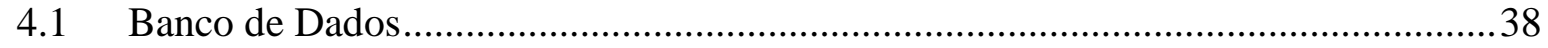

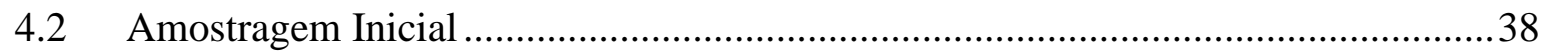

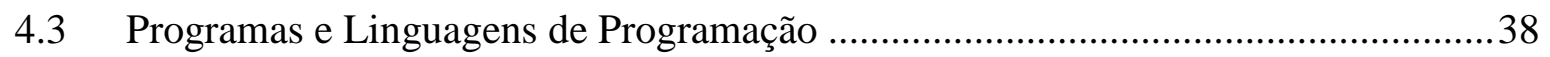

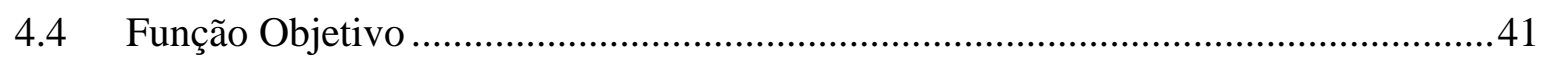

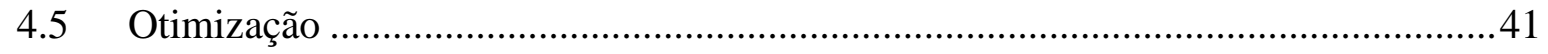

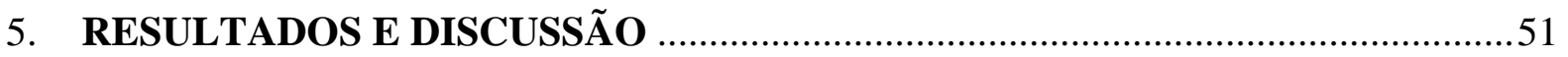

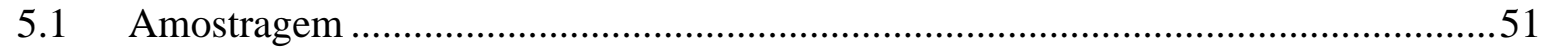

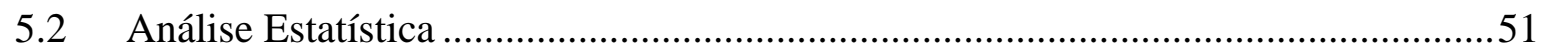

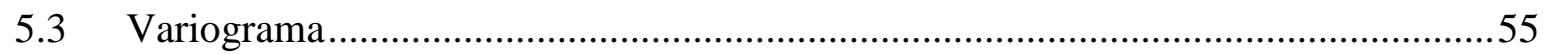

5.4 Transformação Gaussiana e Variograma ...........................................................58

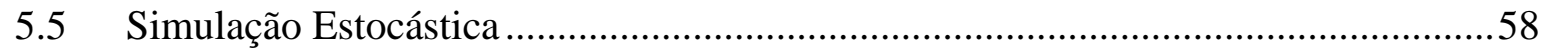

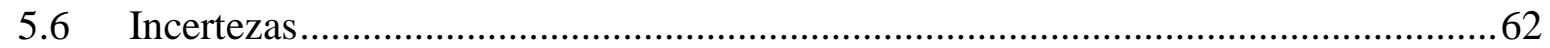

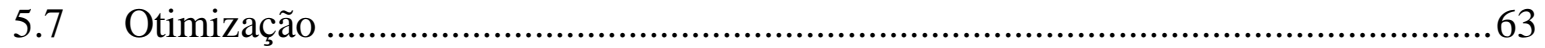

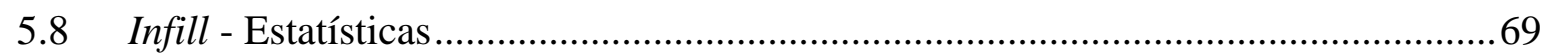

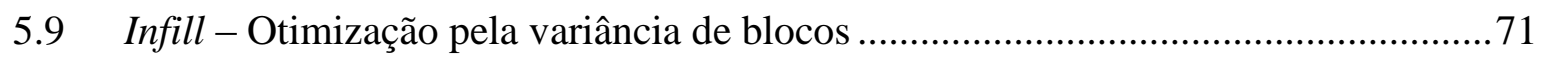

5.10 Infill - Otimização pelo coeficiente de variação dos blocos ............................... 73

5.11 Comparação entre o infill e a população ............................................................ 80

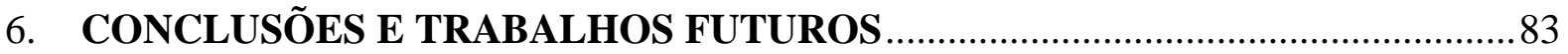

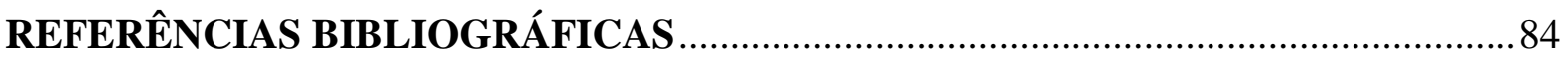

ANEXO 


\section{INTRODUÇÃO}

As geociências estão sujeitas às incertezas associadas à falta e/ou limitação de conhecimento das relações ou dependências intrínsecas aos diversos componentes do sistema terra. Em mineração as incertezas são associadas principalmente à gênese do depósito mineral e à amostragem. A disposição espacial e as proporções do corpo mineralizado são características diretamente associadas à gênese do depósito e realiza-se a amostragem com o intuito de definir o contorno do mesmo, caracterizar o elemento mineral de interesse, além de quantificar os recursos minerais que influenciarão diretamente na viabilidade do empreendimento.

Durante as fases de exploração e avaliação de recursos minerais normalmente há a necessidade da realização de mais do que uma campanha de sondagem e, no jargão da mineração, a execução de novos furos de sonda recebe o nome de infill. Nestas amostragens complementares as amostras são coletadas preferencialmente em regiões pouco amostradas ou ainda onde há maior interesse e os objetivos são aumentar o conhecimento a respeito do depósito além de minimizar as incertezas associadas às estimativas.

Um problema na locação de novos furos de sonda é a definição de onde devem ser realizados de forma a melhorar os cálculos posteriores. O estudo das incertezas pode indicar regiões do domínio com maior imprecisão, onde os novos furos serão preferencialmente efetuados, porém ainda podem existir dúvidas sobre a locação dos furos. Para racionalizar os gastos e obter dados mais representativos é interessante o uso de técnicas de otimização na localização dos furos de infill que levem em conta não só a localização, propriamente dita, mas, sobretudo, o manejo das incertezas associadas às estimativas.

Otimização refere-se a um conjunto de métodos matemáticos computacionais utilizados para obter o resultado ótimo a uma questão de interesse. Considerando a locação das novas amostras com base em métodos computacionais de otimização, podem-se definir áreas de maior interesse associados à alta incerteza. Para atestar a confiabilidade da otimização deve-se proceder com a amostragem dos furos ótimos, que após a locação serão analisados de forma a averiguar ocorrência de diminuição das incertezas associadas à nova campanha amostral. De forma a testar a aplicabilidade da otimização na locação do infill trabalhou-se em um depósito sintético de cobre, onde após definida a posição dos novos furos de sondagem, é possível amostrar sem complicações e custo. Ao se amostrar a locação otimizada comprova-se a aplicabilidade da metodologia de otimização no infill amostral. 
A diminuição das incertezas e controle espacial do bem mineral são importantes para empreendimentos mineiros, assim como a locação otimizada de novas amostras. A otimização do infill deve levar em conta tanto a diminuição da incerteza, local ou global dependendo do interesse das estimativas, quanto o custo envolvido na campanha de amostragem, de forma a potencializar a resposta obtida, minimização de incerteza amostral, com o menor número de novos furos de sondagem.

\section{OBJETIVOS}

O presente trabalho testa a utilização de métodos de otimização, baseados em incertezas associadas à simulação geoestatística, como procedimento auxiliar para a locação de sondagens em campanhas de infill. As etapas de tratamento e análise dos dados serão detalhadas para apresentar os métodos e explanar o desenvolvimento de forma simples. Os objetivos da aplicação dos métodos de otimização ao infill são evitar gastos desnecessários e minimizar as incertezas associadas à amostragem. Comparando os resultados obtidos a partir do infill otimizado com os dados reais pretende-se verificar o ganho de representatividade da nova amostragem.

\section{REVISÃO BIBIOGRÁFICA}

\subsection{Geoestatística}

Segundo Deutsch \& Journel (1998), geoestatística compreende o estudo de fenômenos que variam no espaço e/ou tempo. Diferente da estatística clássica, a geoestatística trata somente dados denominados variáveis regionalizadas (VR), onde a localização de cada variável deve estar implícita na amostra. Uma VR é representada por $\mathrm{Z}(\mathrm{x})$ (onde $\mathrm{Z}$ é a variável de interesse e $\mathrm{x}$ é o vetor posição da amostra), sendo que uma amostras é representada, genericamente, como z(x) (Deutsch \& Journel 1998 e Yamamoto 2001). 
A variável $\mathrm{Z}(\mathrm{x})$ deve ser inicialmente estudada com estatística clássica, procedimento para constatar se os valores condizem com o esperado para a variável, ou seja, se não há presença de valores incongruentes com o comportamento da variável (Yamamoto 2001).

As variáveis regionalizadas são regidas por um conceito fundamental que é chamado de hipótese intrínseca. Segundo essa hipótese, a variância entre duas amostras é a mesma para todo o domínio e só varia em função da distância e orientação de observação. A função básica da geoestatística é o variograma (Yamamoto 2001).

Variáveis regionalizadas possuem algumas características qualitativas que as diferenciam das variáveis aleatórias que, conforme reproduz Yamamoto (2001) são:

- Localização - relacionada com a posição espacial das amostras. A variável $\mathrm{Z}(\mathrm{x})$ diz respeito ao conjunto de observações, onde cada amostra $\mathrm{z}(\mathrm{x})$ possui um valor específico associado àquele ponto específico com coordenadas Leste, Norte e Cota. Sem o vetor localização (x) a geoestatística não pode ser utilizada;

- Suporte - diz respeito à dimensão da amostra. Basicamente, no caso de geologia, se foram realizadas amostragens por volume, área ou comprimento;

- Continuidade - esta característica diz respeito à relação de continuidade espacial entre as amostras. A correlação espacial entre amostras tem relação direta com a distância, de forma que amostras mais próximas são mais semelhantes entre si do que amostras mais distantes;

- Anisotropia - diferenças de comportamento espacial para diferentes direções definem a anisotropia.

A geoestatística oferece uma gama de métodos determinísticos e estatísticos focados em entender e modelar variâncias espaciais (Deutsch \& Journel 1998). Deste modo a geoestatística analisa e compara pares de amostras. Esses pares não são escolhidos ao acaso, mas sim com distâncias e em direções pré-definidas, à distância que separa pares de amostras recebe o nome de passo.

A função variograma correlaciona distância $(h)$ com variância espacial $(2 \gamma(h))$, sendo descrita conforme (Yamamoto 2001 e Deutsch 2002): 


$$
2 \gamma(h)=\frac{1}{n} \sum_{i=1}^{n}\left[Z\left(x_{i}+h\right)-Z\left(x_{i}\right)\right]^{2}
$$

Usualmente, o variograma não é utilizado e para os cálculos trabalha-se com o semivariograma que, conforme pode ser visto em Yamamoto (2001) e Deutsch (2002) entre outros, é escrito como:

$$
\gamma(h)=\frac{1}{2 n} \sum_{i=1}^{n}\left[Z\left(x_{i}+h\right)-Z\left(x_{i}\right)\right]^{2}
$$

Sendo: $\gamma(h)$ a semivariância espacial; $\mathrm{Z}\left(x_{\mathrm{i}}\right)$ a variável regionalizada no ponto $x_{\mathrm{i}}$; $Z\left(x_{i}+h\right)$ a variável regionalizada no ponto $x_{\mathrm{i}}$ adicionado de um vetor distância $h$, e $n$ o número de pares de pontos separados por $h$.

O semivariograma pode ser calculado como função da covariância (Deutsch \& Journel 1998 e Yamamoto 2001):

$$
\gamma(h)=C(0)-C(h)
$$

Sendo: $C(0)$ a covariância para distância nula, que é igual à variância estatística $\left(\sigma^{2}\right)$, e C(h) a covariância para a distância h.

Deutsch \& Journel (1998) apresentam a função genérica da covariância como:

$$
C\left(x, x^{\prime}\right)=E\left\{Z(x) Z\left(x^{\prime}\right)\right\}-E\{Z(x)\} E\left\{Z\left(x^{\prime}\right)\right\}
$$

Onde $\mathrm{C}\left(\mathrm{x}, \mathrm{x}^{\prime}\right)$ é covariância da variável $\mathrm{Z}(\mathrm{x})$ em relação à variável $\mathrm{Z}\left(\mathrm{x}^{\prime}\right) ; E\{Z(x)\}$ é esperança matemática de $\mathrm{Z}(\mathrm{x})$.

As funções covariância para $\mathrm{C}(0)$ e $\mathrm{C}(\mathrm{h})$ podem ser escritas, respectivamente conforme (Deutsch 2002):

$$
C(0)=E[Z(x+0) * Z(x)]-\{E[Z(x)]\}^{2}=E\left\{[Z(x)]^{2}\right\}-\{E[Z(x)]\}^{2}=\sigma^{2}
$$




$$
C(h)=E[Z(x+h) * Z(x)]-\{E[Z(x)]\}^{2}
$$

Para calcular o semivariograma é necessário definir como parâmetros (Figura 01).

- Número de direções a ser consideradas no cálculo;

- As direções onde será calculado o variograma experimental;

- Tolerância angular, que define a janela de busca por amostras para calcular o variograma em determinada direção. Este ângulo é somado e subtraído ao ângulo do azimute e permite calcular o variograma experimental para malhas irregulares;

- Tamanho do passo, que é a distância entre amostras considerada para o cálculo do variograma. Em malhas regulares está distância é a distância de separação dos pontos amostrais e em malhas irregulares usualmente esse tamanho é a média das distâncias entre amostras vizinhas;

- Número de passos, que é o número de vezes que o passo será incrementado. É um parâmetro importante, pois sua definição depende do domínio do variograma;

- Tolerância do passo que é uma proporção da distância do passo, normalmente utiliza-se $50 \%$ do tamanho do primeiro passo, que será somada e subtraída ao passo, este é um parâmetro especialmente útil quando a malha de amostragem é irregular;

- Largura máxima, que é a largura máxima da janela de busca por pares amostrais após a qual se considera a abertura constante. 


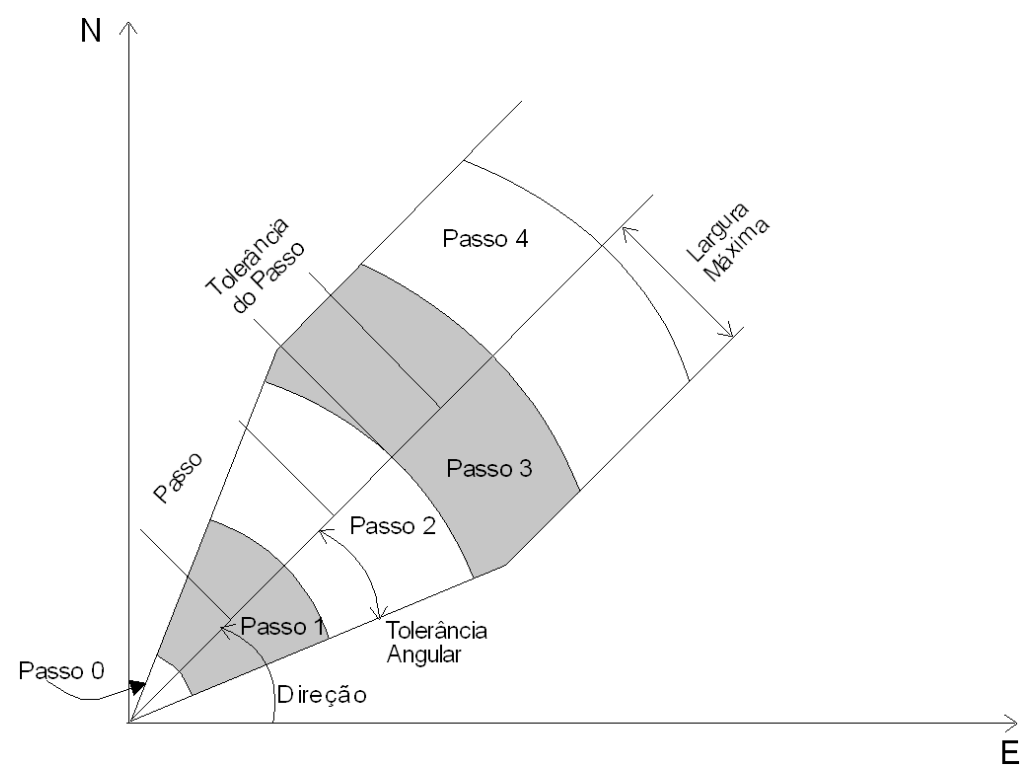

Figura 01 - Representação dos parâmetros de cálculo de variogramas experimentais (Pannatier 1994).

O variograma típico com patamar apresenta dois campos evidentes, o campo estruturado onde há correlação espacial entre amostras, ou seja, existe dependência espacial pares de pontos e o campo aleatório, onde a variável não apresenta mais correlação espacial, as amostras perdem dependência espacial e a variância espacial torna-se constante. $O$ parâmetro que separa estes campos é denominado amplitude, que é a distância máxima aonde existe correlação espacial entre as amostras. Ao atingir o campo aleatório o variograma estabiliza, em torno da variância espacial máxima, caracterizando o patamar. Por fim, pode ou não ocorrer uma descontinuidade próxima à origem, a ela se dá o nome de efeito pepita, ou variância aleatória. A diferença entre o patamar e o efeito pepita, se este ocorrer, chama-se variância espacial (Yamamoto 2001). A representação gráfica de um variograma típico com patamar é ilustrada na Figura 02.

Usualmente o variograma experimental é calculado seguindo um procedimento denominado de análise exploratória (Armstrong 1998). Essa análise consiste em calcular o variograma para quatro ou cinco direções de forma a se observar se há anisotropia. As direções utilizadas costumam ser $0^{\circ}, 45^{\circ}, 90^{\circ}, 135^{\circ}$ e para dados $3 \mathrm{D}$ a quinta direção é ortogonal não coplanar ao plano principal. Apesar disto, o usuário pode definir as direções e os mergulhos conforme a conveniência. Quando existe, a anisotropia pode ser classificada de acordo com o parâmetro que varia com a direção em (Figura 03): 


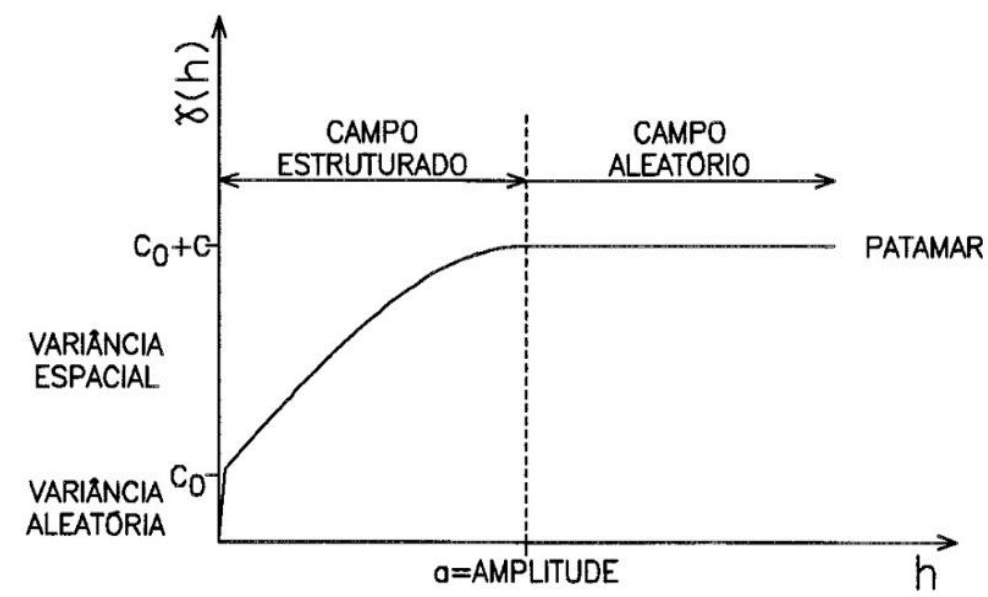

Figura 02 - Variograma típico e suas propriedades (Yamamoto 2001).

- Geométrica - para fenômenos que apresentam um único patamar, mas amplitudes diferentes;

- Zonal - Neste caso o variograma apresentará a mesma amplitude para todas as direções, porém com patamares diferentes;

- Mista - que é a mistura dos dois tipos anteriores, ou seja variam tanto amplitudes quanto patamares nas diferentes direções.
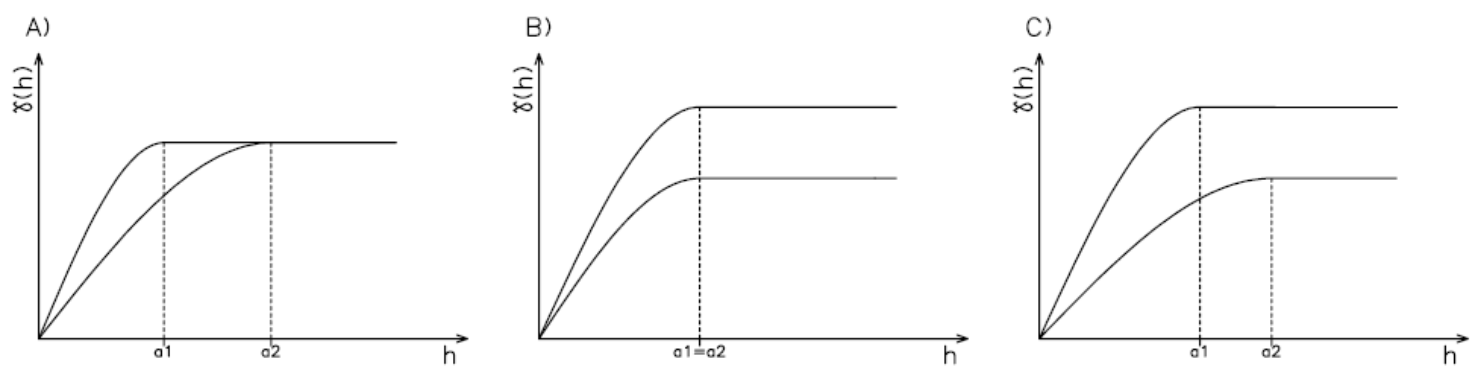

Figura 03 - Representação dos tipos de anisotropia. A) Geométrica; B) Zonal; C) Mista (Yamamoto 2001).

A partir da função variograma é possível interpretar o modelo de variância espacial de uma variável regionalizada e obter o valor da variância espacial para distâncias de interesse no domínio. Técnicas de estimativa que utilizem a variância espacial são passíveis de calcular o valor da variável regionalizada em pontos não amostrados, como é o caso na krigagem. Outros métodos também aplicados são os de cunho estocástico, dos quais as simulações se destacam. 
O variograma experimental não é utilizado diretamente nos métodos de estimativa (Deutsch 2002). Ainda segundo este autor, as razões de não utilizar diretamente o variograma experimental são duas:

- Para a estimativa deve-se conhecer valor de variância espacial $(\gamma(\mathrm{h}))$ para qualquer valor de distância (h). O variograma experimental calculado apresenta valores de variância somente para as distâncias dos passos, isso para cada uma das direções utilizadas. Ou seja, o variograma experimental é uma função discreta (descontínua). Para que se possa realizar as estimativas é de suma importância poder calcular o valor da variância espacial para toda e qualquer distância. Portanto necessita-se de uma função contínua, que descreva esse comportamento.

- Conferir à krigagem a capacidade de usar o variograma e a covariância espacial. Para isso o modelo deve ser positivo e preciso, de modo que as equações de krigagem possam ser resolvidas e que a variância da krigagem seja positiva.

Para satisfazer essas condições, a geoestatística conta com uma gama de funções unidimensionais positivas pré-definidas, os modelos teóricos de variograma. Dentre esta gama podem ser destacadas as funções esférica, exponencial, gaussiana e efeito pepita puro como as mais comuns (Yamamoto 2001 e Deutsch 2002). O ajuste é realizado através de procedimentos interativos, para se obter um resultado bem definido e representativo do comportamento da variância espacial (Deutsch 2002). Estes modelos podem ser descritos como:

- Efeito pepita puro - No caso de uma distribuição que caracterize o modelo efeito pepita puro não há correlação espacial entre as amostras. Desta forma não se deve utilizar os métodos geoestatísticos para estimativas no domínio. Conforme pode ser observado em Yamamoto (2001) e Deutsch (2002), a função do modelo efeito pepita puro (Figura 04A) é:

$$
\gamma(h)= \begin{cases}0 & \text { para } h=0 \\ C & \text { para } h>0\end{cases}
$$

Sendo $C$ o valor da variância espacial. 
- Esférico - um modelo comumente encontrado, nele o incremento da variância é linear em pequenas distâncias e tende a encurvar à medida que se aproxima do patamar (Deutsch 2002). A sua função é descrita como (Deutsch \& Journel 1998) (Figura 04B):

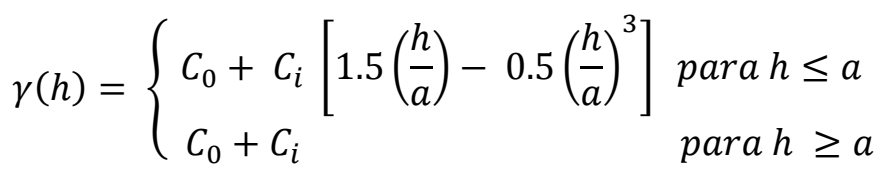

Sendo $C_{0}$ o valor de efeito pepita; $C_{i}$ é a variância espacial, dada pela diferença entre o valor de patamar e efeito pepita; $h$ é a distância; $a$ é a amplitude do variograma.

- Exponencial - é linear próximo à origem e se curva à medida que se aproxima do patamar. Contudo, o incremento da variância é acentuado e o valor do patamar é atingido de modo assintótico (Deutsch 2002). A função exponencial é dada por (Chilès \& Delfiner 1999) (Figura 04C):

$$
\gamma(h)= \begin{cases}C_{0}+C_{i}\left[1-e^{\left(-\frac{h}{a}\right)}\right] & \text { para } h \leq a \\ C_{0}+C_{i} & \text { para } h \geq a\end{cases}
$$

Sendo $e$ o número de Euler da função exponencial.

- Gaussiano - apresenta comportamento parabólico próximo a origem (Deutsch 2002). Esse comportamento denota continuidade a curtas distâncias. Assim como ocorre no modelo exponencial, o patamar é assintótico. Sua função é dada por (Chilès \& Delfiner 1999) (Figura 04D):

$$
\gamma(h)= \begin{cases}C_{0}+C_{i}\left[1-e^{\left(-\frac{h}{a}\right)^{2}}\right] & \text { para } h \leq a \\ C_{0}+C_{i} & \text { para } h \geq a\end{cases}
$$

O ajuste do modelo é realizado de forma interativa alternando-se os parâmetros descritos e verificando-se o modelo teórico é congruente ao variograma experimental. 

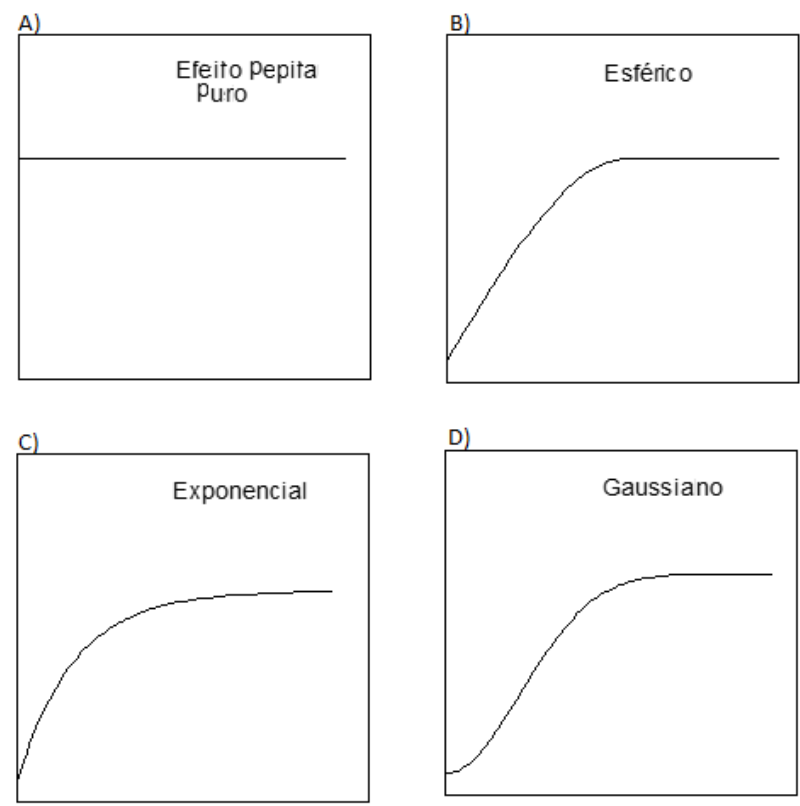

Figura 04 - Representação gráfica dos principais modelos de variograma; A) Efeito Pepita Puro ; B) Esférico; C) Exponencial; D) Gaussiano. Modificado de Rocha (1999).

Após a modelagem do variograma, as estimativas são realizadas com o objetivo de prever os valores da variável regionalizada em locais não amostrados. A krigagem é a principal técnica utilizada em geoestatística. Atualmente krigagem é uma coletânea de técnicas de regressão linear cujo objetivo é estimar com minimização da variância do erro de estimativa (Deutsch \& Journel 1998 e Deutsch 2002). Segundo Deutsch (2002), o estimador da krigagem é representado por:

$$
z^{*}\left(x_{0}\right)-m_{0}=\sum_{i=1}^{n} \lambda_{i}\left[z\left(x_{i}\right)-m_{i}\right]
$$

Onde: $z^{*}\left(x_{0}\right)$ é o valor no ponto estimado; $m_{0}$ é a média populacional; $\lambda_{\mathrm{i}}$ é o peso que cada amostra recebe na estimativa; $z\left(x_{i}\right)$ é o valor das amostras utilizadas na estimativa e $m_{i}$ é a média associada aos locais amostrados.

De forma a minimizar o erro da estimativa $\left(Z^{*}-Z_{0}\right)^{(1)}$ utiliza-se de um artifício onde a medida do erro é dada pela esperança da diferença ao quadrado, conforme $\mathrm{E}\left[\left(\mathrm{Z}^{*}-\mathrm{Z}_{0}\right)\right]^{2}$. Para minimizar este erro os pesos $\lambda$ são utilizados. Utiliza-se a constante $\lambda_{0}$ e os pesos $\lambda_{\mathrm{i}}$ de forma a minimizar $E\left[\left(Z^{*}-Z_{0}\right)\right]^{2}$ (Chilès \& Delfiner 1999). A relação entre os pesos da krigagem e a média amostral é dada por:

\footnotetext{
${ }^{1}$ - $Z^{*}$ é o valor estimado e $Z_{0}$ é o valor amostrado no local da estimativa.
} 


$$
\lambda_{0}=m_{0}-\sum_{i=1}^{n} \lambda_{i} m_{i}
$$

Onde $\lambda_{0}$ é o peso que garante o não viés do erro na estimativa.

Assumindo que a média amostral seja igual à média populacional, o estimador da krigagem pode ser descrito de modo diferente. Conforme apresentado em Chilès \& Delfiner (1999), colocando $\lambda_{0}$ em evidência ter-se-á:

$$
z^{*}(x)=\sum_{i=1}^{n} \lambda_{i} z\left(x_{i}\right)+\lambda_{0}
$$

A krigagem ordinária usa médias desconhecidas e neste caso utiliza-se o estimador da média. A partir da média estimada é possível subtrair essa média dos dados, reduzindo o problema a uma média igual a zero (Chilès \& Delfiner 1999). No caso da krigagem ordinária, a média é considerada constante, garantindo estacionaridade de primeira ordem. Ao utilizar média constante, a equação (12) pode ser escrita conforme:

$$
\lambda_{0}=\left(1-\sum_{i=1}^{n} \lambda_{i}\right) m_{0}
$$

A única maneira de resolver a equação (14) é definindo $\lambda_{0}=0$ (Chilès \& Delfiner 1999), que conduz à condição de não viés da krigagem ordinária (Yamamoto 2001), que é

$$
\sum_{i=1}^{n} \lambda_{i}=1
$$

Desta forma, o estimador da krigagem ordinária pode ser escrito como (Chilès \& Delfiner 1999):

$$
Z_{k o}^{*}\left(x_{0}\right)=\sum_{i=1}^{n} \lambda_{i} Z\left(x_{i}\right)
$$

Onde $Z_{k o}^{*}\left(x_{0}\right)$ é o valor estimado por krigagem ordinária no ponto $\left(x_{0}\right)$. 
Para calcular os pesos $\left(\lambda_{i}\right)$ a relação entre as amostras, feita com base na variância espacial, é utilizada. Como a variância espacial depende da distância, a configuração espacial dos pontos é levada em conta no cálculo. Às diversas configurações espaciais utilizadas dá-se o nome de vizinhança e as configurações mais utilizadas partem da subdivisão do domínio em quadrantes ou em octantes (Yamamoto 2001). Estima-se o ponto não amostrado utilizando um raio de busca por amostras, usualmente definido como, no máximo, a amplitude do variograma. Uma configuração para exemplificar a vizinhança é apresentada na Figura 05.

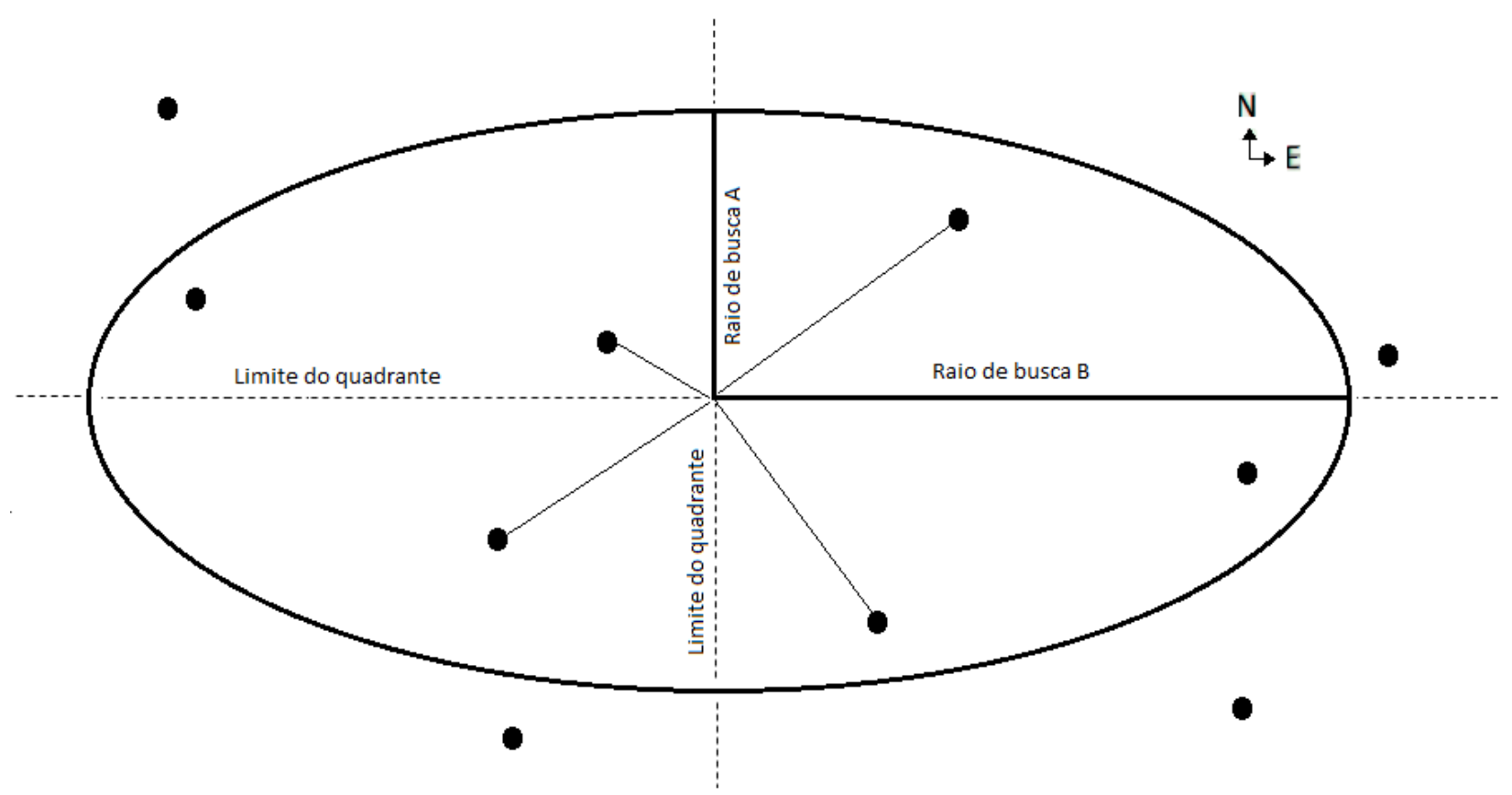

Figura 05 - Exemplo de pesquisa por dados em uma vizinhança por quadrantes, com os raios de busca por amostras diferentes pela ocorrência de anisotropia. Pontos que estejam fora da elipse não são considerados na estimativa (fonte: Autor).

Após definir os parâmetros de vizinhança e escolher as amostras a serem utilizadas procede-se à krigagem. Na Figura 06 pode-se observar um exemplo de vizinhança bidimensional que será utilizada para calcular os pesos da krigagem a partir da resolução de um sistema de equações lineares, denominado sistema de krigagem. 


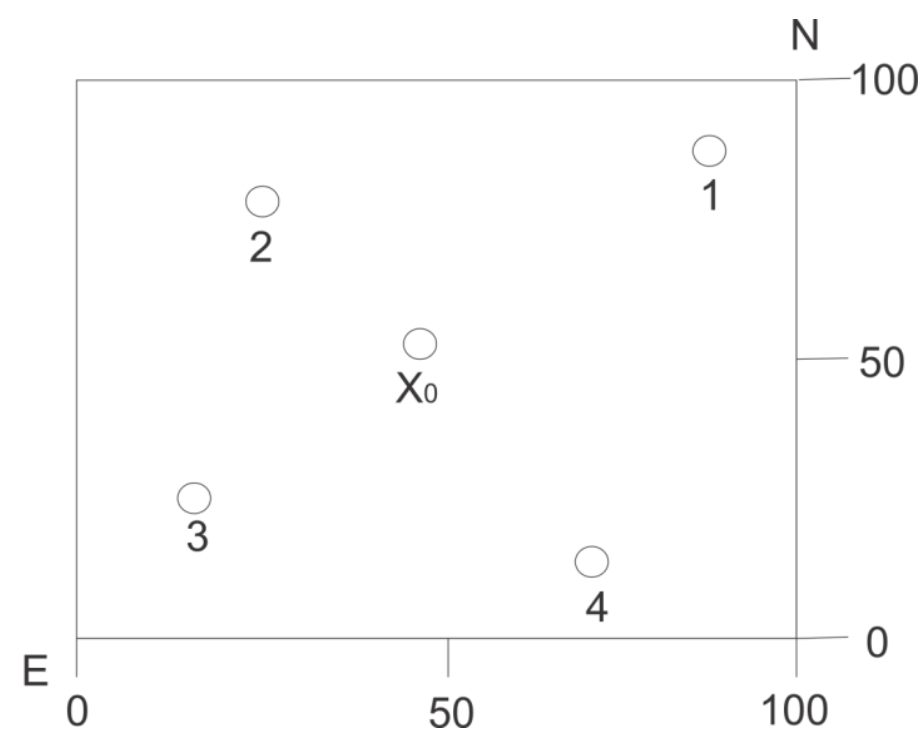

Figura 06 - Exemplo em 2D da vizinhança utilizada para o cálculo dos pesos da krigagem ordinária. $\mathrm{X}_{0}$ é o ponto a ser estimado e os pontos numerados de 1 a 4 são amostras utilizadas no cálculo da estimativa. (fonte: Autor)

O sistema de krigagem é um sistema de equações lineares do tipo $\mathrm{AX}=\mathrm{B}$ e pode ser representado por matrizes. A matriz que representa A é formada pelas variâncias espaciais entre amostras e é calculada a partir do modelo teórico de variograma ajustado ao variograma experimental. A matriz coluna X é a matriz de incógnitas e $\mathrm{B}$ é a matriz coluna constituída pela variância espacial das amostras com relação ao ponto que será estimado, também calculada a partir do modelo teórico de variograma. Assim, considerando-se a configuração apresentada na Figura 06 o sistema de krigagem será:

$$
\left(\begin{array}{ccccc}
\gamma_{11} & \gamma_{12} & \gamma_{13} & \gamma_{14} & 1 \\
\gamma_{21} & \gamma_{22} & \gamma_{23} & \gamma_{24} & 1 \\
\gamma_{31} & \gamma_{32} & \gamma_{33} & \gamma_{34} & 1 \\
\gamma_{41} & \gamma_{42} & \gamma_{43} & \gamma_{44} & 1 \\
1 & 1 & 1 & 1 & 0
\end{array}\right) *\left(\begin{array}{l}
\lambda_{1} \\
\lambda_{2} \\
\lambda_{3} \\
\lambda_{4} \\
\mu
\end{array}\right)=\left(\begin{array}{c}
\gamma_{10} \\
\gamma_{20} \\
\gamma_{30} \\
\gamma_{40} \\
1
\end{array}\right)
$$

Onde $\gamma_{11}, \gamma_{12}, \ldots, \gamma_{44}$ é a variância espacial entre amostras; $\lambda_{1}, \ldots, \lambda_{4}$ são os pesos de krigagem associados a cada amostra; $\gamma_{10}, \ldots, \gamma_{40}$ é a variância espacial das amostras com relação ao ponto que será estimado e $\mu$ é o multiplicador de Lagrange.

Observa-se que existe uma equação a mais do que o número de amostras, cuja incógnita é o multiplicador de Lagrange $(\mu)$, esta equação é utilizada para satisfazer a condição de não viés da krigagem ordinária (Yamamoto 2001). Outras características da 
matriz de krigagem são a simetria de A, uma vez que $\gamma_{12}$ e $\gamma_{21}$, por exemplo, possuem a mesma distância e foram tomados na mesma direção, pela hipótese intrínseca a variância espacial é dependente da distância e da direção de cálculo e; a diagonal principal é sempre igual a zero, pois $\gamma_{(h)}$ para distâncias nulas é, por definição, igual a zero.

O multiplicador de Lagrange é utilizado no cálculo da variância da krigagem ordinária (Yamamoto 2001). A equação da variância de krigagem ordinária é:

$$
\sigma_{K O}^{2}=\sum_{i=1}^{n} \lambda_{i} \gamma_{i}\left(X_{i 0}\right)+\mu
$$

Sendo $\gamma\left(X_{i 0}\right)$ a variância espacial entre o valor a ser estimado e o amostrado.

Segundo Yamamoto (2001) a variância da krigagem é homocedástica o valor da variância independe dos valores amostrais, dependendo apenas da configuração espacial das amostras no entorno do ponto que será estimado (Armstrong 1994). A utilização da variância de krigagem é ineficaz em apresentar a confiabilidade da estimativa quando comparado com o valor estimado, evidenciando uma limitação na aplicabilidade da variância de krigagem como medida de incerteza (Armstrong 1994). Os resultados da krigagem são sempre dados cuja dispersão é inferior àquela dos dados originais, o que indica o efeito de suavização que a krigagem possui (Chilès \& Delfiner 1999).

Uma forma de lidar com a suavização da estimativa krigagem, é utilizar a simulação estocástica (Olea 2003). Simulação estocástica compreende métodos de predição cujos resultados são múltiplas respostas equiprováveis que honram a distribuição e o variograma originais (Deutsch \& Journel 1998; Chilès \& Delfiner 1999). Assim como nas técnicas de krigagem, as técnicas de simulação utilizam o variograma, porém Deutsch \& Journel (1998) destacam que as duas principais diferenças entre estes conjuntos de métodos são:

- O objetivo da krigagem é fornecer a melhor estimativa local de uma variável sem levar em conta a reprodução das estatísticas dos dados. No caso da simulação ocorre a reprodução das estatísticas globais, assim a reprodução do padrão global e a continuidade espacial são evidenciadas no resultado; 
- A simulação é realizada de forma a fornecer a acurácia global ou a local. Esses valores são obtidos comparando-se os diferentes resultados, em um ponto ou numa área.

As simulações podem ser aplicadas tanto a dados categóricos quanto contínuos. No caso da aplicação a dados categóricos é possível honrar padrões geométricos específicos. Para dados contínuos o objetivo é representar os modelos de covariância do domínio (Deutsch \& Journel 1998). Os algoritmos gaussianos são os mais recomendados para estimativas de dados contínuos.

Quando um ponto, com localização tomada ao acaso, é simulado e na sua vizinhança são levados em consideração tanto pontos amostrados quanto pontos previamente simulados, esta simulação é dita simulação sequencial (Deutsch \& Journel 1998). Para obter diferentes resultados, contudo com mesma probabilidade de ocorrência, vários caminhamentos aleatórios são realizados para escolha dos pontos a serem simulados a cada iteração do processo (Deutsch \& Journel 1998).

A simulação sequencial gaussiana utiliza dados transformados em uma distribuição gaussiana. Segundo Deutsch (2002), existem dois motivos para a utilização de uma distribuição gaussiana, que são:

- Utilizar outras distribuições não garante a representação da distribuição amostral nos dados simulados. Uma vez trabalhando em um espaço gaussiano, todas as distribuições serão gaussianas, garantindo a semelhança entre os dados originais e os estimados;

- Conforme exposto pelo teorema do limite central, uma distribuição tenderá à normal por intermédio da adição de resíduos. Assim a adição de resíduos aleatórios na obtenção dos dados simulados tende a distribuição à gaussiana.

Um método de transformação dos dados é chamado normal score transformation. Realiza-se uma transformação não linear na distribuição inicial de modo a transformá-la numa distribuição normal (Deutsch \& Journel 1998). A transformação se dá utilizando a distribuição cumulativa inversa da gaussiana e a probabilidade cumulativa amostral, modificando-se os dados originais para adequá-los a uma distribuição gaussiana (Deutsch \& Journel 1998). Outro método de transformação gaussiana é chamado de modelagem por anamorfose gaussiana, este método utiliza funções não lineares que estabelecem a relação 
bijetora da transformação, os polinômios de hermite modelam o comportamento da distribuição cumulativa amostral (Wakernagel 2003).

Segundo Deutsch \& Journel (1998) o procedimento para a simulação sequencial gaussiana é:

- Transformar o dado original em uma distribuição gaussiana normal com média zero e variância 1;

- Definir aleatoriamente um caminhamento em que todos os pontos a serem simulados serão visitados;

- No ponto a ser simulado realizar a krigagem simples;

- Sortear por simulação de Monte Carlo um resíduo com distribuição normal com média zero e variância igual a $\sigma_{S K}^{2}(x)$;

- Somar o resíduo ao valor estimado por krigagem simples para obter o valor simulado. Desta forma, um ponto simulado é calculado conforme:

$$
Z_{s}(x)=Z^{*}(x)+R(x)
$$

Onde $Z_{s}(x)$ é o valor simulado em um ponto, $Z^{*}(x)$ é o valor estimado por krigagem simples naquele ponto e $R(x)$ é o valor do resíduo.

- Após todos os pontos desejados terem sido simulados, reinicia-se processo utilizando um novo caminho aleatório.

O último processo, após cada iteração, é a transformação inversa dos valores gaussianos aos valores originais.

\subsection{Incertezas}

Incerteza é definida como a falta de certeza na descrição de um objeto, uma característica ou um processo (Bárdossy \& Fodor 2004). As incertezas advindas de modelos geomatemáticos são consideradas de caráter humano, relativo a imperfeições teóricas (Bárdossy e Fodor 2004), sendo representados pela diferença entre o modelo apresentado e a realidade natural. Em projetos e empreendimentos de alto risco, como a mineração, o estudo das incertezas é tema de diversos trabalhos e pesquisas. O estudo de incerteza em mineração é realizado em diferentes momentos do planejamento e da vida útil da lavra. Pesquisas sobre 
incerteza da reserva mineral em planejamento de lavra a céu aberto como apresentado em Lamghari \& Dimitrakopoulos (2013), que estuda a incerteza no conteúdo mineral do corpo de minério e sua influência no planejamento de lavra são de amplo interesse na indústria de mineração.

Conforme apresentado em Caers (2011) estimativas apresentam erros. Contudo podese dimensionar o erro gerado durante o cálculo, que pode ser obtido com a variância da krigagem. A variância e o desvio padrão da krigagem fornecem uma medida da incerteza associada ao estimador (Chilès \& Delfiner 1999), contudo, seu valor independe do valor amostral, depende apenas da vizinhança onde a amostra se encontra. Segundo Chilès \& Delfiner (1999), a krigagem calcula uma média linear, o que torna os valores estimados menos dispersos que aqueles dos dados originais. Comparando as equações da variância de krigagem e variância amostral pode-se obter uma relação da variância da estimativa geral. Desta forma, com a variância da krigagem apresentada em (18) e a variância amostral dada por:

$$
\sigma_{Z(x)}^{2}=\frac{1}{n} \sum_{i=1}^{n}\left[Z\left(x_{i}\right)-\bar{Z}\right]
$$

Onde $\sigma_{Z(x)}^{2}$ é a variância da variável $Z(x), n$ é o número de amostras, $Z\left(x_{i}\right)$ é uma amostra específica e $\bar{Z}$ é a média amostral calculada como: $\bar{Z}=\frac{1}{n} \sum_{i=1}^{n} Z\left(x_{i}\right)$.

A variância da estimativa pode ser descrita conforme:

$$
\sigma_{Z^{*}}^{2}=\sum_{i=1}^{n} \lambda_{i} \gamma\left(x_{i 0}\right)
$$

De (21), conforme exposto em Chilès e Delfiner (1999), deriva-se:

$$
\sigma_{Z^{*}}^{2}=\sigma_{Z(x)}^{2}-\sigma_{K O}^{2}
$$

Assim a variância dos valores estimados difere da variância amostral o valor exato da variância da krigagem, o que confere o efeito de suavização (Chilès \& Delfiner 1999). Contudo, o efeito de suavização ocorre de forma mais evidente em vizinhanças globais, em 
que se considera um grande número de amostras na estimativa (Chilès \& Delfiner 1999). A variância da estimativa vai ser sempre menor do que a amostral mesmo com um ponto estimado distante de todas as amostras (Chilès \& Delfiner 1999).

Apesar da variância da krigagem ser homocedástica há alguma aplicabilidade em seu cálculo como a sua capacidade em indicar precisão (Chilès \& Delfiner 1999). De forma local, a variância indica que incertezas são menores perto de dados amostrados, regionalmente a variância reflete a variabilidade em uma região do domínio amostral (Chilès \& Delfiner 1999).

No caso das simulações sequenciais o cálculo das incertezas é diferente, uma vez que cada simulação reproduz as estatísticas descritivas dos dados amostrais. Uma forma de interpretar os resultados das diversas simulações é calcular uma função de distribuição acumulada $(c d f)$ a partir das realizações em cada ponto simulado. Conforme Deutsch \& Journel (1998), a chamada função de distribuição cumulativa condicional ( $c c d f$ ) é usada para medir a incerteza no local $x$ onde a simulação foi realizada. A $c c d f$ é uma $c d f$ condicionada especificamente para um comportamento particular da distribuição, como no caso de valores ou de regiões de interesse. A partir da $c c d f$ de um bloco, ou ponto, simulado, pode-se obter a variância da simulação naquela localização e calculando-se a variância deste modo em todo o domínio é possível evidenciar regiões que apresentam incertezas mais altas.

A diferença entre a incerteza associada à simulação e a da estimativa da krigagem é evidente. Conforme exposto, a variância da krigagem é baseada apenas na variância espacial e considera apenas a configuração (quantidade e distância) de amostras na vizinhança sem levar em conta os valores da VR. No caso da variância da simulação o valor do dado simulado, nas $n$ simulações, é considerado para derivar a incerteza associada ao ponto simulado. No caso da krigagem, a variância indica uma incerteza associada à disposição espacial dos dados, sendo seu caráter local, na simulação a variância indica os comportamentos que a variável pode assumir globalmente, sendo que o valor da variância indica a flutuação assumida nos locais simulados. Outra diferença reside no fato que a variância da krigagem é homocedástica, considerando só a configuração espacial e não o valor das amostras, o que não ocorre com a variância do bloco calculada na simulação, pois para cada uma das simulações os dados utilizados no cálculo variam, evidenciada pelo caráter sequencial da simulação. 


\subsection{Otimização}

A palavra otimização remete a uma série de métodos matemático-analíticos que tem como objetivo a seleção da melhor solução a problemas de caráter contínuo ou discreto (Snyman 2005). A otimização de funções discretas recebe o nome de combinatória, sendo a sua contraparte contínua (Kennedy, Eberhart \& Shi 2001). O objetivo dos métodos é maximizar ou minimizar o resultado de uma determinada função, variando-se os valores de seus parâmetros (Kennedy, Eberhart \& Shi 2001 e Snyman 2005). À função que será analisada dá-se o nome de função objetivo (Kennedy, Eberhart \& Shi 2001 e Snyman 2005) e deve possuir $n$ parâmetros passiveis de serem variados, sendo que a cada iteração da otimização modificam-se os valores e compara-se a resposta da função antes e após a mudança (Kennedy, Eberhart \& Shi 2001). Havendo melhoria no resultado da função, adotase a nova parametrização. O número de iterações que a função deve realizar é definida pelo usuário assim como o critério de parada, finalizando a otimização quando um destes controles for atingido (Schoen 2009).

Um conceito importante associado à otimização é o espaço de parâmetro (parameter space). Um espaço de parâmetros é composto pelos possíveis valores que podem ser assumidos pelas variáveis da função objetivo (Kennedy, Eberhart \& Shi 2001). Pode ser vista como uma árvore de busca, no caso da otimização combinatória, ou um plano de $n$ dimensões no caso contínuo, sendo $n$ o número de variáveis (Kennedy, Eberhart \& Shi 2001). No caso discreto o tamanho do espaço é definido pelo número de variáveis e a correlação que elas possuam entre si, conferindo ao espaço um número finito de possíveis de resultados (Kennedy, Eberhart \& Shi 2001). Dados contínuos assumem infinitos valores para cada variável, dessa forma o espaço de parâmetros é constituído de $n$ eixos, que variam em intervalos definidos (Kennedy, Eberhart \& Shi 2001). Análogo ao espaço de parâmetros, o espaço da função (function space) retorna o resultado da função em vista dos parâmetros definidos (Kennedy, Eberhart \& Shi 2001). Por fim, o espaço de ajuste (fitness space) se refere ao grau de sucesso de cada configuração dos parâmetros sobre a otimização (Kennedy, Eberhart \& Shi 2001). A relação entre o espaço de parâmetros e o da função possibilita a visualização do comportamento da função objetivo, como "picos" ou "vales", como o interesse da otimização é conhecer o máximo ou mínimo global da função, a pesquisa é direcionada aos valores ótimos, i.e. o maior pico ou o menor vale (Kennedy, Eberhart \& Shi 
2001). Contudo, há casos em que a função possui diversos picos e vales com valores distantes dos de interesse, esses comportamentos recebem o nome de máximo ou mínimo locais (Kennedy, Eberhart \& Shi 2001). Apresentam-se na figura 07 um espaço de parâmetro simples, com apenas uma variável, relacionado à função objetivo, apontando os máximos e mínimos globais e locais da função.

Uma função discreta possui número finito de possibilidades em que se pode variar seus parâmetros e sua complexidade é relativa ao número de parâmetros e à correlação entre os parâmetros (Kennedy, Eberhart \& Shi 2001 e Snyman 2005). Dessa forma, há um número máximo de configurações a testar quando se busca a melhor resposta, diferente de dados contínuos que possuem infinitos valores passíveis de serem assumidos pelas variáveis, mesmo limitando-se o intervalo (Kennedy, Eberhart \& Shi 2001 e Snyman 2005). Esta limitação, associada às variáveis contínuas, deve ser levada em consideração quando se trabalha com otimização contínua. Segundo Romeijn (2009) não havendo a possibilidade de realizar infinitas interações nos valores das variáveis deve-se assumir um método que garanta o resultado satisfatório para o problema apresentado, Pearl (1984) denomina este tipo de análise como heurística. A boa definição da função objetivo e de seus parâmetros são necessárias para que um número limitado de iterações apresente um resultado adequado ao problema apontado (Romeijn 2009).

Heurística é uma técnica que busca uma boa solução com custo computacional razoável, demandando pouco esforço em sua pesquisa por parâmetros ótimos (Voss 2009). Métodos heurísticos de otimização lidam com pesquisa local (local search), cujo princípio básico é a alteração de parâmetros localmente e de forma sucessiva (Voss 2009). Os componentes envolvidos no deslocamento são chamados de atributos ou elementos, podendo ser substituídos ou permutados sucessivamente em cada iteração do processo (Voss 2009). Cada movimentação deve ser "medida" para guiar a pesquisa, utilizando a função objetivo que fornece a informação da melhora ou piora resultante da movimentação (Voss 2009). Sequenciar as alterações induz ao risco de limitar a pesquisa a um ótimo local ótimo, sendo necessário um mecanismo para guiar a pesquisa, como por exemplo, a meta-heuristica (Voss 2009). 


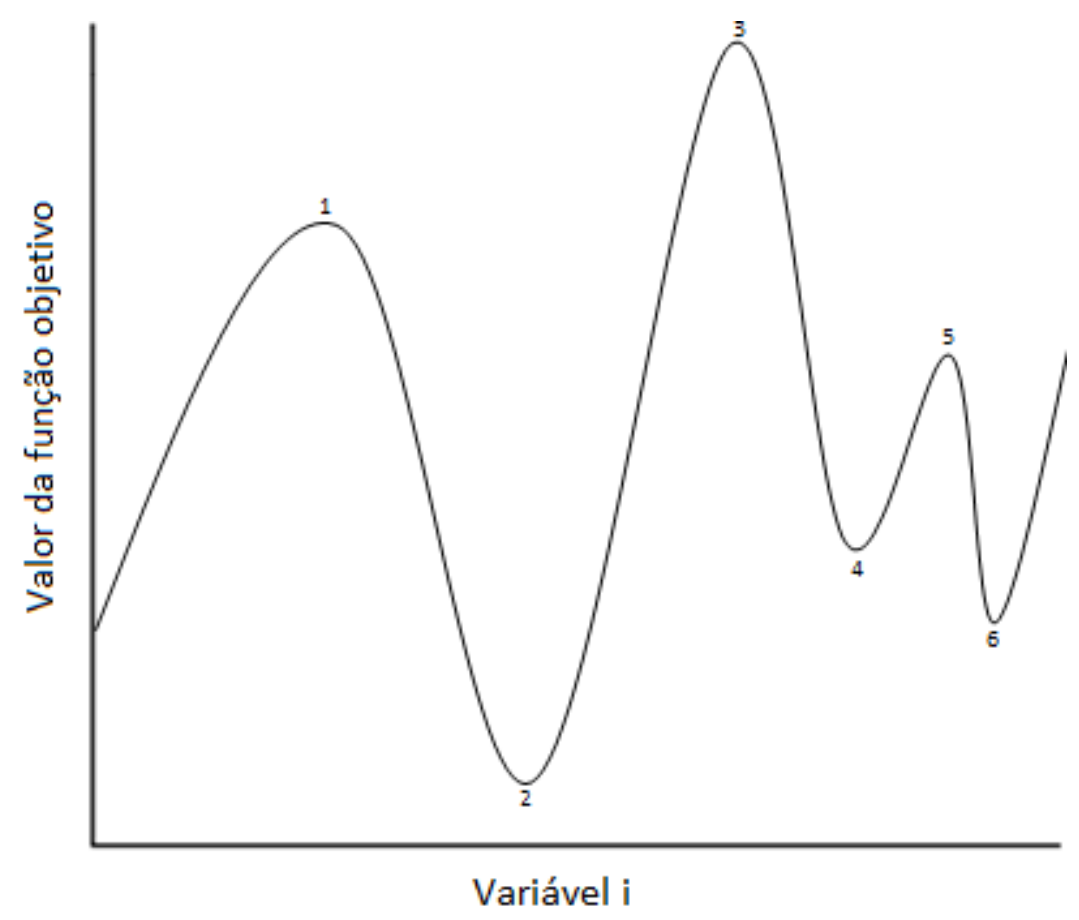

Figura 07 - Exemplo de espaço de parâmetros de uma dimensão relacionado a uma função objetivo. Os picos ímpares são os máximos da função, com o pico 3 sendo o máximo global (no intervalo estudado) e os demais os máximos locais. Os vales pares representam os mínimos da função, com o vale 2 sendo o mínimo global (no intervalo estudado) e os demais vales os mínimos locais (fonte: Autor).

A otimização tem por objetivo definir a configuração dos parâmetros cuja aplicação na função objetivo resultaria no máximo, ou mínimo, valor admissível. A esta definição dá-se o nome de otimização global (Romeijn 2009). Assumindo que funções tendem a possuir diversos mínimos locais, a otimização global garante evitar a obtenção de um caráter local indesejado e continuar a pesquisa no espaço de parâmetros (Romeijn 2009 e Gall 2014). Métodos heurísticos de otimização apresentam limitação em evadir de um comportamentos locais, ao se obter um mínimo local o método não admite aumento na resposta da função objetivo, portanto não seria possível "subir a colina" (hill climbing) limitando sua resposta ao mínimo local obtido (Kennedy, Eberhart \& Shi 2001, Romeijn 2009, Voss 2009 e Gall 2014). A opção a problemática dos métodos heurísticos é utilizar meta-heurística. Otimização metaheurística é referência a uma gama de métodos que guia o processo heurístico na solução de um problema, sendo iterativo ele modifica as operações heurísticas de forma a produzir soluções mais adequadas (Voss 2009). Métodos meta-heurísticos também não garantem que o melhor valor global seja alcançado, assim como os heurísticos, contudo são passíveis de evadir de comportamentos locais (Gall 2014). A resposta de um método meta-heurístico deve 
ser satisfatória para problemas de otimização complexos, que envolvam incertezas, dinamismo ou sistemas estocásticos (Bianchi, Dorigo \& Gambardella 2008 e Voss 2009). Em geral, métodos meta-heurísticos se baseiam em comportamentos observados na natureza (Bianchi, Dorigo \& Gambardella 2008), como é o caso do resfriamento de um material no simulated annealing (Abdi, Fathian \& Safari 2012) ou no comportamento de coletivo de animais, como no caso do particle swarm optimization.

Definida a função objetivo, seus parâmetros e os intervalos da pesquisa, deve-se definir o método de otimização que será aplicado. Existem diferentes métodos que garantem a eficácia da otimização e deve-se escolher um método que possua, na literatura, ampla aplicação comprovada em problemas semelhantes aos de interesse (Bianchi, Dorigo \& Gambardella 2008). Cada método difere, em geral, na forma que os parâmetros variam durante as iterações. Métodos estocásticos trabalham sobre elementos aleatórios que possam ser resultado de um processo estocástico ou apresentam como resultado uma variável aleatória (Romeijn 2009). Um método estocástico de procura por configurações ótimas de parâmetros é a pesquisa aleatória (Kennedy, Eberhart \& Shi 2001 e Romeijn 2009). Cada iteração da pesquisa aleatória modifica os parâmetros de forma aleatória, sem seguir padrão definido, contudo mantendo a configuração com melhor resposta até o momento em que configuração melhor seja obtida (Romeijn 2009). A pesquisa aleatória converge ao ótimo global, tendendo aos valores da função objetiva de forma assintótica, ou seja, quanto maior o número de iterações, o método está mais passível de atingir um valor específico, no caso o melhor valor global (Burkard \& Fincke 1985 e Romeijn 2009).

De forma a evitar comportamentos locais, alguns métodos sequenciais de otimização aceitam, com algum controle, iterações que resultem em piora no valor dos dados (Romeijn 2009). Um desses métodos de otimização é o simulated annealing em que se simula o processo de resfriamento de um objeto sólido a partir de seu "recozimento" (annealing), representado pelo rearranjo dos átomos que compõem o sólido ao se atingir o equilíbrio térmico (Bianchi, Dorigo \& Gambardella 2008; Romeijn 2009 e Gall 2014). A representação do rearranjo das partículas no simulated annealing é sobre o espaço de parâmetros, onde a pesquisa por configurações ótimas é realizada (Bianchi, Dorigo \& Gambardella 2008). No método um só parâmetro é modificado por iteração dessa forma há o sequenciamento das posições das partículas, limitando a pesquisa à vizinhança próxima àquela obtida na iteração anterior (Gall 2014). Contudo, para evitar a limitação a um máximo ou mínimo local, o método admite aceitar configurações que obtenham piora no resultado considerado ótimo até 
o momento (Bianchi, Dorigo \& Gambardella 2008 e Romejn 2009). Este aceite não é desordenado, mas sim feito conforme um chamado "cronograma de resfriamento" (cooling schedule), assim quanto maior for a "temperatura do sistema" no momento da iteração ela será mais propensa a aceitar uma partícula posicionada em local com piora no resultado da função objetivo (Bianchi, Dorigo \& Gambardella 2008, Romeijn 2009 e Gall 2014). O comportamento descrito é seguido de forma a melhor representar a maior entropia que as partículas apresentam quanto maior for sua temperatura, podendo tender a regiões em que não posicionariam corretamente (Gall 2014). Quanto menor a temperatura do sistema, a partícula é menos propensa a admitir piora no resultado da iteração (Romenijn 2009 e Gall 2014). Desta forma, garante-se que a otimização evite um comportamento local para tender a um global, ou a um valor local com melhor resposta, isso devido ao movimento de "subida" (uphil) admissível no algoritmo (Bianchi, Dorigo \& Gambardella 2008 e Gall 2014). Apresenta-se na Figura 08 o esquema de movimentação de uma partícula, locada no espaço de parâmetros, durante a otimização por simulated annealing.

O particle swarm optimization, ou PSO, é um método de otimização estocástico que tem por objetivo simular o comportamento social de uma comunidade de animais possuindo viés sócio-psicológico (Kennedy \& Eberhart 1995 e Kennedy 2010). O método representa a interação de um grupo de animais com um objetivo em comum e a dinâmica do coletivo em busca da solução ao problema é: saber qual é a proximidade do objetivo na posição atual; recordar a melhor posição que estiveram e saber o vizinho que obteve o maior sucesso (Kennedy, Eberhart \& Shi 2001 e Kennedy 2010). O nome do método faz referência a trabalhar no espaço de parâmetros com vários pontos pesquisando por novos valores para a resolução do problema, chamados de "partículas" (particles), utilizando entre 10 e 100 partículas (Kennedy 2010) que simulam esse comportamento simultaneamente como um “enxame” (swarm) (Kennedy, Eberhart \& Shi 2001 e Kennedy 2010). 


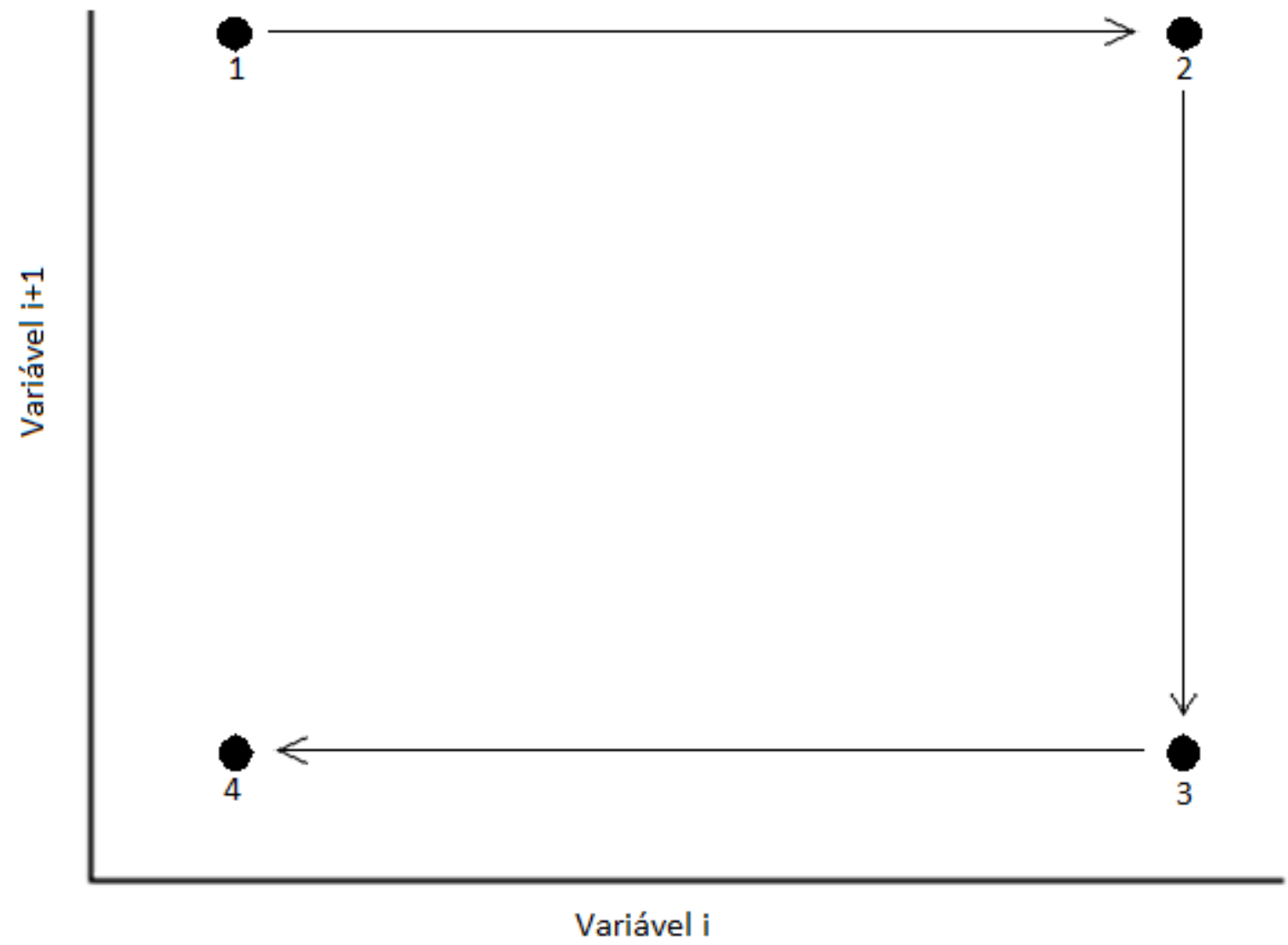

Figura 08 - Esquema de funcionamento do algoritmo de simulated annealing em espaço de parâmetros 2D. A locação inicial será aleatória, no ponto 1, que será movido inicialmente na variável i até o local do ponto 2. Havendo melhora no resultado da função objetivo, a locação em 2 é aceita, do contrário pode ser aceito, ou não, considerando o cooling schedule utilizado. Esse processo se repete de 2 para 3, modificando apenas a variável i+1 e em 3 o teste da função objetivo será realizado novamente. De 3 para 4 o processo e o teste são realizados de forma análoga (fonte: Autor).

Inicialmente $n$ pontos são locados aleatoriamente no espaço de parâmetros, utilizando a função objetivo compara-se o resultado para cada partícula, definindo a melhor localizada individualmente e movendo as demais inicialmente em direção a ela, sendo este local sua melhor posição até o momento, havendo em interação subsequente partícula melhor localizada todo enxame será modificado (Kennedy 2010). A movimentação de cada partícula por iteração é relacionada à "velocidade" que ela assume e essa está relacionada ao melhor local que a partícula já esteve e seu melhor vizinho (Shaw \& Srivastava 2007, Kennedy 2010). As equações (23) e (24) apresentam a movimentação que a partícula realiza a cada iteração, sendo a primeira referente à "velocidade" da movimentação e a segunda à nova posição da partícula movida. Esse método é o PSO inercial, onde se considera a movimentação anterior da partícula na sua movimentação atual (Shaw \& Srivastava 2007 e Kennedy 2010): 


$$
\begin{gathered}
\mathrm{v}_{\mathrm{i}}^{\mathrm{k}}=\mathrm{v}_{\mathrm{i}}^{\mathrm{k}-1}+\mathrm{b} \operatorname{random}(.)\left(\mathrm{m}_{\mathrm{i}}^{\mathrm{l}}-\mathrm{m}_{\mathrm{i}}^{\mathrm{k}-1}\right)+\mathrm{crandom}(.)\left(\mathrm{m}^{\mathrm{g}}-\mathrm{m}_{\mathrm{i}}^{\mathrm{k}-1}\right) \\
\mathrm{m}_{\mathrm{i}}^{\mathrm{k}}=\mathrm{m}_{\mathrm{i}}^{\mathrm{k}-1}+\mathrm{a} \mathrm{v}_{\mathrm{i}}^{\mathrm{k}}
\end{gathered}
$$

Sendo: i a partícula a ser movida; $\mathrm{k}$ a iteração atual; $\mathrm{v}_{\mathrm{i}}^{\mathrm{k}}$ a "velocidade" com que a partícula se move na iteração $k ; \mathrm{v}_{\mathrm{i}}^{\mathrm{k}-1}$ é a velocidade que a partícula possuía na iteração anterior; random(.) um número obtido de forma aleatória no intervalo $[0,1] ; \mathrm{m}_{\mathrm{i}}^{\mathrm{k}-1}$ é a posição da partícula na iteração anterior; $m_{i}^{l}$ a melhor posição que a partícula i já esteve (utiliza um $\mathrm{l}$ para indicar seu caráter local); $\mathrm{m}^{\mathrm{g}}$ a posição da partícula melhor locada (g indica seu caráter global); $\mathrm{m}_{\mathrm{i}}^{\mathrm{k}}$ é a posição que a partícula vai assumir; $\mathrm{v}_{\mathrm{i}}^{\mathrm{k}}$ a velocidade que a partícula acresce a sua posição atual; as constantes b e c se referem ao peso que o usuário pode atribuir a memória da partícula e a sua vizinhança, respectivamente; a é o chamado peso de inércia, cujo valor deve ser reduzido com o decorrer da otimização (Shaw \& Srivastava 2007).

Como a locação inicial das partículas se da de forma aleatória, a velocidade inicial de cada partícula é zero, sendo modificada a cada movimentação subsequente (Shaw \& Srivastava 2007 e Kennedy 2010). A cada iteração as partículas se movem segundo a equação e limitadas pelo espaço de parâmetros (Shaw \& Srivastava 2007 e Kennedy 2010). O algoritmo deve avaliar a resposta da função objetivo para cada nova posição da partícula, atualizando a sua melhor posição no tempo e, se necessário, a partícula melhor localizada (Kennedy 2010). O movimento das partículas tende a uma região do espaço de parâmetros centrada na melhor posição global e seu melhor local. A variação destes valores também modifica a trajetória das partículas e analogamente a região do espaço em que elas se movimentam (Kennedy 2010). Conforme exposto em Kennedy (2010), a otimização por PSO representa as interações de um número de indivíduos, com um objetivo comum, cada um sabendo seu estado atual, seu melhor desempenho anterior e o seu vizinho mais bem sucedido, assim todos são fontes e alvos de um processo dinâmico, de forma a descobrir boas soluções para problemas complexos, que envolvam não linearidade, grande dimensão, ótimos locais, entre outros comportamentos complexos. Apresenta-se na Figura 09 o esquema de movimentação da otimização pelo método PSO utilizando-se 3 partículas. 


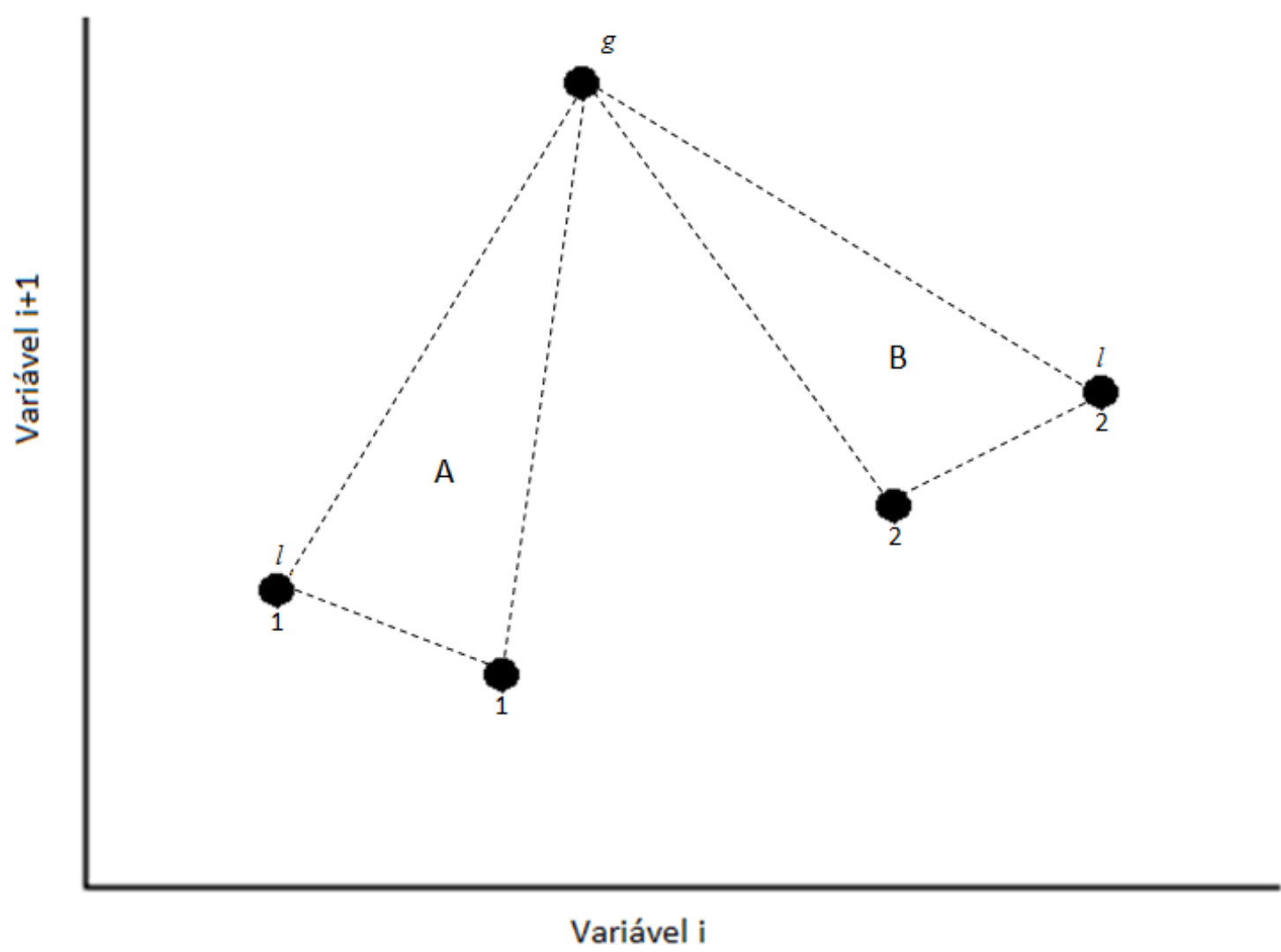

Figura 09 - Particle swarm optimization representada esquematicamente. São utilizadas 3 partículas, sendo 1 e 2 as partículas que pesquisam melhores soluções no espaço amostral e a partícula $g$ que representa a melhor posição já obtida por uma partícula até a presente iteração. O ponto com o índice $l$ indica a melhor posição que a referida partícula já encontrou no espaço de parâmetros. As áreas $A$ e $B$ representam a região onde cada partícula pode se movimentar na referida iteração, entre seu melhor local até o momento e a partícula melhor locada (fonte: Autor).

Otimização é um tema de interesse em algumas áreas das geociências, sendo aplicada em geofísica, como é o caso de Shaw \& Srivastava (2007) que estudaram a aplicação do PSO para inversão de dados geofísicos. Na mineração possui grande aplicabilidade e o maior interesse reside em otimizar diferentes etapas do empreendimento mineiro, como o trabalho de Silva \& Boisvest (2013) onde diversos métodos são aplicados a fim de inferir os melhores locais para locação de novas sondagens em um modelo 2D, baseado na variância de krigagem e no aumento da tonelagem do depósito. A aplicação de otimização na lavra possui grande importância, sendo fonte de diversos trabalhos, como Kizilkale \& Dimitrakopoulos (2013), onde a otimização da taxa de mineração que deve ser aplicada baseando-se na incerteza financeira da mina é estudada. Outro exemplo é o trabalho de Lamghari \& Dimitrakopoulos (2013) em que um método meta-heurístico é aplicado ao cronograma de produção utilizando a incerteza da reserva em lavra a céu aberto. 


\section{MATERIAIS E MÉTODOS}

\subsection{Banco de Dados}

O banco de dados é um depósito sintético criado por Takafuji (2015). Trata-se de uma sequência de arenitos e folhelhos dobrados, associados a falhamento posterior. Na região de falha encontra-se um quartzito associado ao cobre mineralizado.

A Figura 10 apresenta um perfil do depósito e na Tabela 01 apresentam-se as estatísticas do bem mineral de interesse.

\subsection{Amostragem Inicial}

A base de dados inicial é composta por 32 furos de sonda locados de forma aleatória seguindo uma malha irregular e concentrada em porções específicas do domínio, conforme pode ser observado na Figura 11 que é o mapa geológico do depósito com a localização das bocas dos furos.

Um furo é vertical e os demais são perpendiculares ao plano de falha que contém a mineralização. Assim os as sondagens foram simuladas na direção N270 com $45^{\circ}$ de mergulho e os valores de teor de cobre tomados a cada metro ao longo dos testemunhos.

\subsection{Programas e Linguagens de Programação}

Nos dados amostrados utilizou-se a biblioteca de geoestatística GSLIB@. O GSLIB@ é um programa livre de geoestatística desenvolvido na Universidade de Stanford. Foi desenvolvido na linguagem de programação FORTRAN@ e seu código fonte pode ser encontrado em Deutsch \& Journel (1998). Apesar da biblioteca do GSLIB@ ser antiga, em comparação a programas mais recentes de geoestatística, ele ainda é totalmente funcional. 

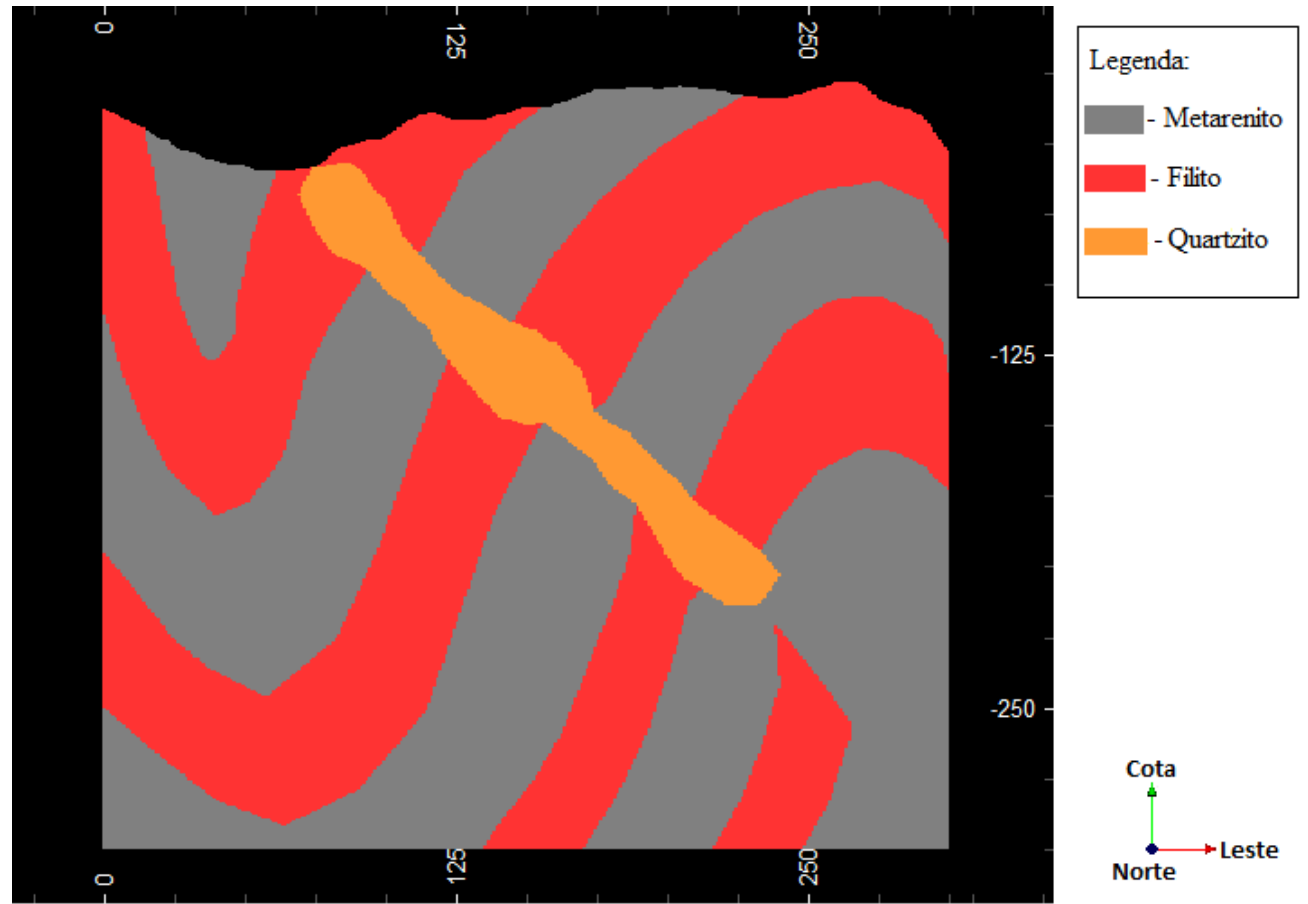

$-125$

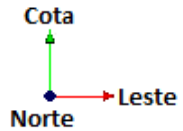

Figura 10 - Perfil geológico do depósito sintético mostrando as camadas dobradas de metarenito e folhelhos e a zona de falha com quartzito remobilizado mineralizado.

Tabela 01 - Parâmetros da variável cobre da base de dados original, considerada a população.

Estatísticas descritivas

Base de dados

\begin{tabular}{cc}
\hline Média & 0.686 \\
Variância & 0.160 \\
Mínimo & 0.500 \\
Máximo & 30.50 \\
Mediana & 0.545 \\
\hline
\end{tabular}




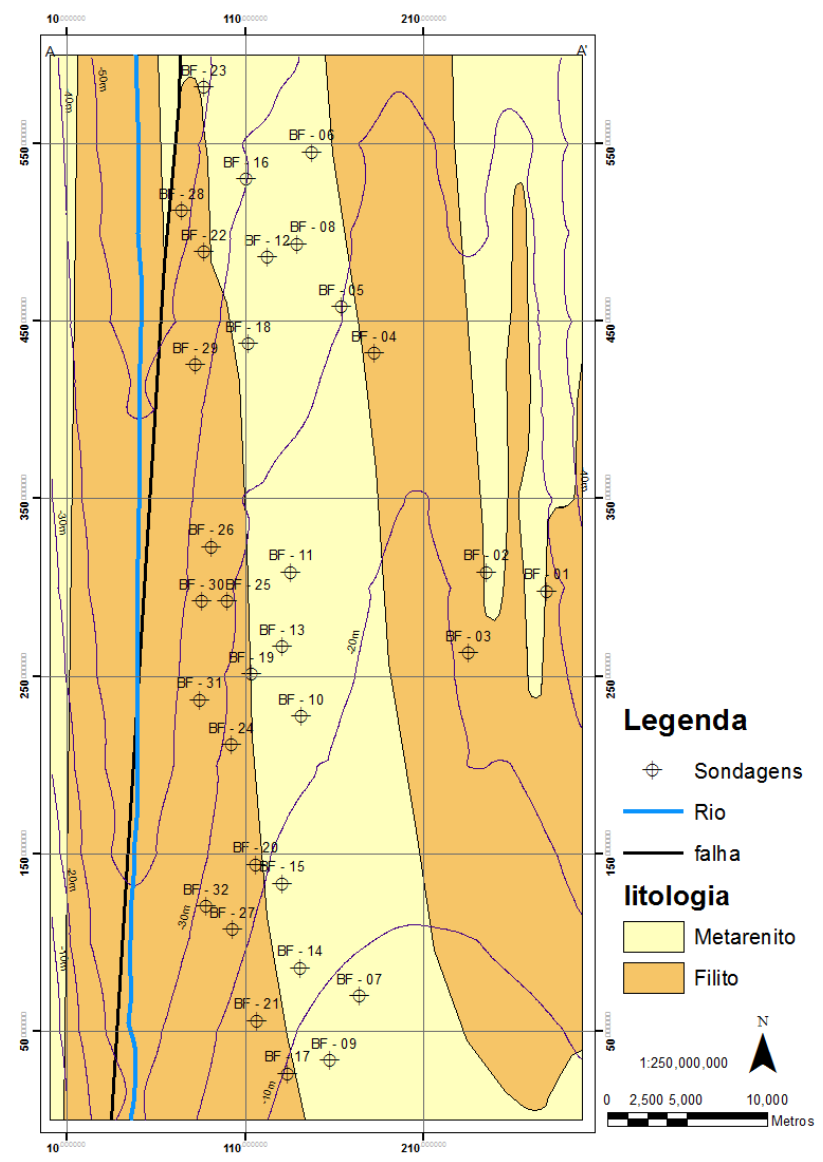

Figura 11 - Mapa geológico da área, baseado no corpo confeccionado, e as 32 sondagens iniciais que foram usadas no presente trabalho. (fonte: Autor)

No caso deste trabalho foram utilizadas as rotinas nscore e sgsim, que realizam a transformação gaussiana e a simulação sequencial gaussiana respectivamente. Para utilizar o GSLIBC deve-se primeiro gerar um arquivo onde são especificados os valores dos parâmetros que serão lidos pela rotina. No sgsim modificou-se o código fonte para controlar quais blocos seriam simulados, limitando-os aos arredores das amostras mineralizadas. Para isso definiu-se uma fronteira convexa, envolvendo-as, uma vez que a simulação fora da fronteira, falseando as proporções da ocorrência mineral, acarretaria em resultados indesejados na otimização. Por ser uma biblioteca aberta e seu código fonte estar disponível, foi possível fazer as modificações que atendessem as necessidades do trabalho.

O desenvolvimento e/ou adaptação dos algoritmos apresentados neste trabalho utilizou a linguagem de programação Python@ $\odot$. A partir dela as rotinas de GSLIB@ foram executadas, assim como os arquivos de parâmetros foram dinamicamente alterados. A 
fronteira convexa aplicada aos dados foi definida a partir de uma biblioteca já disponível para Python®. A implementação e teste da função objetivo, bem como dos algoritmos de otimização também foram realizadas nesta linguagem.

O programa Datamine@ foi utilizado para amostrar os dados. Inicialmente amostrouse 32 furos objetivando inferir o infill ótimo. Para efeito de comparação entre as locações otimizadas, optou-se por amostrar os furos com otimização ótima na base sintética de dados, que também fora realizada no Datamine@

\subsection{Função Objetivo}

A função objetivo a ser utilizada necessitava contemplar a incerteza associada à simulação dos dados amostrais. Não se optou pela variância de krigagem, pois esta medida é homocedástica. Deste modo a medida de incerteza utilizada foi aquela derivada do resultado da simulação estocástica. No caso da função objetivo a soma global da incerteza foi utilizada, sendo sua minimização o objetivo principal dos métodos de otimização. Foram realizados testes para averiguar quais das medidas de incerteza apresentam melhor resultado à otimização, variância ou coeficiente de variação dos blocos.

A função objetivo foi definida como a soma da variância ou do coeficiente de variação dos blocos da simulação, programou-se em Python@ a realização este cálculo. Inicialmente desconsideram-se os blocos não simulados, posteriormente calcula a variância, ou o coeficiente de variação do bloco, e por fim soma os valores. Essa função é utilizada durante as iterações da otimização para aferir se há minimização do valor com os parâmetros obtidos. A simulação da amostragem inicial foi utilizada para definir o valor base das funções objetivo.

Para comparar o resultado de cada função objetivo, os método de otimização foram implementadas duas vezes, uma com base na soma da variância de blocos, e outra no coeficiente de variação do bloco. A variância é a forma básica de se medir a incerteza de uma variável aleatória, pois é uma dispersão em torno da média, comprovando seu uso como função objetivo.

\subsection{Otimização}


Para testar a melhor técnica de otimização ao problema proposto optou-se por três diferentes métodos que foram: pesquisa aleatória, simulated annealing e particle swarm optimization, do mais simples ao mais complexo respectivamente.

Cada função loca $n$ amostras, cuja locação do colar é variada a fim de se pesquisar por valores ótimos de posição. A variação do colar é no valor de Leste e Norte dos furos, sendo o valor de Cota fixo. A atitude dos furos é mantida fixa de forma a ser perpendicular ao plano de falha do depósito, sendo a direção dos furos $270^{\circ}$ e o mergulho $45^{\circ}$. Os furos locados são valorados com base na média da simulação da amostragem inicial. Após a valoração dos novos furos calcula-se a simulação da base de dados atualizada, que utiliza o mesmo modelo de variograma, vizinhança e raiz de caminho aleatório. O espaço de parâmetros que esta sendo explorado possui $2 n$ eixos, uma vez que cada furo é relacionado às variáveis Norte e Leste. A pesquisa dentro do espaço é definida conforme o método de otimização, calculandose o resultado da função objetivo para a configuração dos furos obtida em cada iteração. A variação dos valores das coordenadas Leste e Norte são limitadas, inicialmente, pelos valores de máximo e mínimo admissível ao modelo de blocos, em seguida à movimentação implementada no algoritmo de otimização. Os furos valorados são adicionados à base de dados original, composta pela amostragem inicial, gerando a base de dados atualizada, contendo a amostragem inicial e o infill locado na otimização.

Os parâmetros da otimização por pesquisa aleatória que devem ser estabelecidas pelo usuário são:

- Função objetivo a ser minimizada (variância ou coeficiente de variação);

- Resultado da simulação base inicial realizada sobre a amostragem inicial;

- Número de iterações que serão realizadas;

- Número de novos furos a ser locado;

- Arquivo contendo a amostragem inicial;

- Limites mínimo e máximo para Leste e Norte;

- Valor de Cota das bocas dos furos;

- Atitude dos furos (azimute e mergulho), comprimento da manobra a ser implementada (distancia entre as amostras); e

- Comprimento máximo que os furos podem assumir. 
Definidos os parâmetros, o programa deve ser executado e o resultado será a posição da boca dos $n$ furos locados e o valor da função objetivo com base na simulação dos furos locados. A pesquisa aleatória é realizada segundo:

1. Geração de $n$ furos locados aleatoriamente de forma que todos os furos possuam ao menos uma amostra com teor de cobre;

2. Cálculo da simulação dos dados atualizados, amostragem inicial adicionada dos novos furos locados;

3. Cálculo da função objetivo com base na simulação dos dados atualizados;

4. Início das $m$ iterações;

5. Geração de $n$ furos locados aleatoriamente de forma que todos os furos possuam ao menos uma amostra com teor de cobre;

6. Cálculo da simulação dos dados atualizados;

7. Cálculo da função objetivo com base na simulação dos dados atualizados;

8. Havendo diminuição no valor da função objetivo, a locação obtida pela iteração é definida como ótima e o valor da função objetivo, obtida dessa locação, é o ótimo a ser minimizado;

9. Repetir o processo até o fim das $m$ iterações;

10. Retorno da posição Leste, Norte, Cota da boca dos $n$ furos ótimos e o resultado da função objetivo com a amostragem atualizada.

A locação dos $n$ furos é realizada por uma função que os gera e confere se ao menos uma amostra do furo possuí valor de cobre, caso contrário modifica a posição até que esta condição seja satisfeita. A simulação realizada pelo programa é adicionada automaticamente e as rotinas nscore e sgsim do GSLIB@ são executadas utilizando como arquivo de entrada a base de dados original adicionada com os novos dados locados. São realizadas 100 simulações com base no novo dado. A função objetivo calcula automaticamente o valor da soma da variância ou do coeficiente de variação dos blocos da nova simulação. Para cada nova iteração esse processo é realizado seguindo a ordem indicada, sendo o passo final a comparação entre o ótimo até aquela iteração e o resultado atual da função objetivo. Não havendo melhora, outra iteração é iniciada sem que se altere a parametrização ou o valor da configuração ótima. Apresenta-se na Figura 12 o fluxograma da otimização por pesquisa aleatória. 
A otimização por simulated annealing utiliza os mesmos parâmetros definidos para a otimização por pesquisa aleatória, porém há um parâmetro adicional que é o método de resfriamento. No caso do algoritmo desenvolvido neste trabalho o resfriamento pode ser linear (0 no arquivo de parâmetros) ou exponencial (1 no arquivo de parâmetros). O método linear é considerado lento, sendo que para cada iteração o valor da temperatura, que define a probabilidade do programa aceitar uma piora no resultado da função objetivo, é calculado linearmente comparando o número da iteração atual com o número de iterações. A função é dada por:

$$
1-\left[\frac{i+1}{\text { niter }}\right]
$$

Sendo i a iteração atual e niter o número total de iterações.

Esta função varia de 1, valor inicial, até 0, valor final. Quanto menos iterações realizadas, maior a probabilidade de aceitar uma configuração ótima que resulte em piora da função objetivo.

O método rápido de resfriamento também trabalha com base no valor da iteração relacionado o ao número de iterações, contudo sua diminuição se da de forma mais acentuada. A função que define este valor é dada pela equação a seguir:

$$
\frac{\left[\frac{\text { niter }+1}{\mathrm{i}+1}\right]}{\text { niter }}
$$

Esta função varia de um valor pouco maior que 1, até tender a zero. Seu resultado decresce acentuadamente se comparado ao da linear, como fica evidente observando a segunda iteração onde o valor da função é a metade do valor inicial.

Os valores de temperatura foram implementados no algoritmo do simulated annealing relacionados a um valor de controle, que deve ser obtido aleatoriamente em um intervalo de 1 a 0. Quando a iteração não resultar na diminuição no valor da função objetivo, ainda pode-se admitir a substituição, no caso de o valor da temperatura ser maior que o valor do controle. Como o valor da temperatura decresce com a otimização, há menor probabilidade de se admitir resultados indesejáveis com o tempo. 
Uma diferença implementada no algoritmo aplicado no presente trabalho se da no fator "memória" que o simulated annealing recebeu. Na função utilizada são realizadas 3 comparações, a primeira com a memória do melhor valor obtido durante a otimização, a segunda com o ótimo obtido até a presente iteração, e por fim se houve piora frente ao ótimo. Esse controle foi adicionado para evitar que o melhor resultado obtido seja descartado no fim da otimização.

A sequência de execução do algoritmo de simulated annealing é:

1. Geração de $n$ furos aleatórios, de forma que todos possuam ao menos uma amostra com teor de cobre;

2. Realização da simulação com base na amostragem atualizada;

3. Cálculo da função objetivo sobre a simulação dos dados atualizados;

4. Inicio das $m$ iterações;

5. Cálculo da temperatura da iteração;

6. Perturbação aleatória na posição dos novos furos;

7. Conferencia da nova posição dos furos. Havendo furo vazio, este é movido novamente até que possua ao menos uma amostra na mineralização;

8. Simulação dos dados amostrais originais adicionando-se os novos;

9. Calculo da função objetivo;

10. Comparar o resultado da função com o melhor valor já obtido (memória), se houver diminuição o valor é atualizado e a configuração é considerada a melhor;

11. Comparar o resultado com o ótimo até a iteração, havendo diminuição, este valor é considerado o novo ótimo e sua configuração é armazenada;

12. Se o valor for maior que o considerado ótimo, calcula-se o valor de controle, obtido aleatoriamente entre 0 e 1 ;

13. No caso do valor da temperatura ser maior que o do controle o valor do ótimo será atualizado assim como sua configuração;

14. Repetir os passos de 5 a 13 até que a última ( $m$-ésima) iteração seja realizada;

15. Retorna a posição Leste, Norte e Cota da boca dos $n$ furos considerados ótimo com o valor da função objetivo desta configuração, e a memória do melhor valor obtido durante a otimização com a configuração de boca de furos. 


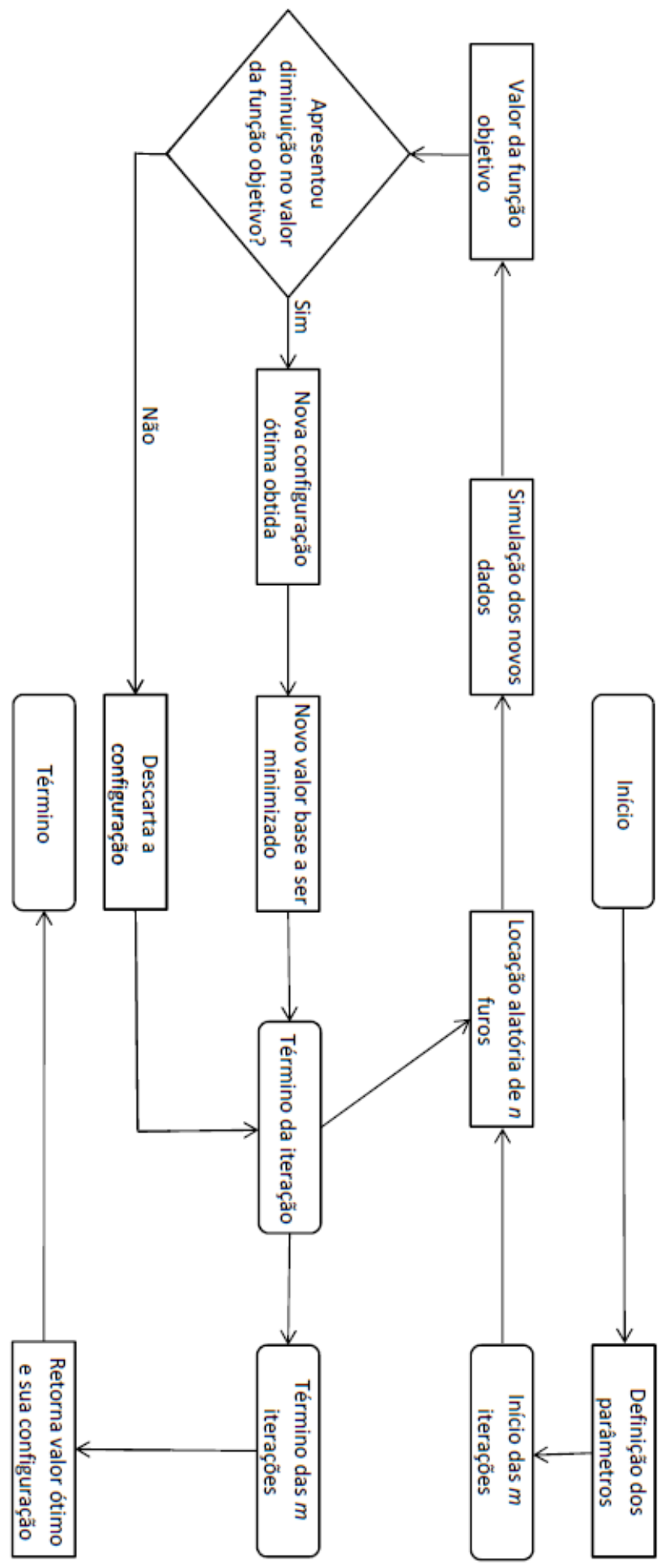

Figura 12 - Fluxograma da otimização por pesquisa aleatória. Só apresenta um nó decisório, que representa a comparação entre o valor ótimo e a resposta da iteração. 
Ao retornar o resultado da otimização, ou seja, o ótimo obtido pelo método, e o melhor resultado encontrado, não se incorre o risco de perda de informação. Há possibilidade, ainda, dos resultados serem idênticos, para a mesma otimização, visto que quando um novo melhor resultado for obtido, este será considerado o ótimo a partir da referida iteração. Contudo, mesmo com a memória aplicada ao método, isso não infere em melhoria obrigatória em relação a simples otimização direta, uma vez que o método é estocástico. $\mathrm{O}$ aumento no número de iterações é a única solução direta e que aumenta a probabilidade de obtenção de melhor valor. Apresenta-se na Figura 13 o fluxograma do algoritmo simulated annealing implementado no trabalho.

O último algoritmo implementado é o da otimização por particle swarm. A principal diferença deste método para os outros é a utilização de mais de um ponto no espaço de parâmetros, portanto novos parâmetros precisam ser fornecidos pelo usuário. Estes são: número de partículas utilizadas durante a otimização, a inércia e o valor de alfa. Os demais são aqueles descritos para os outros métodos de otimização. O valor de alfa refere-se ao peso que será dado à interação entre a partícula e o melhor valor global, de seu valor se obtém o valor beta, que representa o peso do melhor local (memória) na movimentação da partícula. Desta forma, alfa é o peso social e beta o peso da memória envolvida na movimentação da partícula. A inércia verifica se o usuário vai utilizar a velocidade da iteração anterior para considerar a movimentação atual da partícula. Caso a velocidade anterior não seja considerada, caso não-inercial, a partícula tem só a velocidade instantânea de movimentação. A velocidade instantânea representa o deslocamento que a partícula fará na iteração, um valor aleatório em direção à posição global e a memória, que deve ser acrescido à posição atual da partícula após seu cálculo.

No caso da movimentação inercial a velocidade anterior da partícula é considerada e somada à movimentação instantânea da iteração. Além do peso da memória e da melhor posição global, é atribuído um peso à inércia. O peso inercial deve ser relacionado à velocidade da movimentação e seu valor deve ser reduzido no decorrer da otimização. Optouse por calcular este peso conforme o cálculo de temperatura do algoritmo de simulated annealing, assim como ocorre no resfriamento lento onde o valor decresce linearmente com o tempo. 


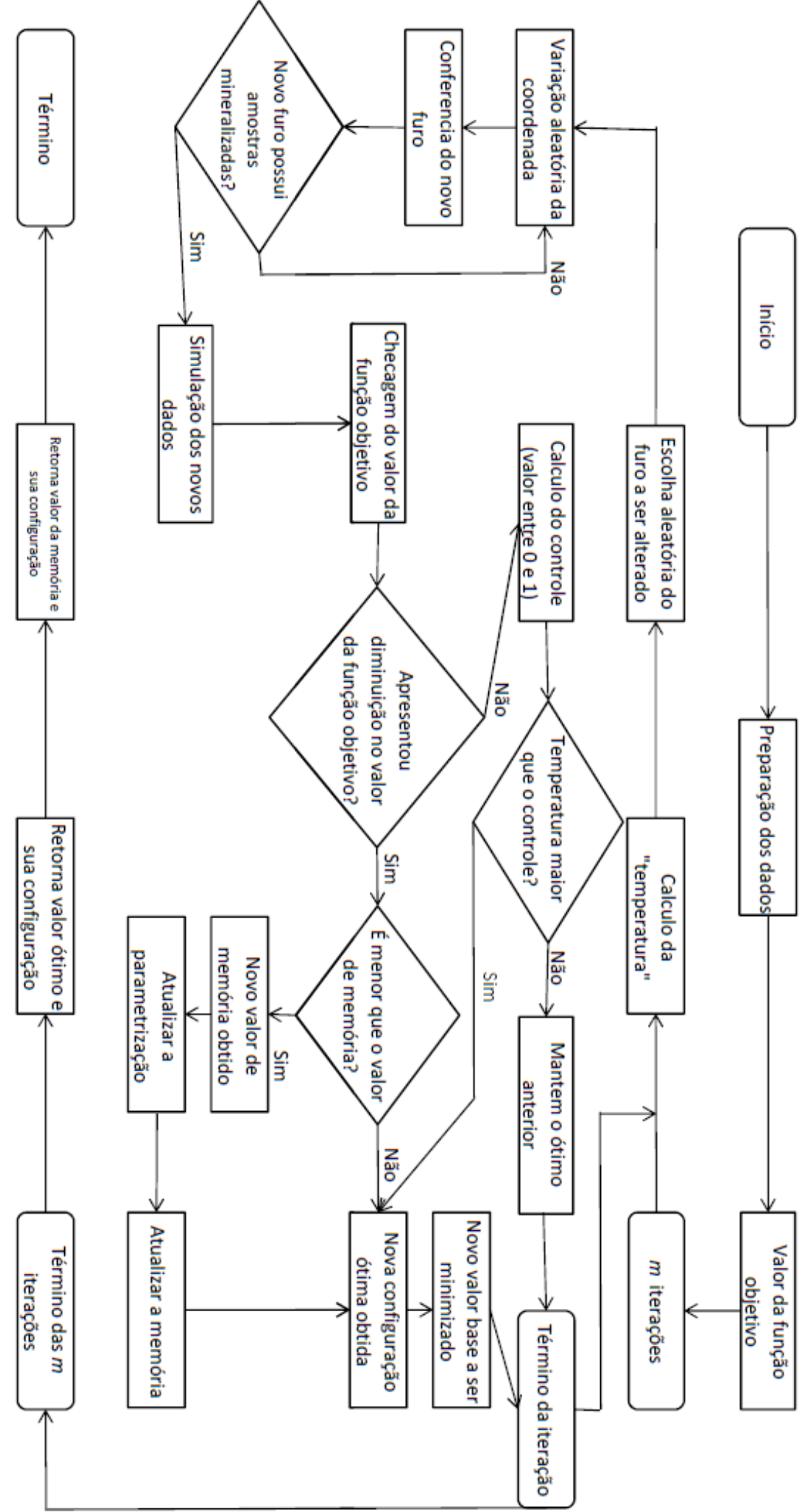

Figura 13 - Fluxograma da otimização por simulated annealing. 
A sequencia de trabalho do algoritmo de particle swarm optimization desenvolvido é:

1. Preparação para a otimização:

1.1. Geração de $p$ partículas no espaço de parâmetros, cada qual com $n$ furos aleatórios ( $2 n$ valores por partícula, Leste e Norte), de forma que todos os furos possuam ao menos uma amostra com teor de cobre;

1.2. Realização da simulação com base na amostragem original atualizada para cada partícula;

1.3. Cálculo da função objetivo para cada partícula;

1.4. Guardar o resultado da função objetivo para cada partícula individualmente, como memória;

1.5. Gravar a configuração de cada partícula como memória individual;

1.6. Definir a partícula que possua menor valor de função objetivo;

1.7. Arquivar a configuração da partícula com melhor resultado global;

1.8. Guardar o valor mínimo global;

1.9. Calcular o peso beta (associado à memória da partícula) como a subtração de 1 por alfa (peso associado à melhor posição global);

2. Inicias as $m$ iterações;

3. Cálculo do peso de inércia da iteração;

4. Conferir o método de movimentação, não inercial ou inercial:;

4.1. Caso não inercial, para cada partícula individualmente:

I. Cálculo da diferença entre a posição da partícula e a posição da partícula com melhor posição global;

II. Multiplicar a diferença por um valor aleatório sorteado entre 0 e 1 ;

III. Multiplicar o resultado por alfa;

IV. Guardar o resultado como influência global;

V. Cálculo da diferença entre a posição da partícula e a posição do melhor resultado obtido anteriormente pela partícula (local);

VI. Multiplicar a diferença por um valor aleatório obtido entre 0 e 1;

VII. Multiplicar o resultado por beta;

VIII. Somar a multiplicação de VII à influência global, o resultado será a velocidade instantânea da partícula;

IX. Multiplicar velocidade de inércia pelo peso da inércia; 
X. Somar o resultado com a posição atual da partícula para obter sua nova posição;

XI. Conferir a posição da partícula dentro do modelo de blocos, se houver furo fora da zona mineralizada a movimentação é refeita até que todos os valores estejam dentro da referida zona;

4.2. Caso inercial, para cada partícula individualmente:

I. Cálculo da diferença entre a posição da partícula e a posição da partícula com melhor posição global;

II. Multiplicar a diferença por um valor aleatório obtido entre 0 e 1;

III. Multiplicar o resultado por alfa;

IV. Reservar o resultado como influência global;

V. Cálculo da diferença entre a posição da partícula e a posição do melhor resultado obtido anteriormente pela partícula (local);

VI. Multiplicar a diferença por um valor aleatório sorteado entre 0 e 1 ;

VII. Multiplicar o resultado por beta;

VIII. Somar o resultado obtido em VII à influencia global para obter a velocidade atual da partícula;

IX. Somar a velocidade atual com a velocidade da partícula na iteração anterior ( 0 quando $m=1)$;

X. Multiplicar a soma pelo peso da inércia;

XI. Somar o resultado com a posição atual da partícula para obter sua nova posição;

XII. Conferir a posição da partícula em relação ao modelo de blocos, caso haja algum furo fora da zona de mineralização a movimentação é refeita até que todos os furos satisfaçam esta condição;

5. Calcular a função objetivo na nova posição da partícula;

6. Verificar se houve minimização em relação ao valor local, caso tenha havido atualizar a posição e o valor local da partícula;

7. Verificar se houve minimização da função objetivo considerando a melhor posição global, caso tenha ocorrido atualizar a posição e o valor do ótimo global;

8. Realizar o mesmo processo para as $p-1$ partículas restantes; 
9. Repetir o processo até o fim a $m$-ésima iteração;

10. Manter a configuração de boca dos $n$ furos e o valor da melhor partícula obtida globalmente.

Apresenta-se na Figura 14 o fluxograma da otimização por particle swarm. O cálculo da velocidade instantânea não foi apresentado, porém ele segue o procedimento já mencionado.

\section{RESULTADOS E DISCUSSÃO}

Neste item serão apresentados e discutidos inicialmente os resultados das análises estatísticas e geoestatísticas dos dados amostrais, bem como a simulação estocástica e suas respectivas incertezas associadas. Posteriormente esta discussão e apresentação de resultados é feita para os métodos de otimização considerando ambas as funções objetivo e, por fim, com base nos novos furos indicados como ótimos pelos métodos de otimização, compará-los entre si e também com a população de cobre na mineralização.

\subsection{Amostragem}

A amostragem foi realizada nos 32 furos de sonda a cada metro perfurado. Os furos foram coletados na malha irregular apresentada na Figura 15, com distância média de $30 \mathrm{~m}$. Para o tratamento estatístico e geoestatístico dos dados as amostras foram regularizadas para 5 metros e todas análises posteriores utilizaram estas amostras.

\subsection{Análise Estatística}

A estatística básica foi calculada para os dados antes e após a regularização. Observando as Figuras 16 e 17, que são, respectivamente, os histogramas e curva de frequência acumulada para os dados não regularizados e regularizados, vê-se que são distribuições assimétricas positivas com as estatísticas descritivas mostradas na Tabela 02. 


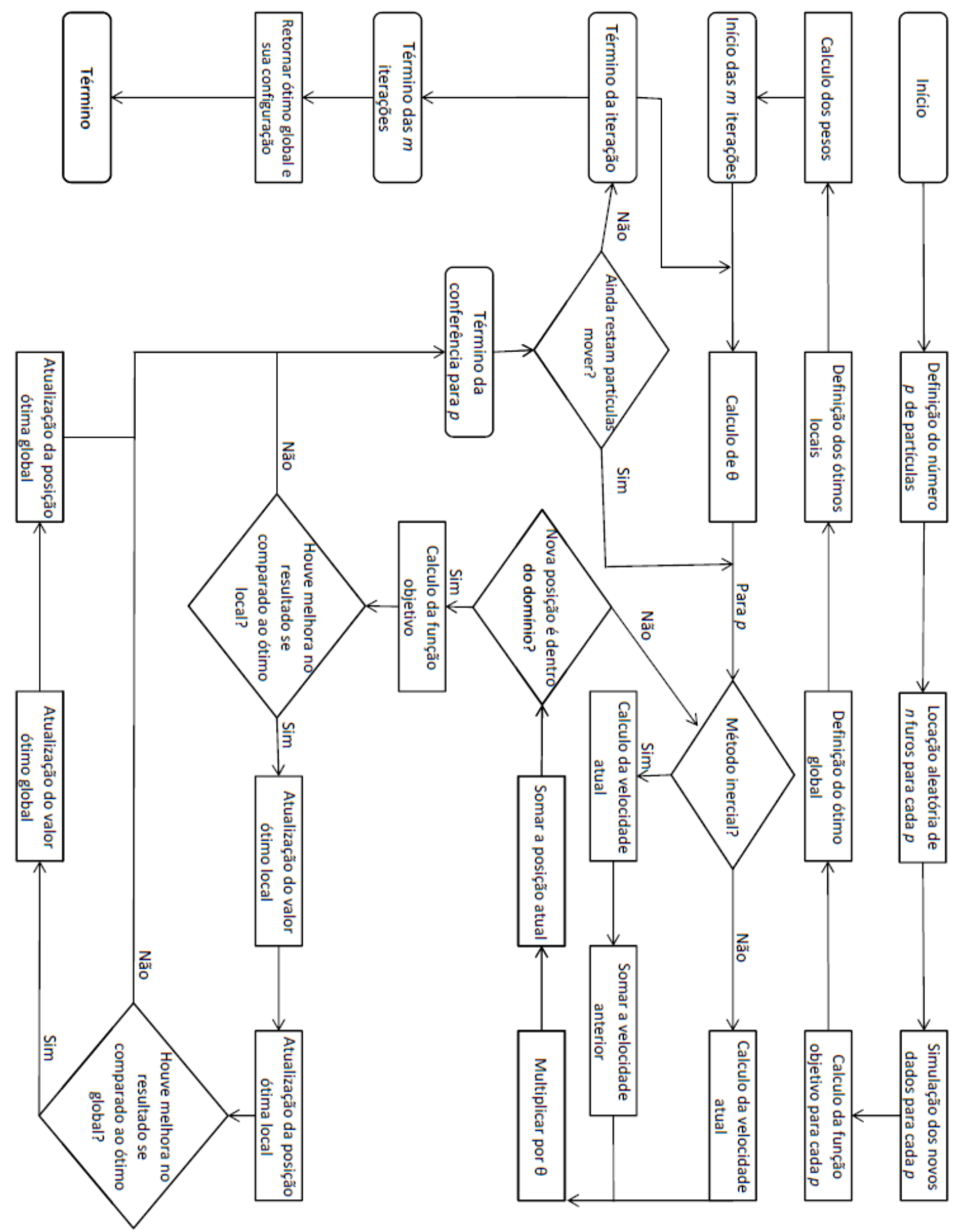

Figura 14 - Fluxograma da otimização por particle swarm optimization. 


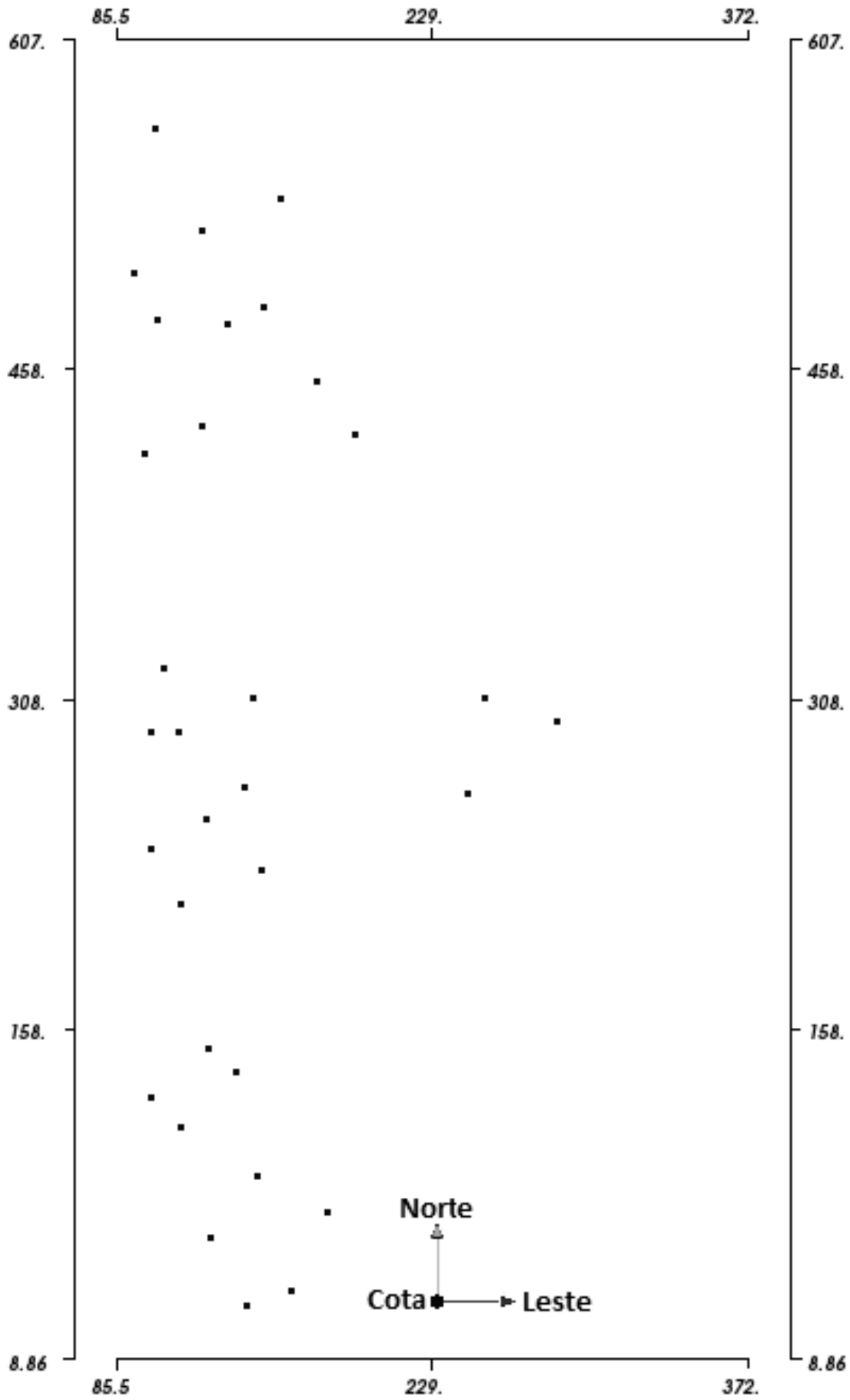

Figura 15 - Mapa base com a distribuição espacial das amostras. 


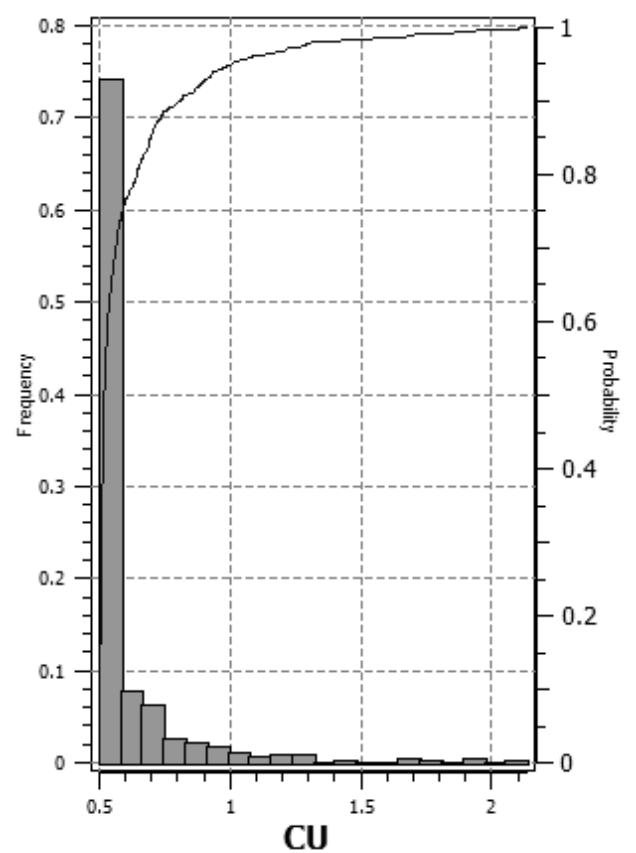

Figura 16 - Histograma da variável cobre.

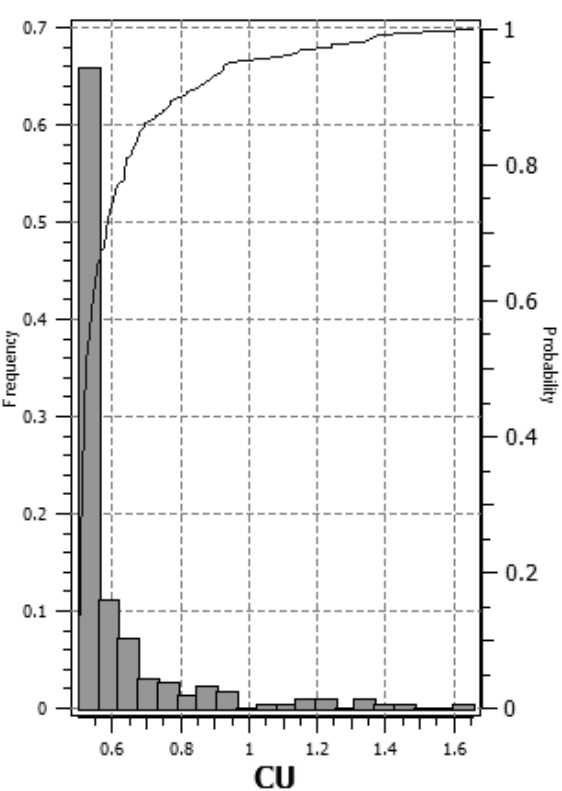

Figura 17 - Histograma da variável cobre regularizada. A linha azulada representa a distribuição acumulada (cdf) e as barras representam a densidade de probabilidade (pdf). 
Tabela 02 - Estatísticas descritivas da variável cobre antes e depois da regularização das amostras.

\begin{tabular}{ccc}
\hline & $\begin{array}{c}\text { Estatísticas descritivas } \\
\text { Não regularizada }\end{array}$ & Regularizada \\
\hline Número de amostras & 1058 & 226 \\
Média & 0.605 & 0.602 \\
Variância & 0.048 & 0.034 \\
Mínimo & 0.500 & 0.501 \\
Máximo & 2.134 & 1.656 \\
Mediana & 0.519 & 0.524 \\
\hline
\end{tabular}

A redução após a regularização foi da ordem de $80 \%$ aproximadamente. A variância diminuiu e a média também é menor na amostra regularizada, assim como os valores de máximo e da mediana. A amostragem apresenta valores menores aos populacionais, que foram apresentados na Tabela 01, sendo a variância em maior intensidade, está diferença ocorre devido à diferença entre os valores de máximo e mínimo das distribuições. $\mathrm{O}$ valor mais próximo do dado populacional é a mediana, os outros valores apresentam discrepância, tanto a média e a variância, indicando que a amostragem não foi representativa do domínio.

\subsection{Variograma}

O cálculo dos variogramas experimentais foi iniciado pela análise exploratória conforme descrito no item 3.3. Os parâmetros do cálculo são apresentados na Tabela 03 e os variogramas experimentais para as cinco direções podem ser observados no Anexo (A1 até A5).

Interpretou-se a presença de anisotropia mista neste variograma. Como a direção $0^{\circ}$ apresentou a maior amplitude dentre as direções de cálculo, ela foi escolhida para representar posicionar o eixo da elipse que representa a anisotropia. Deste modo o variograma foi recalculado para as direções $0^{\circ}, 90^{\circ}$ no plano horizontal, e vertical. Os parâmetros utilizados foram os apresentados na Tabela 04 e os o variograma na Figura 18.

A modelagem do variograma utilizou quatro estruturas, conforme apresentado na Tabela 05 . O efeito pepita é baixo, aproximadamente $10 \%$ do valor do patamar, o modelo 
escolhido foi o esférico. O modelo teórico de variograma ajustado pode ser observado na Figura 18.

Tabela 03 - Parâmetros de cálculo do variograma experimental na análise exploratória.

\begin{tabular}{cccccc}
\hline \multicolumn{2}{c}{ Parâmetros variogramas experimentais } & & \\
Direções & $0^{\circ}$ & $45^{\circ}$ & $90^{\circ}$ & $135^{\circ}$ & Vertical $\left(0^{\circ}\right)$ \\
\hline Tolerância angular & 22.5 & 22.5 & 22.5 & 22.5 & 22.5 \\
Mergulho & $0^{\circ}$ & $0^{\circ}$ & $0^{\circ}$ & $0^{\circ}$ & $90^{\circ}$ \\
Passo & 45 metros & 30 metros & 30 metros & 30 metros & 7.5 metros \\
Tolerância do passo & 22.5 metros & 15 metros & 15 metros & 15 metros & 3.75 metros \\
Número de passos & 8 & 11 & 6 & 11 & 11 \\
Largura máxima & 300 metros & 300 metros & 300 metros & 300 metros & 300 metros \\
\hline
\end{tabular}

Tabela 04 - Parâmetros de cálculo do variograma considerando as três direções principais.

\begin{tabular}{cccc}
\hline & \multicolumn{2}{c}{ Parâmetros variogramas modelados } \\
\hline Direções & $0^{\circ}$ & $90^{\circ}$ & $0^{\circ}$ \\
Tolerância angular & 45 & 45 & 22.5 \\
Mergulho & $0^{\circ}$ & $0^{\circ}$ & $90^{\circ}$ \\
Passo & 45 metros & 30 metros & 7.5 metros \\
Tolerância do passo & 22.5 metros & 15 metros & 3.75 metros \\
Número de passos & 8 & 6 & 11 \\
Largura máxima & 300 metros & 300 metros & 300 metros \\
\hline
\end{tabular}

Tabela 05 - Parâmetros do modelo teórico de variograma utilizado no ajuste.

Parâmetros da modelagem

Efeito pepita $=0.004$

Modelo Esférico

Direção da rotação $0^{\circ}$ (sem mergulho)

\begin{tabular}{ccccc}
\hline Estrutura & 01 & 02 & 03 & 04 \\
Variância espacial & 0.035 & 0.008 & 0.003 & 0.002 \\
Amplitude X & 98 & 225 & 225 & 225 \\
Amplitude Y & 55 & 80 & 100 & - \\
Amplitude Z & 30 & - & - & - \\
\hline
\end{tabular}



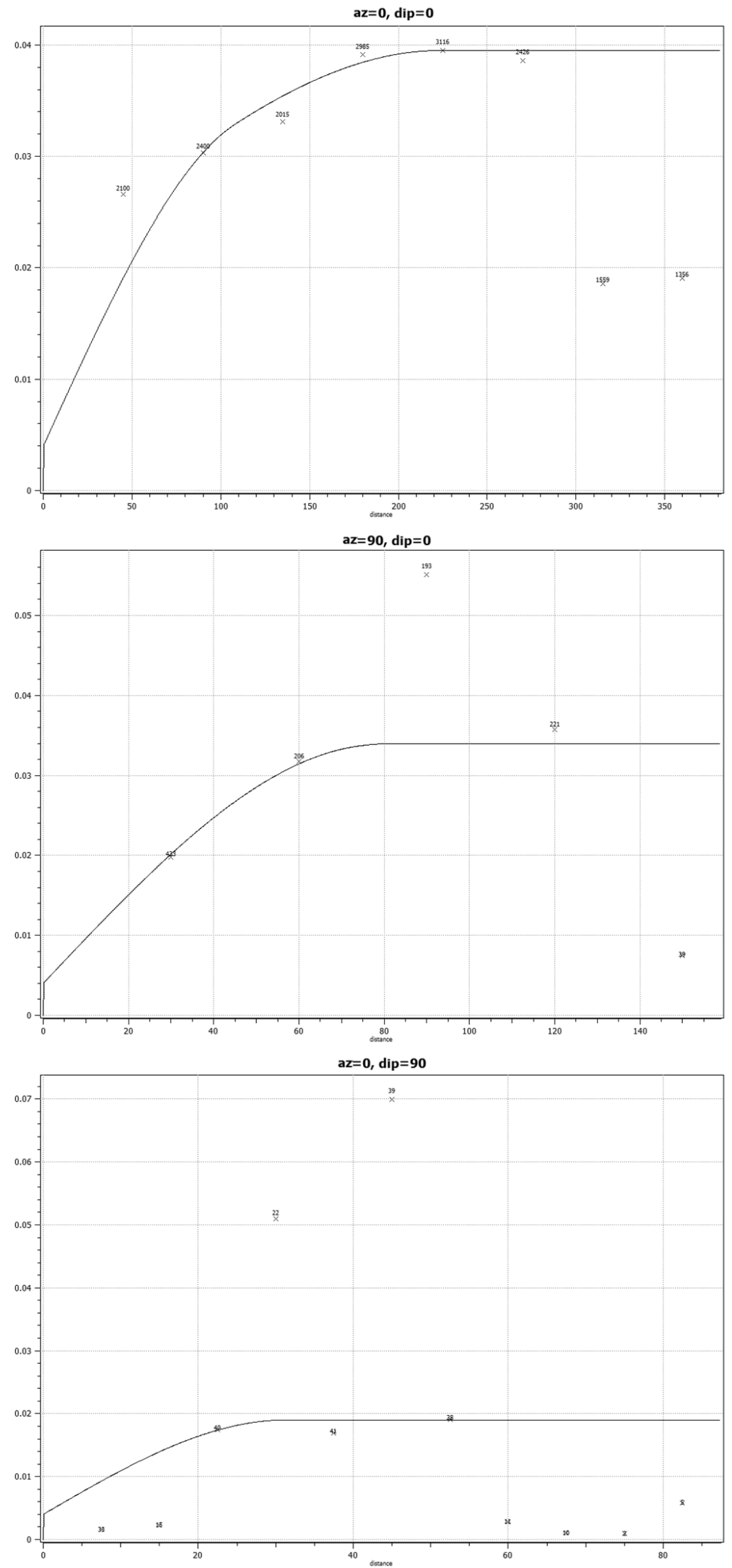

Figura 18 - Modelo teórico de variograma ajustado ao variograma experimental. 


\subsection{Transformação Gaussiana e Variograma}

Para o cálculo da simulação estocástica, por simulação sequencial gaussiana, os dados precisam apresentar distribuição gaussiana normal $(\mathrm{N}[0,1])$. Os dados de cobre não apresentam esta distribuição, portanto precisaram ser transformados. A técnica de transformação aplicada foi a transformação por "normal score" (nscore). Analisando os resultados concluiu-se que a transformação foi satisfatória, pois a média é igual a zero e a variância tende a um como pode ser observado na Tabela 06.

Tabela 06 - Estatística descritiva da amostragem transformada.

\begin{tabular}{lc}
\hline & Estatísticas descritivas \\
\hline Média & 0 \\
Variância & 0.994 \\
Máximo & 2.705 \\
Mínimo & -2.705 \\
Mediana & 0 \\
\hline
\end{tabular}

A análise exploratória foi realizada novamente para os dados transformados, as Figuras A6 até A10 do Anexo apresentam este resultado. A elipse que representa a anisotropia possui a mesma posição que a interpretada para os dados não transformados e, assim, o variograma foi recalculado para as três direções descritas na Tabela 04. O variograma resultante pode ser observado na Figura 19.

O ajuste do modelo teórico utilizou quatro estruturas esféricas (Figura 19) e seus parâmetros são as apresentados na Tabela 07.

\subsection{Simulação Estocástica}

A validação cruzada foi realizada várias vezes buscando definir os parâmetros de vizinhança que melhor estimassem os pontos amostrais dos dados transformados. Apresentam-se na Tabela 08 os parâmetros da melhor vizinhança e na Figura 20 o diagrama de dispersão entre os valores amostrais e os valores estimados. Esta vizinhança foi a que apresentou coeficiente de Pearson igual a 0,78 e 216 amostras estimadas. 
A Tabela 09 apresenta os parâmetros utilizados na definição do modelo de blocos utilizados na simulação. O tamanho dos blocos em cada direção (X, Y e Z) foi definido com base no espaçamento médio entre amostras e no eixo $\mathrm{Z}$ o bloco foi definido com base no tamanho da amostra regularizada. O número de blocos foi definido pelos limites espaciais do domínio em relação ao comprimento do bloco.

Foram realizadas 100 simulações e os dados foram transformados para a distribuição original após a simulação. De modo geral, os resultados da simulação apresentaram teores de cobre maiores nas menores cotas e nas cotas maiores foram simulados teores menores. Podese observar alguma dispersão dos teores simulados. Na Figura 21 o resultado de uma simulação, escolhida ao acaso, é representada.

Tabela 07 - Parametrização da modelagem do variograma dos dados transformado.

Parâmetros da modelagem dos dados transformados

Efeito pepita $=0.2$

Modelo Esférico

Direção da rotação $0^{\circ}$ (sem mergulho)

\begin{tabular}{ccccc}
\hline Estrutura & 01 & 02 & 03 & 04 \\
Variância espacial & 0.7 & 0.05 & 0.05 & 0.08 \\
Amplitude U & 98 & 225 & 225 & 225 \\
Amplitude V & 40 & 80 & 100 & - \\
Amplitude W & 55 & - & - & - \\
\hline
\end{tabular}



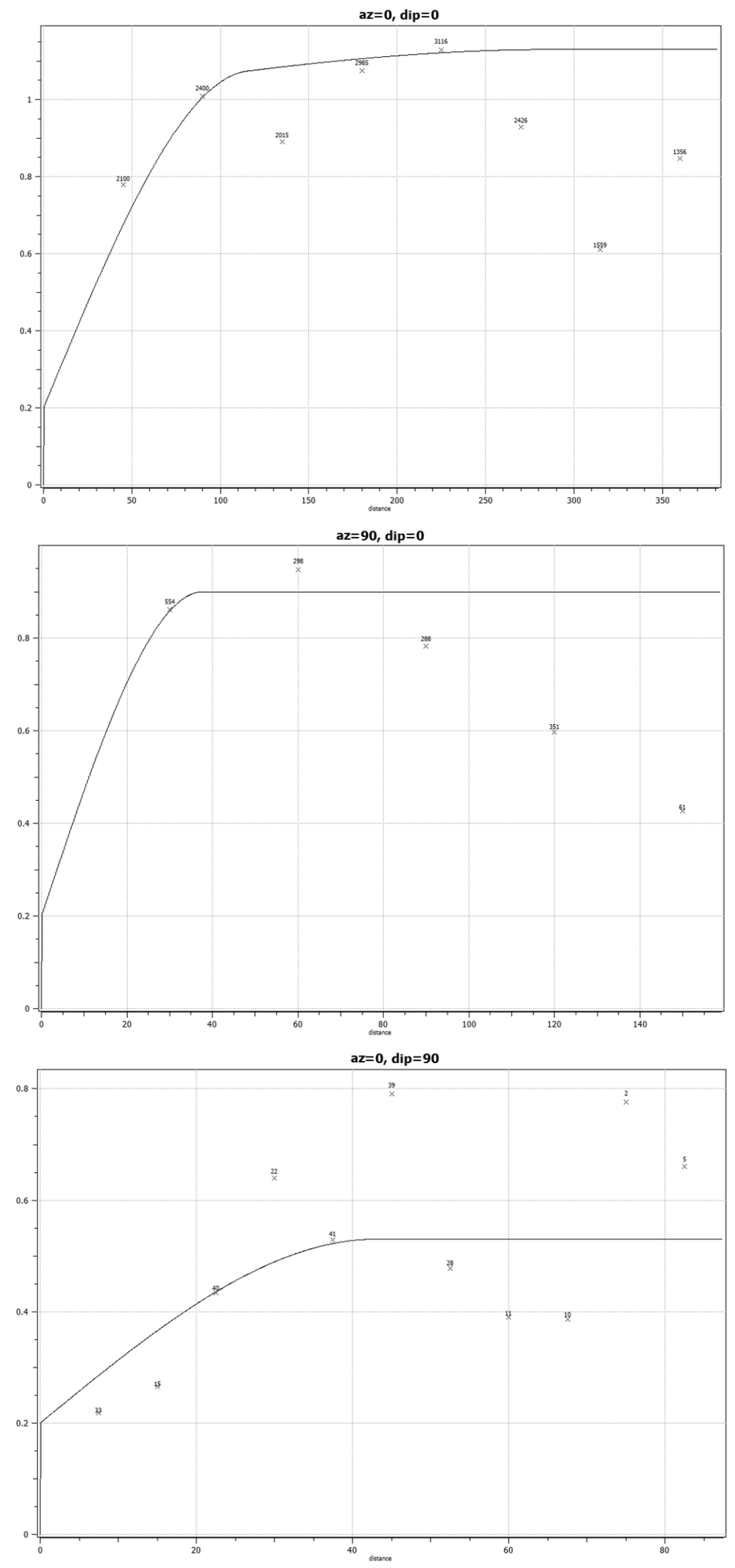

Figura 19 - Variograma experimental com modelo teórico ajustado. 
Tabela 08 - Parâmetros de vizinhança utilizados na simulação estocástica.

\section{Parâmetros de vizinhança}

Rotação $0^{\circ}$

Divisão dos espaço em octantes

Número ótimo de amostras por setor - 1

Mínimo de amostras para estimativa - 4

$\begin{array}{cccc}\text { Direção } & \text { X } & \text { Y } & Z \\ \text { Raio de busca } & 225 & 100 & 50\end{array}$

Tabela 09 - Parâmetros do modelo de blocos.

\begin{tabular}{cccc}
\hline & \multicolumn{2}{c}{ Parâmetros do modelo de blocos } \\
\hline Direção & $\mathrm{X}$ & $\mathrm{Y}$ & $\mathrm{Z}$ \\
Origem & 40 & 20 & -160 \\
Comprimento & 15 & 22.5 & 5 \\
Número de blocos & 20 & 28 & 32 \\
\hline
\end{tabular}

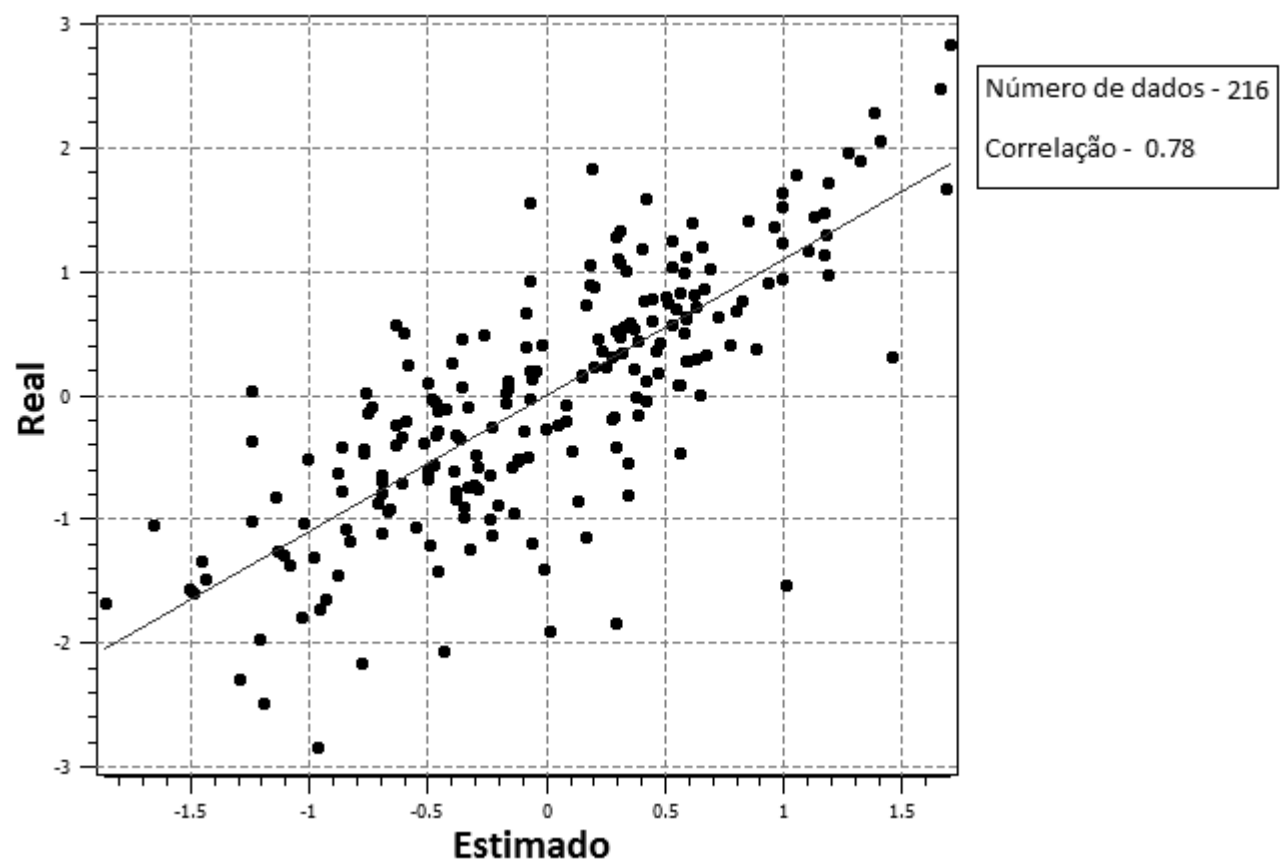

Figura 20 - Diagrama de dispersão entre valores amostrados e valores estimados na validação cruzada para os dados transformados. 
166. 188. 211. 233. 255.
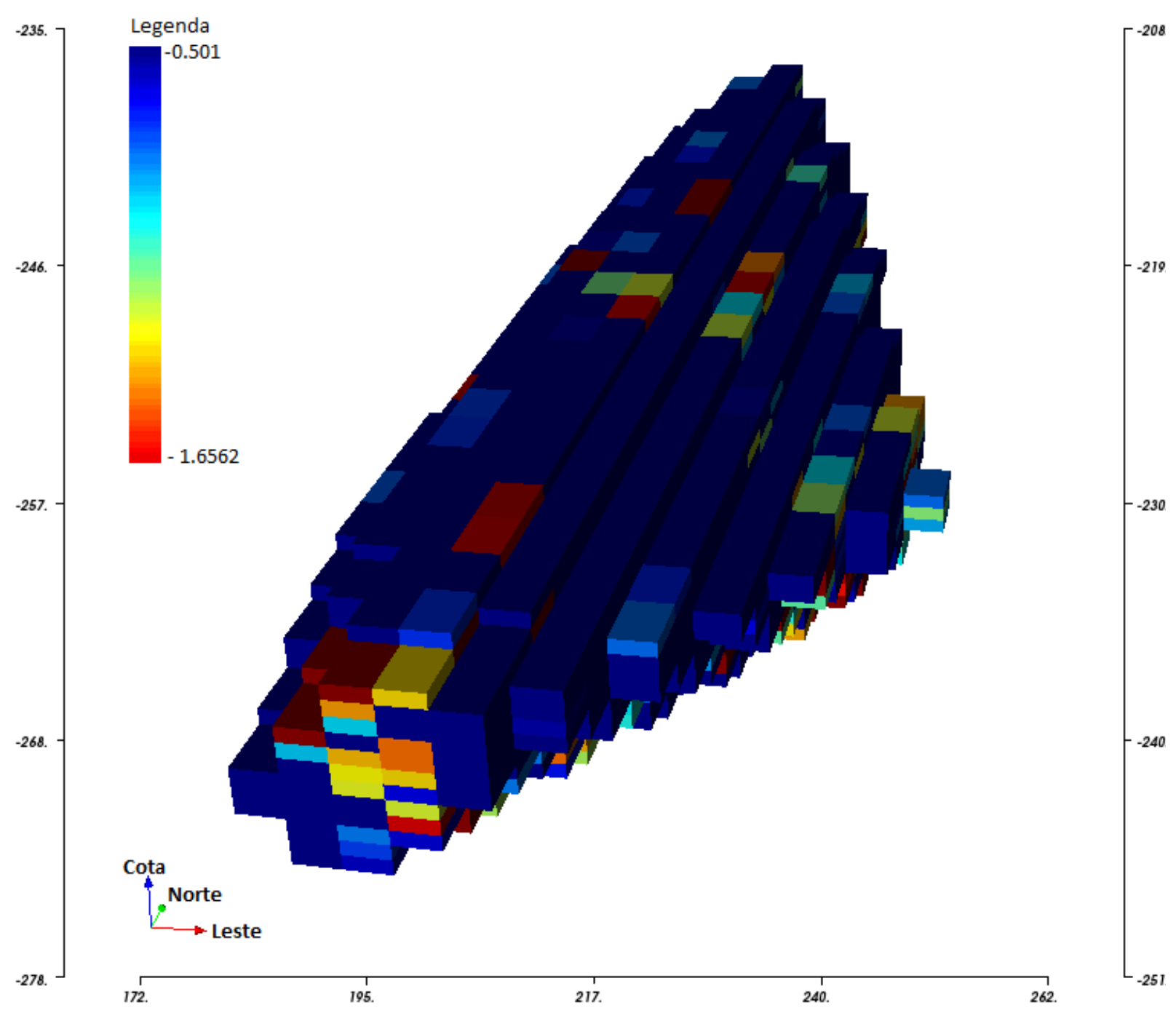

Figura 21- Representação de uma simulação tomada ao acaso.

\subsection{Incertezas}

A variância das 100 simulações foi calculada e é apresentada na Figura 22. De modo geral, a variância da simulação é menor na porção central do modelo e à medida que os blocos se distanciam do centro a tendência é do aumento dos valores de dispersão. A variância é zero quando o bloco é condicionado pela amostragem, ou seja, se o centro do bloco for uma amostra, o valor do bloco é o valor da amostra, não havendo variação. A porção leste possui os maiores valores de variância, assim como a porção inferior do modelo. 


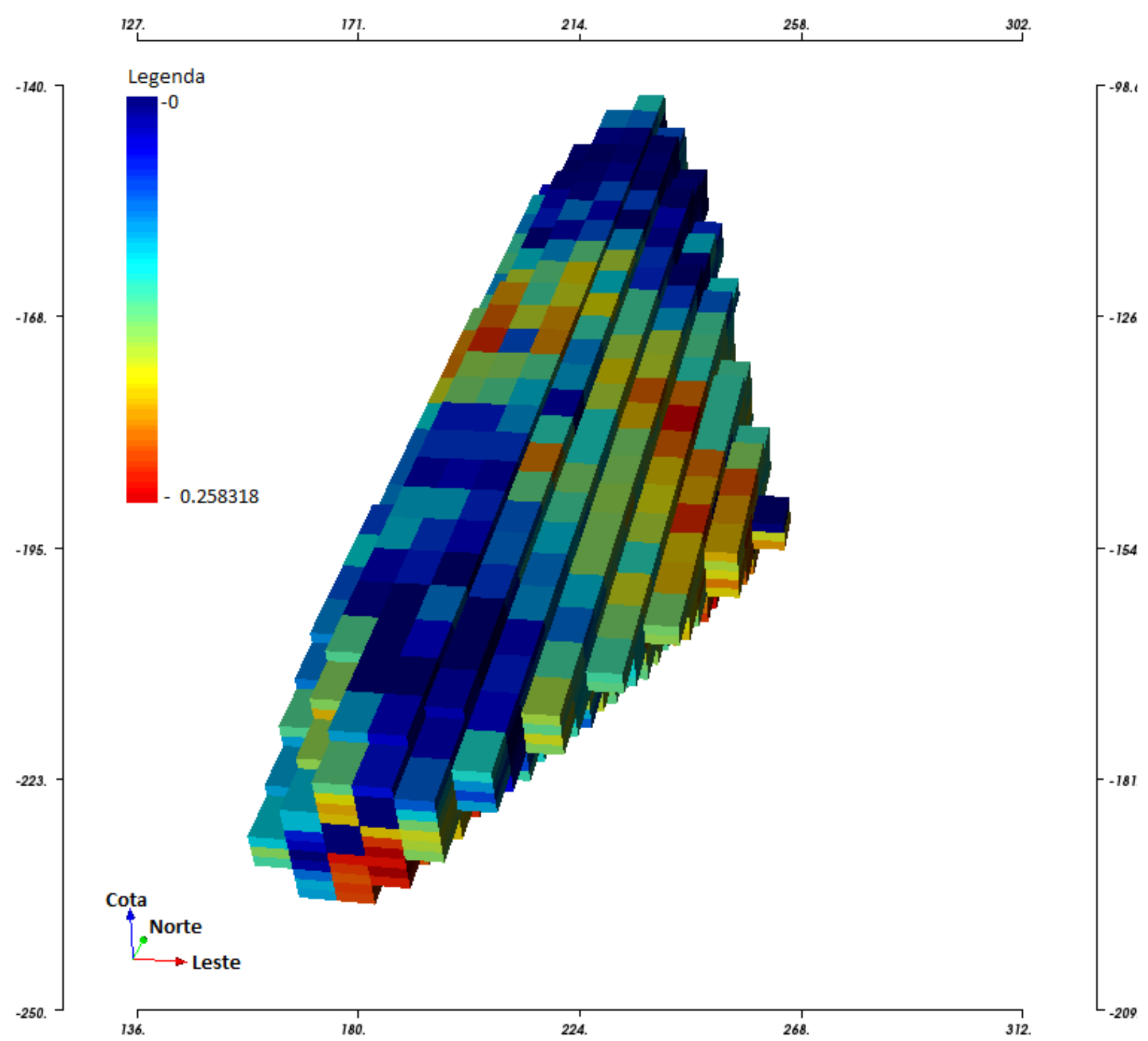

Figura 22 - Variância da simulação.

\subsection{Otimização}

A otimização foi calculada com duas funções objetivo de interesse e por diferentes métodos de otimização. A definição do método de otimização com melhor resultado envolve testes de desempenho na resolução do problema, onde, para uma mesma função objetivo e número de novos furos de sonda locados, comparou-se o resultado obtido entre os métodos de otimização. A definição da função objetivo com melhor resultado envolve a comparação entre a minimização obtida com cada função, para um mesmo número de novos furos locados e mesmo método de otimização, cujo resultado será posteriormente amostrado de forma a evidenciar se houve a ocorrência de minimização da incerteza associada à amostragem inicial. 
As funções objetivo contempladas são a soma da variância de blocos da simulação e a soma do coeficiente de variação dos blocos da simulação, a serem minimizadas pelos métodos de otimização. Para um número de bocas de furo " $m$ " fixo, cada método de otimização testado buscou minimizar o valor da função objetivo através da variação das locações de furo. A otimização foi realizada considerando a adição de um furo, depois dois e este número foi incrementado de um em um, a cada otimização, até 15 furos. Após o $15^{\circ}$ furo o incremento passou a ser de cinco em cinco furos até o " $m$ " máximo de 50 furos. Consideraram-se até 50 furos para verificar se haveria estabilização dos resultados da função objetivo a partir de um determinado " $m$ ”. A iteração que, para um mesmo método de otimização e número " $m$ " de novos furos de sonda, apresentasse o menor valor de função objetivo, proporcionalmente ao valor inicial, seria a mais indicada. Outro critério de interpolação foram os locais onde os novos furos foram locados, quanto menos agrupados e mais afastados da amostragem inicial melhor seria o resultado da otimização. Para uma mesma função objetivo os sete métodos foram comparados entre si para definir qual resultaria na melhor resposta frente ao problema de locação dos furos. As Figuras 23 a 26 apresentam os gráficos de comparação entre o número de furos e o resultado da otimização para cada método testado. As Figuras 23 e 24 apresentam os resultados com a função objetivo minimizando a variância e as Figuras 25 e 26 são o resultado para função objetivo minimizando o coeficiente de variação. Os resultados das otimizações foram obtidos utilizando-se mil iterações por otimização. 


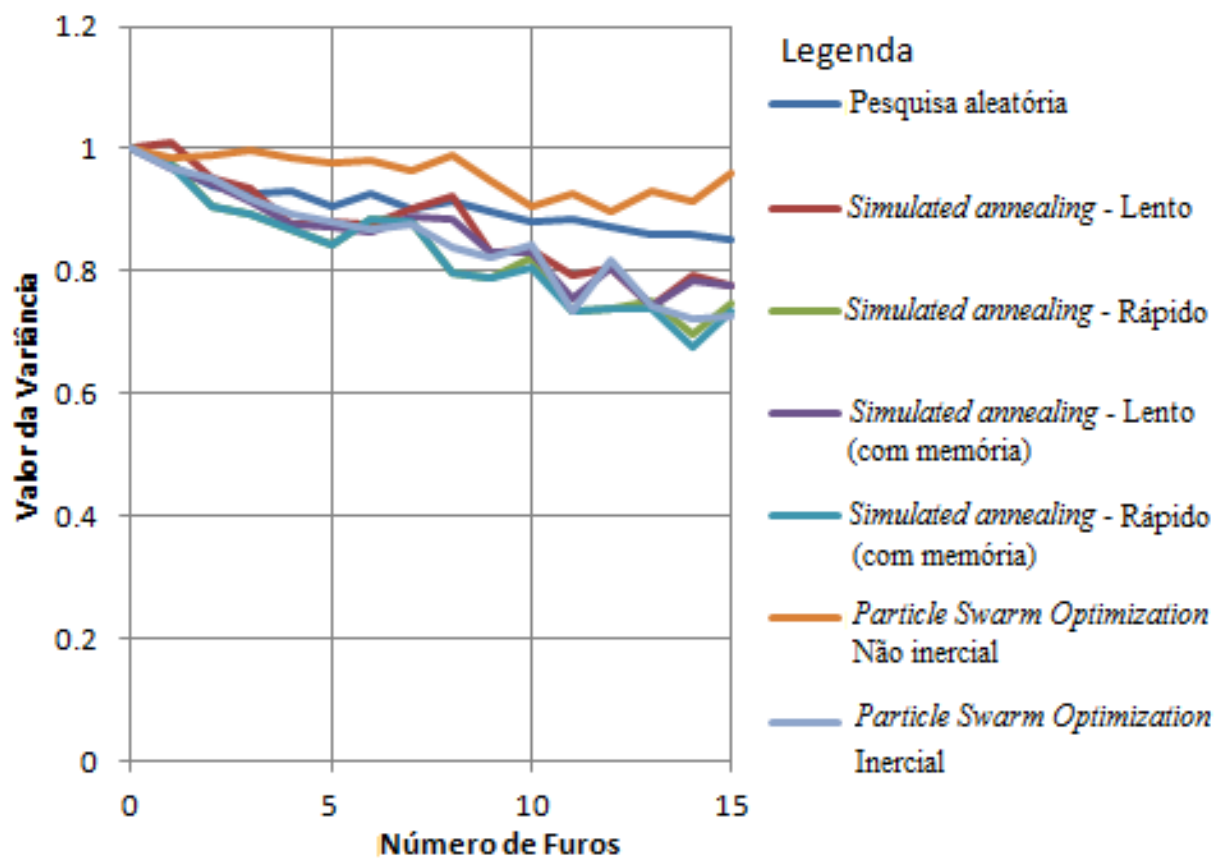

Figura 23 - Gráfico apresentando o resultado da otimização de 1 a 15 novos furos de sonda com a minimização da soma da variância de simulação como função objetivo.

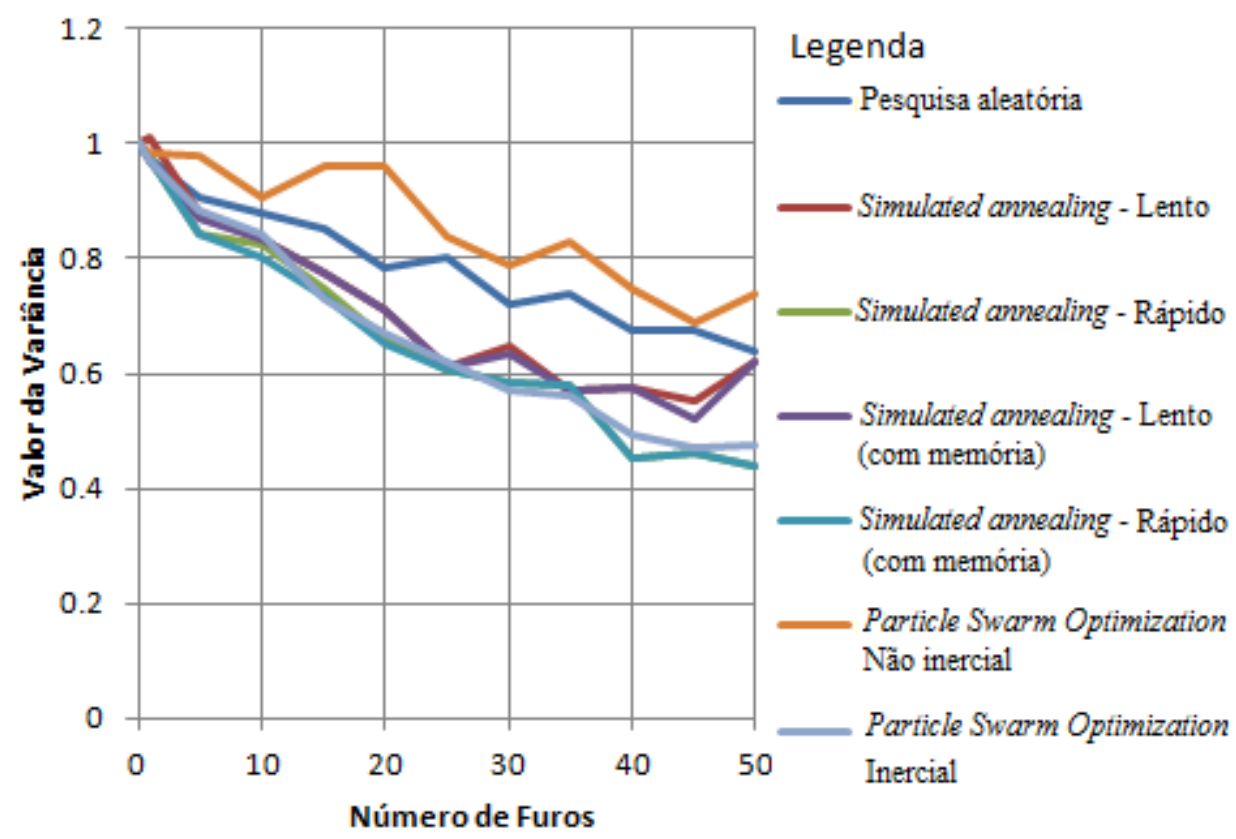

Figura 24 - Gráfico apresentando o resultado da otimização de 5 a 50 novos furos com a minimização da soma da variância da simulação como função objetivo. $\mathrm{O}$ número de furos zero representa o valor da função objetivo com base na amostragem inicial. 


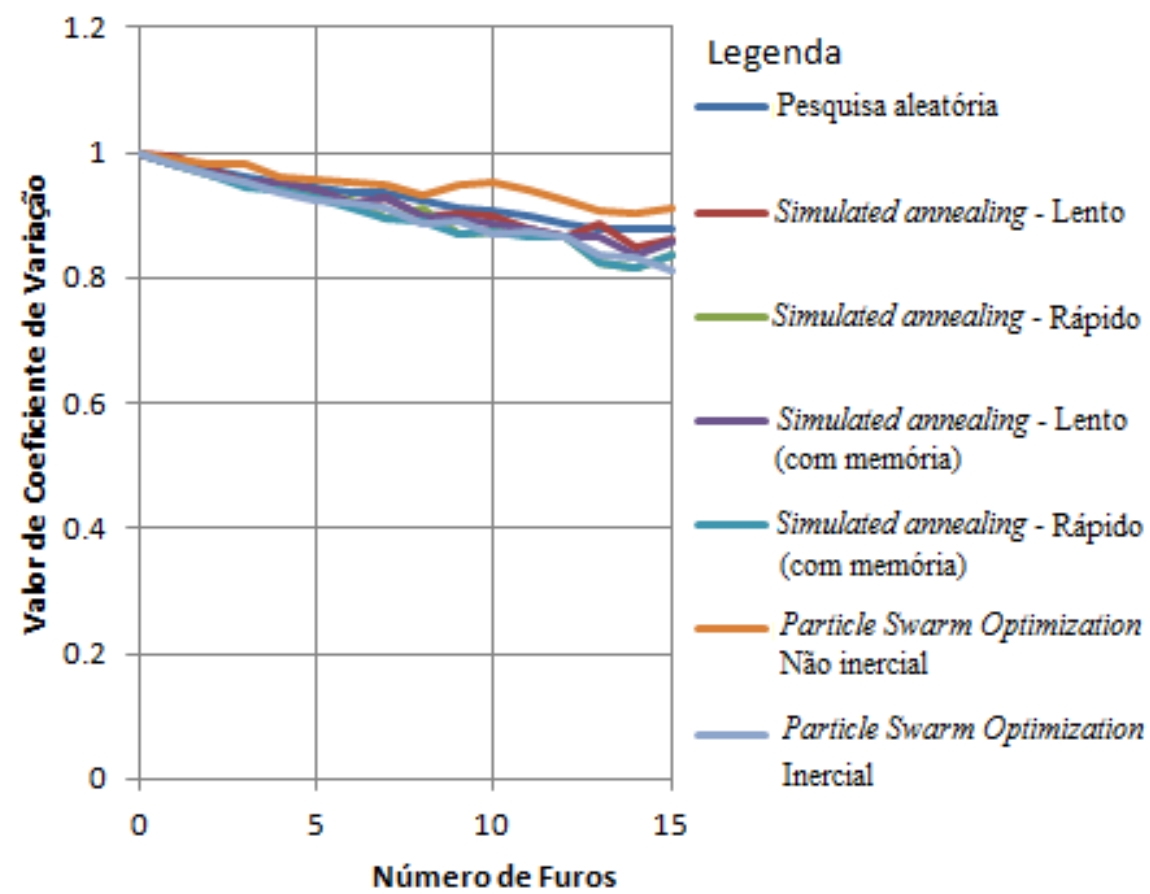

Figura 25 - Resultado da otimização de 1 a 15 novos furos de sonda com a minimização da soma dos coeficientes de variação como função objetivo.

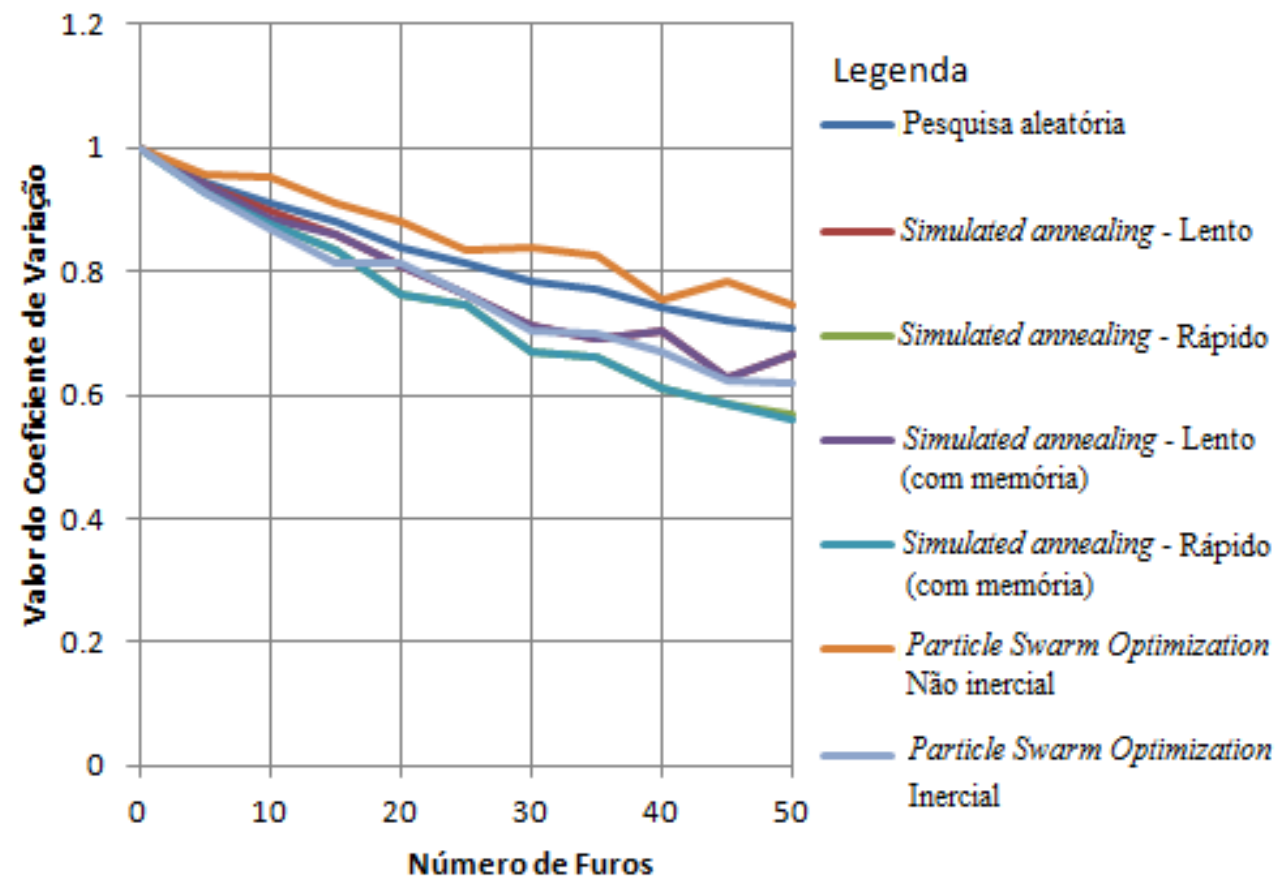

Figura 26 - Gráfico apresentando o resultado da otimização de 5 a 50 novos furos de sonda com a minimização da soma dos coeficientes de variação como função objetivo. O número de furos zero representa o valor da função objetivo com base na amostragem inicial. 
Na Figura 23 o valor mais expressivo obtido no intervalo indicado foi para 14 furos, com o método simulated annealing rápido com memória. Avaliando a Figura 24 observa-se que a maior diminuição de função objetivo (que minimizou a variância inicial em aproximadamente $45 \%$ ) foi obtida pelo método simulated annealing rápido com e sem memória, que se encontram sobrepostos no gráfico, com 50 furos de sondagem. Observa-se que os métodos particle swarm optimization inercial e o simulated annealing rápido tendem a apresentar resultados semelhantes. Analisando a Figura 25 observa-se queda menor nos valores da função objetivo, quando compara à Figura 23. Comportamento que se repete ao comparar a Figura 26 com a Figura 24, sendo que a soma das variâncias apresenta valor mínimo da ordem de $58 \%$ do valor inicial, indicando que a função objetivo utilizando-a é mais eficiente. $\mathrm{O}$ método simulated annealing com resfriamento rápido, com ou sem memória, gerou melhores resultados para ambas funções objetivo.

Para um mesmo método pode ocorrer aumento do valor da função objetivo com mais amostras, principalmente pelo caráter estocástico. Por serem técnicas meta-heurísticos não há garantia de melhora, ou de obtenção do melhor resultado. O método de pior resultado foi o particle swarm optimization não inercial, isso se deve principalmente pelo método estar limitado a uma região do espaço de parâmetros definida no sorteio aleatório inicial, onde não há como explorar amplamente o espaço para pesquisa por novas configurações. O melhor método foi o simulated annealing rápido com memória, que, por vezes, se sobrepõe ao método rápido convencional. O método rápido é melhor que o lento por haver menor probabilidade, no decorrer das iterações, do método rápido aceitar pioras no valor da função objetivo considerada ótima. Por vezes houve convergência de resultados entre os métodos simulated annealing com e sem memória de resfriamento rápido, indicando eficácia do método, mesmo sem aplicar a memória aos dados. Outro método com resultado eficaz é o particle swarm optimization inercial, que apresenta probabilidade de escape à região do sorteio aleatório inicial, uma vez que se considera a influência da movimentação anterior a cada nova movimentação das partículas multiplicada por um peso, que fornece uma alternativa à região inicial. Não houve convergência a um valor mínimo de proporção evidente. No caso da variância, entre 40 e 50 novos furos observa-se tendência dos métodos em convergir o resultado da função objetivo a um valor constante.

Além da comparação entre os resultados da minimização, deve-se considerar o tempo de processamento das otimizações como um todo. O método de pesquisa aleatória é mais rápido, tendendo a encerrar a uma otimização em 30 minutos, independente do número de 
amostras a serem locadas. Isto o tornaria interessante, contudo seu resultado não é o melhor obtido frente ao objetivo da otimização. O método simulated annelaing, é mais lento, levando em média 40 minutos, aproximadamente 2 segundos por iteração. Por fim o particle swarm optimization leva em média de 2 a 3 horas para realizar a otimização independente do número de furos locados, isto mantendo fixo o número de partículas em 10. Este tempo só foi obtido ao se configurar a iteração para rodar em paralelo as 10 simulações a serem realizadas na movimentação de cada partícula. Considerou-se o simulated annealing como o melhor método pois além de ser de fácil aplicação, é rápido e eficaz quando comparado aos outros métodos.

Apesar da função objetivo utilizando a soma da variância de bloco ter sido considerada mais eficaz deve-se ter em conta a distribuição espacial dos novos furos de sonda. Desta forma comparou-se para um mesmo número de novos furos a posição que fora inferida para a boca do furo. Quanto mais distantes os furos locados estivessem entre si e em relação aos furos originais, maior seria a adequação do método de otimização e da função objetivo.

Para comparar as posições de infill resultantes de cada função objetivo optou-se por utilizar a amostragem com 11 novos furos, com base em um mesmo método de otimização, simulated annealing com resfriamento rápido e memória. Utilizando a soma das variâncias do bloco o resultado foi minimizado na ordem de aproximadamente $27 \%$ do valor original, no caso do coeficiente de variação a diminuição foi $14 \%$ do valor original. Este intervalo foi escolhido por apresentar diminuição abaixo de $20 \%$ do valor da variância. A configuração resultante da otimização foi plotada para efeito de comparação da dispersão dos dados para cada função, e indicar qual dos métodos apresentou melhor locação dos novos furos de forma espacial. Na Figura 27 são apresentados os dois resultados de 11 furos locados pela minimização da variância e do coeficiente de variação como função objetivo. A dispersão dos furos definidos pela variância é mais próxima da amostragem original e entre si, formando um cluster na porção centro-norte do domínio. A locação obtida pela minimização do coeficiente de variação apresentou menos proximidade entre os dados originais e entre si, espalhando mais os dados pelo domínio.

Comparando-se as funções e de modo a comprovar a aplicação da otimização optouse por realizar a amostragem dos 11 furos otimizados para cada função objetivo e assim 
comparar se o resultado da minimização resultou em diminuição da incerteza associada à simulação dos dados originais.

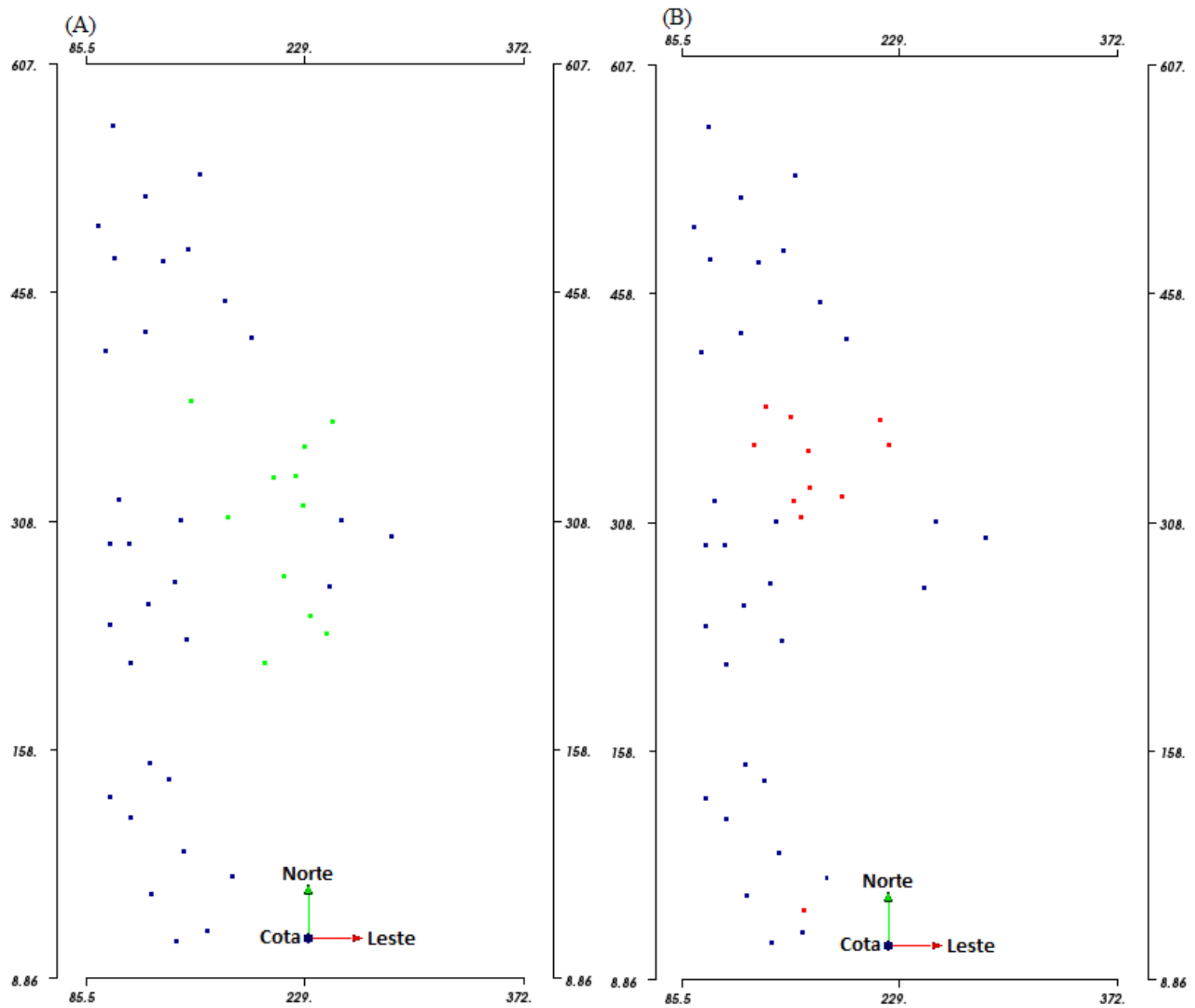

Figura 27 - Configuração da boca de furo obtida pela otimização simulated annealing com resfriamento rápido. Os pontos em azul representam a amostragem original. Em (A) os pontos ótimos em verde foram obtidos pela função objetivo que visava minimizar o coeficiente de variação. Em (B) os pontos vermelhos representam o resultado otimizado para a função objetivo que minimizou a variância.

\subsection{Infill - Estatísticas}

A otimização aplicada no domínio resultou na locação da boca dos $n$ furos que minimizaram a função objetivo. Com a localização definida pela otimização, os furos foram realizados na base de dados sintética utilizando o software Datamine@ . As estatísticas descritivas dos dados com o infill são apresentadas na Tabela 10. Em comparação com as estatísticas populacionais, apresentadas na Tabela 01, a média e a variância foram maiores 
nos dados com infill devido à diferença entre os valores de máximo, maiores após o infill. $\mathrm{O}$ aumento da variância indica que a amostragem é mais representativa dos dados populacionais, pois a amostragem inicial não foi capaz de reproduzir a dispersão real do cobre no depósito. A mediana das novas amostragens aproximou-se da populacional. Em ambas amostragens o valor de máximo não foi reproduzido. $\mathrm{O}$ infill utilizando a minimização do coeficiente de variação gerou amostras com média e mediana maiores e menor variância. Os histogramas destas novas amostras podem ser observados no Anexo, A11 a A14.

Tabela 10 - Estatísticas descritivas da variável cobre da amostragem atualizada pelo infill, baseado na otimização da variância e do coeficiente de variação.

\begin{tabular}{ccccc}
\hline & \multicolumn{2}{c}{ Estatísticas descritivas } & \\
Variância & Coeficiente de Variação \\
\hline Número de & Não regularizado & Regularizado & Não regularizado & Regularizado \\
amostras & 1539 & 321 & 1569 & 328 \\
Média & 0.653 & 0.649 & 0.656 & 0.657 \\
Variância & 0.107 & 0.076 & 0.079 & 0.072 \\
Mínimo & 0.500 & 0.501 & 0.500 & 0.501 \\
Máximo & 4.373 & 2.895 & 2.957 & 2.362 \\
Mediana & 0.531 & 0.539 & 0.534 & 0541 \\
\hline
\end{tabular}

Para efeito de comparação realizou-se a locação aleatória de 11 furos na base de dados original a fim de comparar com a locação por intermédio da otimização. As amostras foram definidas a partir do sorteio aleatório de novas bocas de furo, todos os furos possuem a mesma atitude, 270 de azimute e 45 de mergulho. A Tabela 11 apresenta as estatísticas descritivas destes dados, seus histogramas, não regularizados e regularizados, são apresentados em A15 e A16.

Comparando-se as estatísticas desta amostragem com a populacional e àquela da amostragem otimizada. Pode-se afirmar que ela não é mais representativa, pois a média, a mediana, o máximo e a variância são menores que as obtidas pela otimização e que as populacionais. 
Tabela 11 - Estatísticas descritivas da variável cobre com furos de infill locados aleatoriamente.

\begin{tabular}{ccc}
\hline & $\begin{array}{c}\text { Estatísticas descritivas } \\
\text { Não regularizada }\end{array}$ & Regularizada \\
\hline Número de amostras & 1436 & 302 \\
Média & 0.631 & 0.625 \\
Variância & 0.072 & 0.055 \\
Mínimo & 0.500 & 0.501 \\
Máximo & 2.763 & 1.882 \\
Mediana & 0.525 & 0.536 \\
\hline
\end{tabular}

\subsection{Infill - Otimização pela variância de blocos}

A amostragem obtida na otimização pela variância de blocos foi transformada em uma distribuição gaussiana pelo método nscore, com os dados transformados realizou-se a análise exploratória. $\mathrm{O}$ valor de passo utilizado foi de 15 metros, no plano horizontal e 7,5 metros na vertical, os valores de tolerância do passo foram iguais a 50\% do tamanho do passo e o número de passos foi igual a 20 no plano horizontal e 11 na vertical. Apresentam-se na Tabela 12 os parâmetros utilizados no cálculo do variograma experimental dos dados transformados. Os variogramas de cada direção podem ser observados no Anexo, A17 até A21.

A diferença entre o variograma experimental da amostragem inicial e da atualizada pode ser notada principalmente na estruturação dos variogramas direcionais. Os variogramas calculados com a nova amostragem apresentam menor influência do efeito pepita e diminuição da amplitude. O patamar foi maior, o que era esperado tendo em vista que a variância da amostragem atualizada aumentou. A principal diferença entre os variogramas exploratórios foi na direção $135^{\circ}$ e $90^{\circ}$ que deixaram de apresentar comportamento aleatório e apresentaram variogramas estruturados. $\mathrm{O}$ variograma calculado na direção vertical foi o que mostrou menor variação entre a amostragem inicial e a atualizada. As direções dos eixos da elipse que representam a anisotropia foi definida em $0^{\circ}$ e $90^{\circ}$ sendo a primeira a direção com maior amplitude. O variograma foi recalculado para ajustar o modelo, os parâmetros do cálculo são apresentados na Tabela 13. Na Tabela 14 são apresentados os parâmetros do 
modelo teórico de variograma ajustado. Na Figura 28 apresentam-se os variogramas modelados.

Tabela 12 - Parâmetros de cálculo do variograma experimental na análise exploratória dos dados atualizados com base na variância de blocos, transformados em uma distribuição gaussiana.

\begin{tabular}{|c|c|c|c|c|c|}
\hline \multicolumn{6}{|c|}{ Parâmetros variogramas experimentais } \\
\hline Direções & $0^{\circ}$ & $45^{\circ}$ & $90^{\circ}$ & $135^{\circ}$ & Vertical $\left(0^{\circ}\right)$ \\
\hline Tolerância angular & 22.5 & 22.5 & 22.5 & 22.5 & 22.5 \\
\hline Mergulho & $0^{\circ}$ & $0^{\circ}$ & $0^{\circ}$ & $0^{\circ}$ & $90^{\circ}$ \\
\hline Passo & 15 metros & 15 metros & 15 metros & 15 metros & 7.5 metros \\
\hline Tolerância do passo & 7.5 metros & 7.5 metros & 7.5 metros & 7.5 metros & 3.75 metros \\
\hline Número de passos & 20 & 20 & 20 & 20 & 11 \\
\hline Largura máxima & 300 metros & 300 metros & 300 metros & 300 metros & 300 metros \\
\hline
\end{tabular}

Tabela 13 - Parâmetros de cálculo do variograma experimental a ser modelado dos dados atualizados com base na variância de blocos, transformados em uma distribuição gaussiana.

\begin{tabular}{cccc}
\hline & \multicolumn{3}{c}{ Parâmetros variogramas modelados } \\
\hline Direções & $0^{\circ}$ & $90^{\circ}$ & $0^{\circ}$ \\
Tolerância angular & 45 & 45 & 22.5 \\
Mergulho & $0^{\circ}$ & $0^{\circ}$ & $90^{\circ}$ \\
Passo & 15 metros & 15 metros & 7.5 metros \\
Tolerância do passo & 7.5 metros & 7.5 metros & 3.75 metros \\
Número de passos & 20 & 20 & 11 \\
Largura máxima & 300 metros & 300 metros & 300 metros \\
\hline
\end{tabular}

Com o modelo ajustado foi realizada a validação cruzada a fim de calcular a simulação e verificar se houve melhora comparando-se à validação cruzada da amostragem inicial. Os parâmetros de vizinhança não foram alterados, exceto os raios da elipse de busca por amostras para cálculo da estimativa. Na tabela 15 os raios de busca podem ser observados. O resultado da validação cruzada é apresentado na Figura 29, onde é possível observar que aproximadamente 5\% da amostragem não foi estimada (303 de 321 amostras), contudo o valor de correlação foi da ordem de 0,81. Após a validação os dados foram simulados com a vizinhança ótima definida pela validação cruzada. Foram realizadas 100 simulações. 


\subsection{Infill - Otimização pelo coeficiente de variação dos blocos}

Com a amostragem atualizada pelo infill locado pela minimização do coeficiente de variação para 11 furos, também se realizou a transformação dos dados em uma distribuição gaussiana com média 0 e variância 1 pelo método nscore. Assim como o procedimento descrito no item 5.9, foi realizada a análise exploratória, que foi definida com os parâmetros apresentados na Tabela 03, com exceção do tamanho de passos, definido com 20m com tolerância de $10 \mathrm{~m}$ e 15 passos. Os parâmetros da direção vertical não foram alterados. Apresentam-se na Tabela 16 os parâmetros utilizados no cálculo do variograma experimental. Os variogramas direcionais calculados são apresentados no anexo (A22 até A26).

Tabela 14 - Parâmetros da modelagem ajustada para o variograma calculado da nova amostragem.

\section{Parâmetros da modelagem}

Efeito pepita $=0.09$

Modelo Esférico

Direção da rotação $0^{\circ}$ (sem mergulho)

\begin{tabular}{cccc}
\hline Estrutura & 01 & 02 & 03 \\
Variância espacial & 0.265 & 0.655 & 0.01 \\
Amplitude U & 90 & 100 & 100 \\
Amplitude V & 54 & 55 & - \\
Amplitude W & 24 & - & - \\
\hline
\end{tabular}



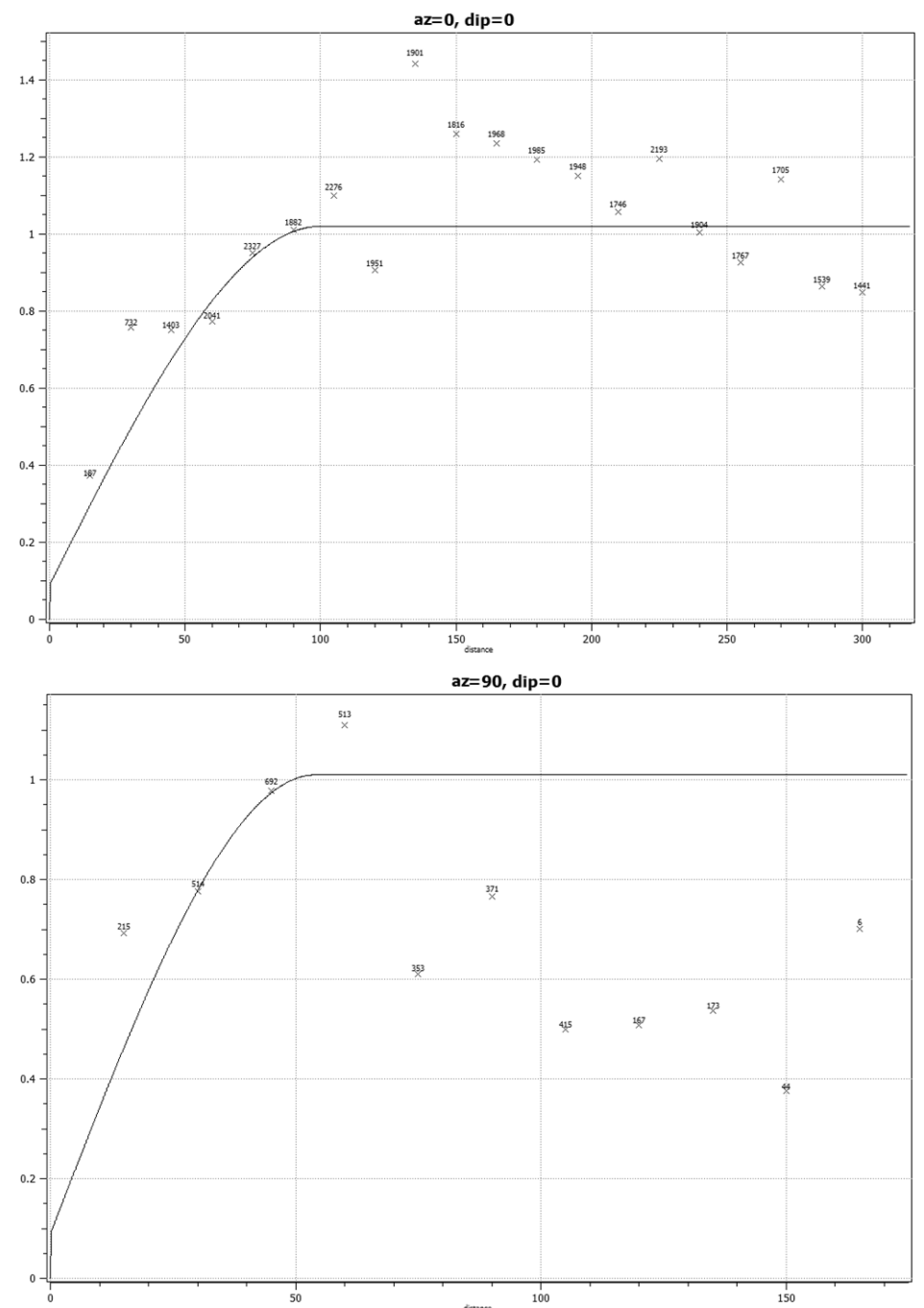

$a z=0, d i p=90$

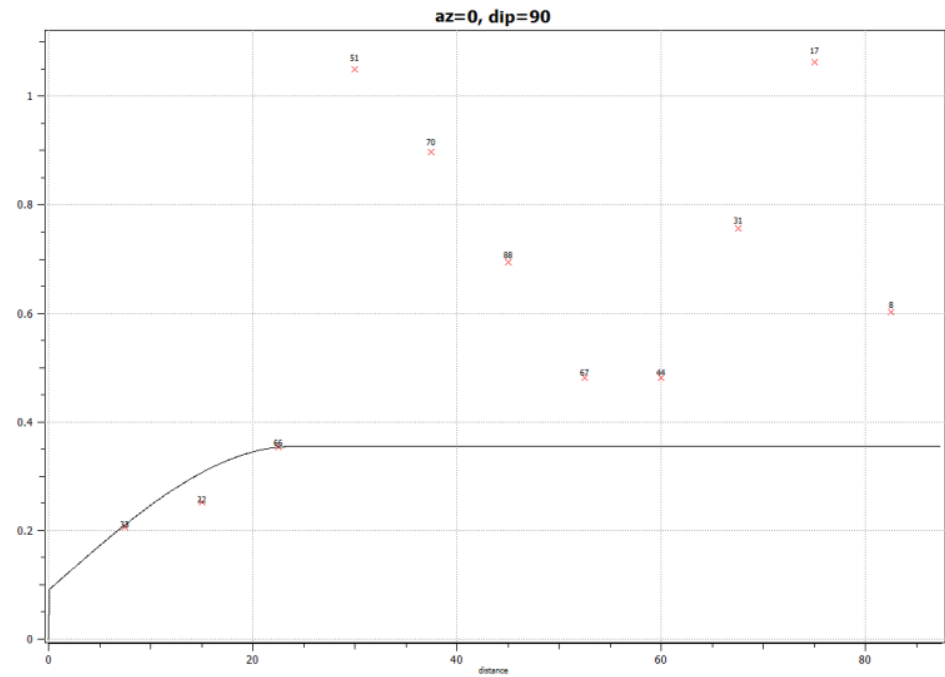

Figura 28 - Variograma experimental calculado para as direções $0^{\circ}, 90^{\circ}$ e vertical e respectivo modelo teórico ajustado. 
Tabela 15 - Parâmetros da vizinhança utilizados na simulação estocástica da amostragem atualizada.

\section{Parâmetros de vizinhança}

Rotação $0^{\circ}$

Divisão dos espaço em octantes

Número ótimo de amostras por setor - 1

Mínimo de amostras para estimativa - 4

$\begin{array}{cccc}\text { Direção } & \mathrm{X} & \mathrm{Y} & \mathrm{Z} \\ \text { Raio de busca } & 100 & 55 & 24\end{array}$

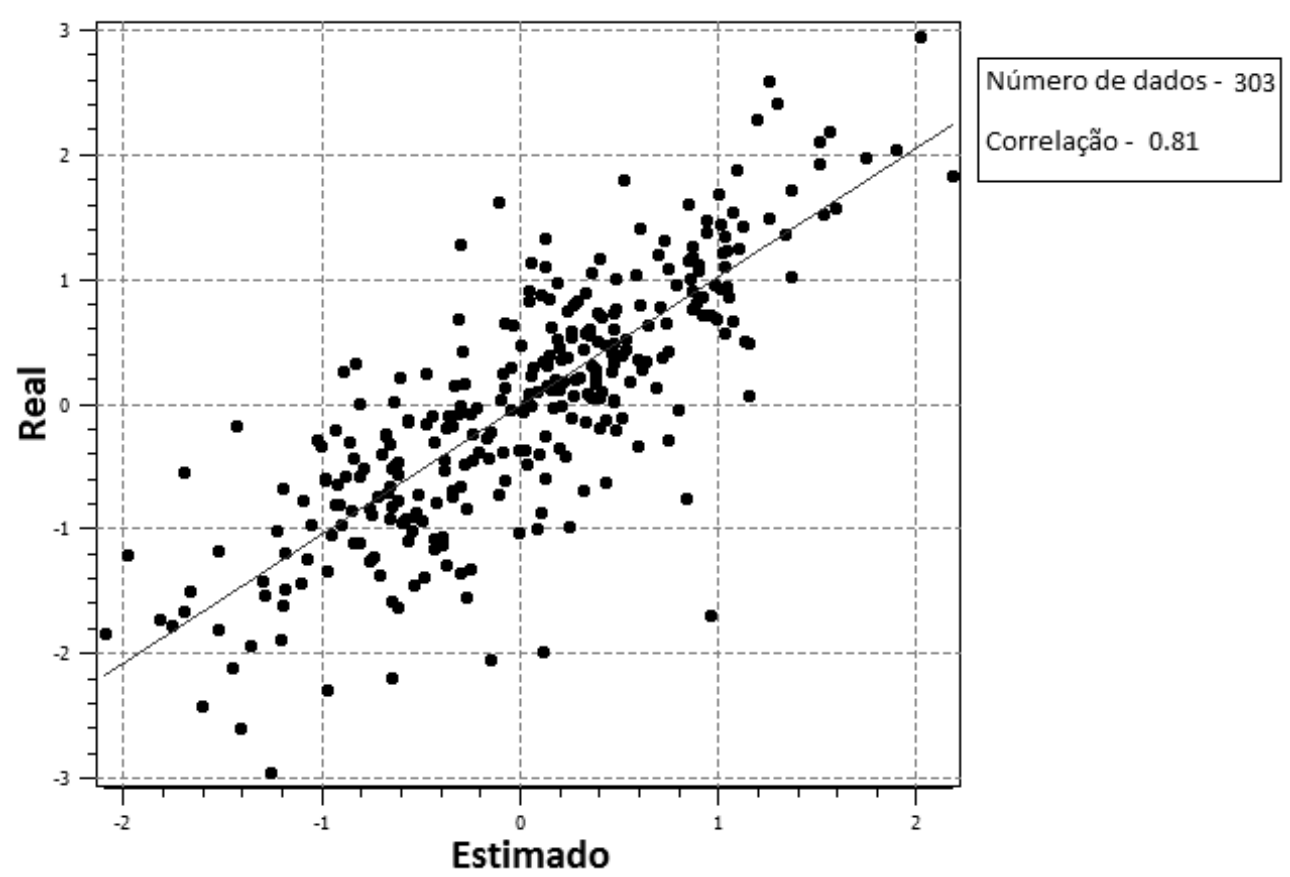

Figura 29 - Diagrama de dispersão entre valor amostral e estimado na validação cruzada para os dados atualizados transformados em distribuição gaussiana. 
Tabela 16 - Parâmetros de cálculo do variograma experimental na análise exploratória dos dados transformados em uma distribuição gaussiana.

\begin{tabular}{cccccc}
\hline \multicolumn{2}{c}{ Parâmetros variogramas experimentais } & & \\
Direções & $0^{\circ}$ & $45^{\circ}$ & $90^{\circ}$ & $135^{\circ}$ & Vertical $\left(0^{\circ}\right)$ \\
\hline Tolerância angular & 22.5 & 22.5 & 22.5 & 22.5 & 22.5 \\
Mergulho & $0^{\circ}$ & $0^{\circ}$ & $0^{\circ}$ & $0^{\circ}$ & $90^{\circ}$ \\
Passo & 20 metros & 20 metros & 20 metros & 20 metros & 7.5 metros \\
Tolerância do passo & 10 metros & 10 metros & 10 metros & 10 metros & 3.75 metros \\
Número de passos & 15 & 15 & 15 & 15 & 11 \\
Largura máxima & 300 metros & 300 metros & 300 metros & 300 metros & 300 metros \\
\hline
\end{tabular}

Comparado aos variogramas experimentais da base de dados inicial, a direção 135 apresentou comportamento de efeito pepita puro, sem estruturação visível. O comportamento na direção $90^{\circ}$ foi similar ao resultado da amostragem inicial. A direção $0^{\circ}$ é mais bem estruturada com menor efeito pepita e maior amplitude. A direção $45^{\circ}$ apresenta comportamento melhor estruturado e com amplitude bem definida. A direção mais discrepante foi a vertical que apresentou melhor estruturação se comparada à amostragem inicial. Comparando-se os variogramas do infill de ambas funções objetivo nota-se que o obtido pela minimização da soma das variâncias de bloco apresenta melhor comportamento para as direções $90^{\circ}$ e $135^{\circ}$, e pior para a direção $45^{\circ}$, enquanto a direção $0^{\circ}$ apresenta semelhanças em ambos casos. O variograma experimental foi recalculado para que fosse realizado o ajuste do modelo de variograma. Optou-se pelas direção $0^{\circ}, 90^{\circ}$ e vertical, tendo em vista que a direção $0^{\circ}$ foi considerado mais bem estruturado e com maior amplitude. Os parâmetros utilizados no cálculo deste variograma experimental são apresentados na Tabela 17.

O ajuste do modelo teórico do variograma foi parametrizado de acordo com o apresentado Tabela 18. A elipse que representa a anisotropia não teve os eixos rotacionados, com a direção principal do variograma na direção $0^{\circ}$ de azimute com modelo esférico. Quando comparado ao variograma da amostragem inicial este variograma apresentou menor efeito pepita e amplitudes. Na Figura 30 pode-se observar o modelo teórico de variograma ajustado, separados por estrutura. 
Tabela 17 - Parâmetros de cálculo do variograma experimental a ser modelado dos dados atualizados com base no coeficiente de variação de blocos, transformados em uma distribuição gaussiana.

\begin{tabular}{cccc}
\hline & \multicolumn{3}{c}{ Parâmetros variogramas modelados } \\
\hline Direções & $0^{\circ}$ & $90^{\circ}$ & $0^{\circ}$ \\
Tolerância angular & 45 & 45 & 22.5 \\
Mergulho & $0^{\circ}$ & $0^{\circ}$ & $90^{\circ}$ \\
Passo & 20 metros & 20 metros & 7.5 metros \\
Tolerância do passo & 10 metros & 10 metros & 3.75 metros \\
Número de passos & 15 & 15 & 11 \\
Largura máxima & 300 metros & 300 metros & 300 metros \\
\hline
\end{tabular}

Tabela 18 - Parâmetros do modelo teórico de variograma ajustado ao variograma experimental.

Parâmetros da modelagem

Efeito pepita $=0.05$

Modelo Esférico

Direção da rotação $0^{\circ}$ (sem mergulho)

\begin{tabular}{cccc}
\hline Estrutura & 01 & 02 & 03 \\
Variância espacial & 0.452 & 0.34 & 0.16 \\
Amplitude U & 114 & 144 & 150 \\
Amplitude V & 32 & 33 & - \\
Amplitude W & 32 & - & - \\
\hline
\end{tabular}



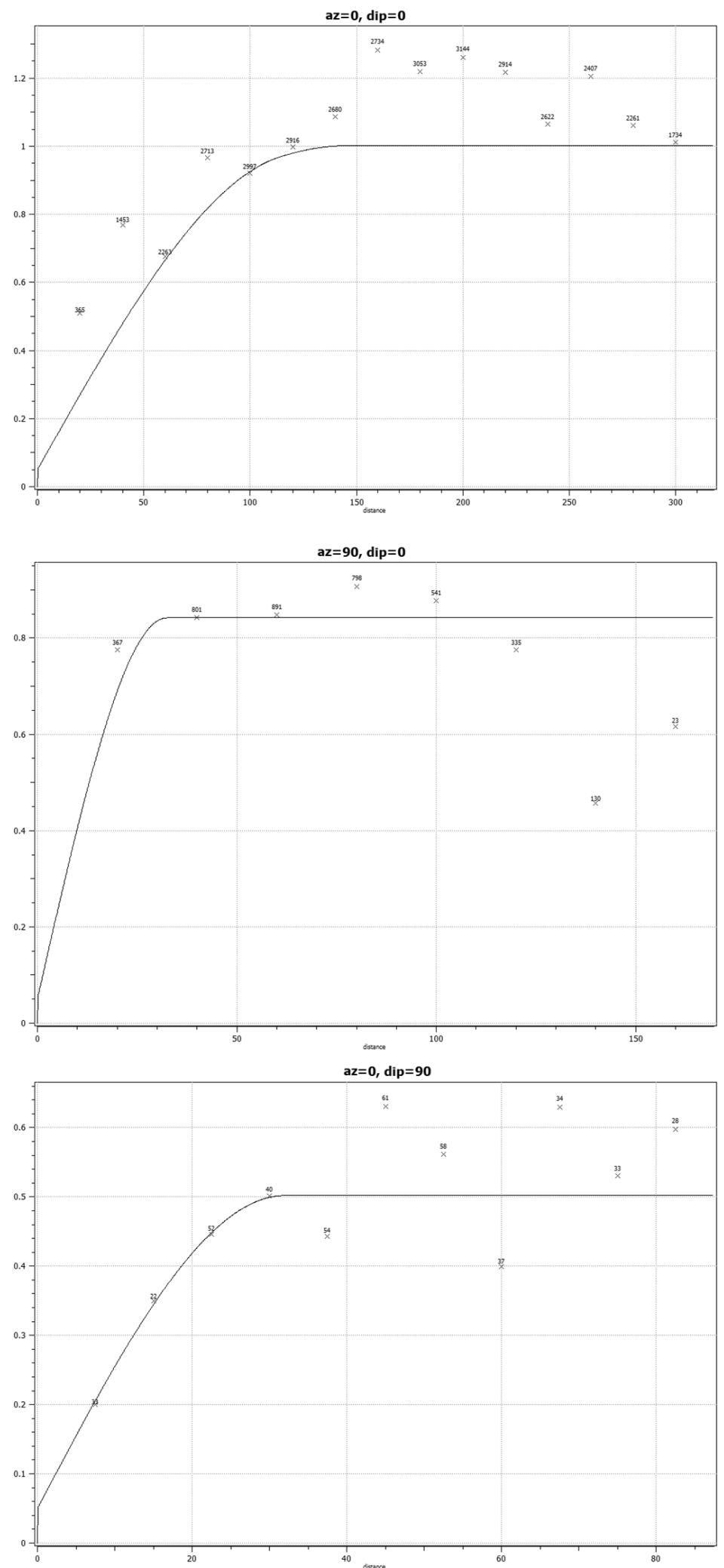

Figura 30 - Variograma experimental calculado para as direções $0^{\circ}, 90^{\circ}$ e vertical e seus respectivos modelos teóricos ajustados. 
Os parâmetros de vizinhança utilizados na validação cruzada foram os mesmos utilizados anteriormente, exceto as distâncias da elipse de busca por amostras vizinhas, que são compatíveis com as amplitudes do modelo teórico de variograma ajustado. O resultado da validação apresentou uma correlação de 0,84 com apenas 22 amostras não estimadas. Na Tabela 19 está representada a parametrização da vizinhança ótima definida pela validação cruzada. A Figura 31 apresenta a dispersão resultante da validação cruzada. Com a definição da vizinhança ótima pode-se simular os dados. Foram realizadas 100 simulações conforme as simulações anteriores.

Tabela 19 - Parâmetros da modelagem ajustados para o variograma calculado da nova amostragem.

\section{Parâmetros de vizinhança}

Rotação $0^{\circ}$

Divisão do espaço em octantes

Número ótimo de amostras por setor - 1

Mínimo de amostras para estimativa - 4

$\begin{array}{cccc}\text { Direção } & \text { X } & \text { Y } & \text { Z } \\ \text { Raio de busca } & 150 & 33 & 32\end{array}$

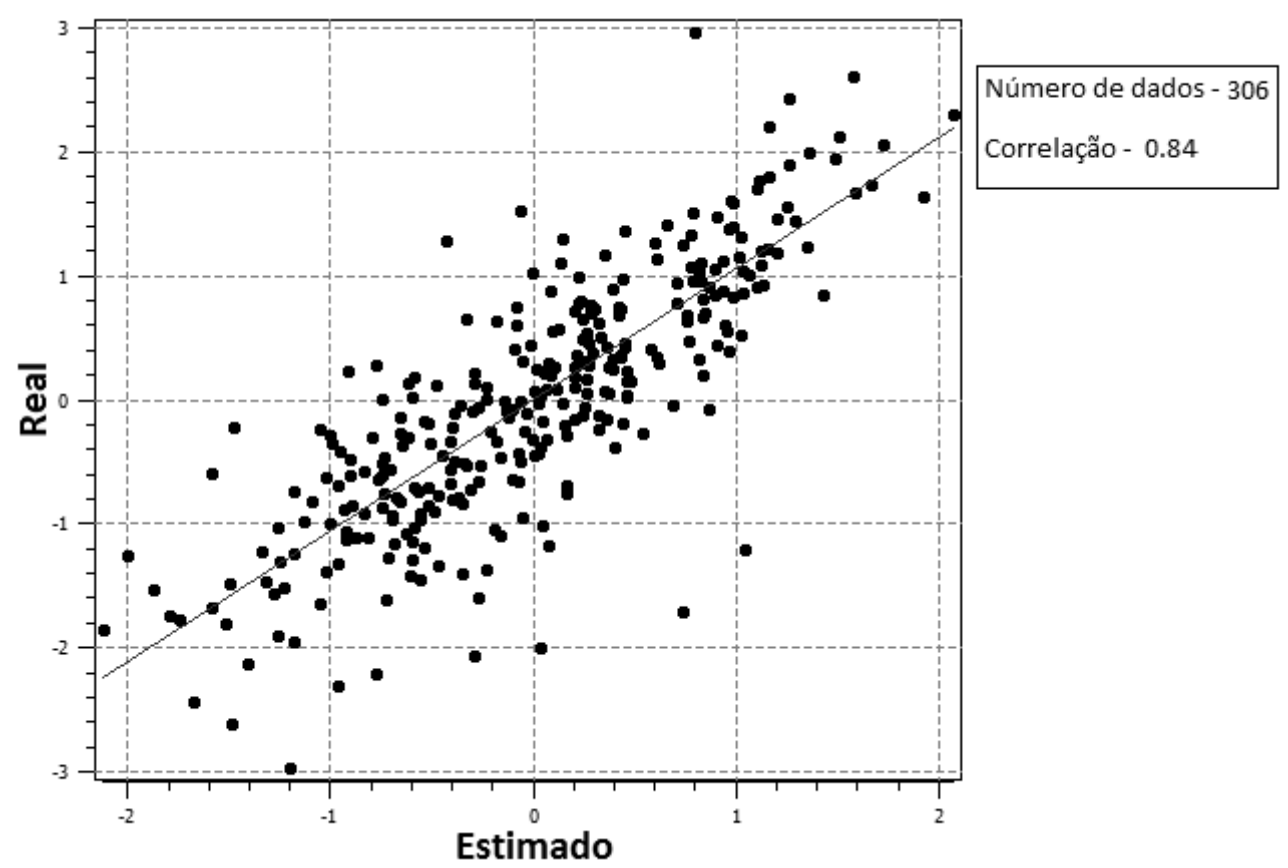

Figura 31 - Diagrama de dispersão entre valor amostral e estimado na validação cruzada para os dados atualizados transformados em distribuição gaussiana. 


\subsection{Comparação entre o infill e a população}

Os dados atualizados pelo infill obtido pela otimização das funções objetivo, soma da variância ou dos coeficientes de variação dos blocos da simulação, foram comparados com o dado populacional por dois métodos. Inicialmente compararam-se as estatísticas descritivas de ambas as amostragens atualizadas com a estatística descritiva do dado populacional, comparação apresentada em 5.8, onde se compara as Tabelas 10 e 01, estatística descritiva dos dados atualizados pelo inifll e populacional, respectivamente. $\mathrm{O}$ resultado da primeira comparação indica que o infill locado pela otimização das funções objetivo possui maior representatividade em relação à amostragem inicial, em relação à média, variância, máximo e mediana. O infill locado pela otimização da função objetivo, que soma a variância de blocos, apresentou valores de variância e máximo mais próximos ao do dado populacional, enquanto a otimização pela função objetivo, que soma os coeficientes de variação dos blocos, apresenta valores de média e mediana mais próximas ao dado populacional. Este comportamento indica que houve aumento na representatividade das amostragens atualizadas pelo infill amostral em relação à amostragem inicial, contudo não é possível definir qual das funções objetivo obtiveram maior êxito em representar o dado populacional.

A segunda comparação foi realizada com base no resultado da simulação dos dados atualizados pelo infill amostral. Esta comparação entre o resultado das simulações de cada infill foi realizada pela construção de gráficos do tipo $Q-Q$ plotando o $e$-type das simulações contra os valores populacionais, quanto mais os pontos se aproximam da reta 1:1 mais as distribuições são semelhantes. Na Figura 32 são apresentados os dois gráficos de dispersão obtidos pela análise do infill obtido pela minimização da soma das variâncias dos blocos. A dispersão pela minimização da soma dos coeficientes de variação é apresentada na Figura 33. 


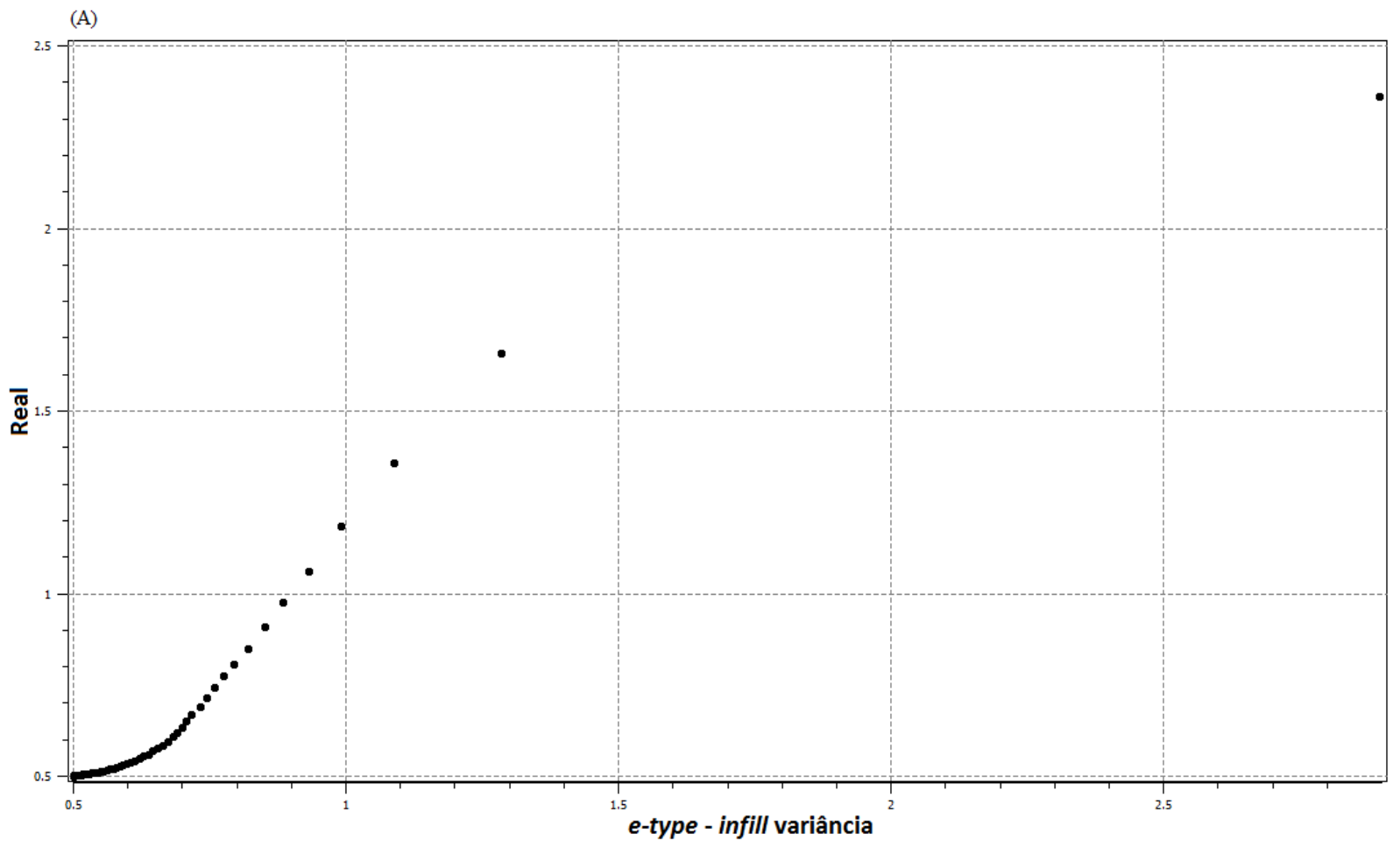

(B)

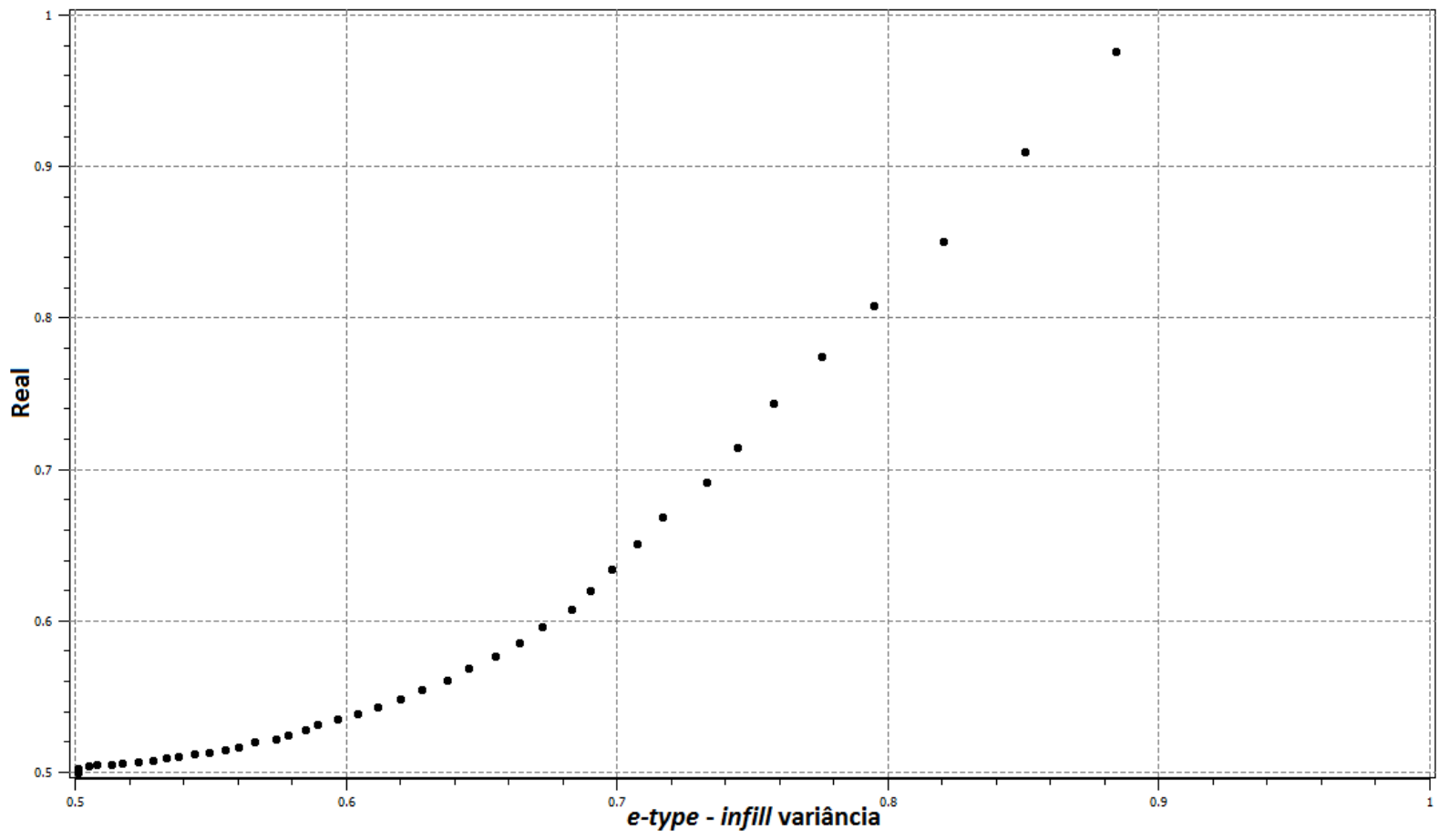

Figura $32-Q-Q$ plot entre o dado populacional e o infill obtido pela minimização da variância de bloco. O intervalo considerado para a população se limitou ao máximo obtido pelo $e$ type. A segunda imagem apresenta o comportamento no intervalo até o valor 1 , de modo a eliminar possíveis outiliers e poder observar a curva detalhadamente. 

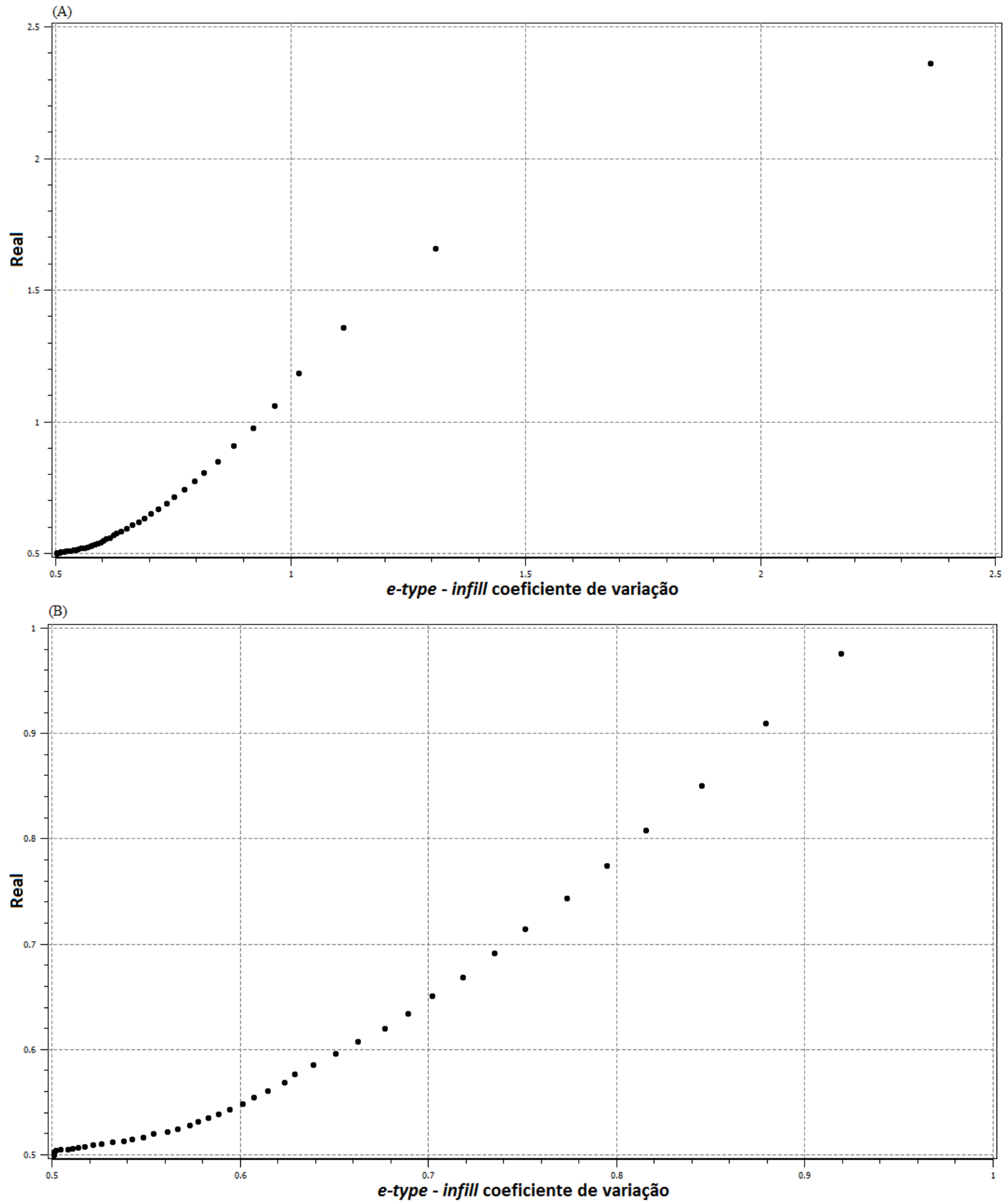

Figura 33 - $Q-Q$ plot entre o dado populacional e o infill obtido pela minimização do coeficiente de variação dos blocos. O intervalo considerado para a população se limitou ao máximo obtido pelo e-type. A segunda imagem apresenta o comportamento no intervalo até o valor 1, para eliminar possíveis outliers e se pode observar a curva de modo detalhado.

Comparando-se a dispersão apresentada nas Figuras 32 e 33 observa-se que ambos infill apresentam superestimativa em relação à população. Contudo a inclinação da curva na Figura 33 tende, progressivamente, a uma reta de forma mais pronunciada do que o 
comportamento observado na Figura 32, isso pode ser verificado tanto em (A) quanto em (B). Este comportamento indica que o infill baseado na minimização da soma dos coeficientes de variação dos blocos resultou em dados mais representativos do comportamento populacional do que a outra otimização que, ao contrário, apresenta superestimativa.

\section{CONCLUSÕES E TRABALHOS FUTUROS}

A metodologia de locação de amostra foi a mesma para os métodos de otimização e o resultado apresentou grande variação, tanto entre os métodos de otimização, quanto entre as funções objetivo. De maneira geral, o método com melhor resultado na minimização de ambas as funções objetivo foi o simulated annealing com memória e resfriamento rápido que, além de obter a maior redução do valor, é mais rápido e mais simples de implementar.

Definido o método com melhor resposta comparou-se o resultado da otimização das funções objetivo, efetuando o infill amostral indicado na otimização. O infill dos dados originais foi tratado da mesma forma que o dado original, realizando-se a simulação semelhante ao aplicado na amostragem inicial. O resultado do infill amostral apresentou maior representatividade em relação ao comportamento populacional, resultado observado nas estatísticas amostrais comparadas ao dado populacional e no gráfico $Q-Q$, que comparou o e-type das simulações com o dado populacional. A curva do e-type relacionado ao dado de cobre populacional tende a uma reta de forma mais pronunciada quando da minimização da soma dos coeficientes de variação dos blocos. O aumento da representatividade das estatísticas descritivas e da correlação pelo gráfico $Q-Q$ indica que o infill amostral otimizado minimizou a incerteza associada à amostragem inicial do depósito sintético.

A metodologia apresenta espaço para melhorias, como incorporação do comprimento total e atitude do furo na otimização, além da adição da topografia, para garantir que os furos sejam locados precisamente no terreno. Ambos os fatores podem ser implementados no método, se for do interesse do usuário. A metodologia aqui descrita pode ser incorporada a algum programa especialista de mineração, para aplicação fácil e de interesse frente a uma pesquisa ou exploração de um corpo mineral. Contudo, o desenvolvimento do algoritmo e os testes subsequentes são extensos e exigem tempo de programação e desenvolvimento. 


\section{REFERÊNCIAS BIBLIOGRÁFICAS}

Abdi K., Fathian M. \& Safari E. 2012. A Novel Algorithm Based on Hybridization of Artificial Immune System and Simulated Annealing for Clustering Problem. The International Journal of Advanced Manufacturing Technology, 60:723-732.

Armstrong, M. 1994. Is Research in Mining Geostats as Dead as a Dodo?; in Geostatistics for the Next Century. Springer, Netherlands, p. 303-312.

Armstrong M. 1998. Basic Linear Geostatistics. Springer, Germany, 155 p.

Bárdossy G. \& Fodor J. 2004. Evaluation of Uncertainties and Risk in Geology - New Mathematical Approaches fo their Handling. Springer, New York, 230 p.

Bianchi L., Dorigo M. \& Gambardella L. M. 2008. A Survey on Metaheuristics for Stochastic Combinatorial Optimization. Natural Computing, 8:239-287.

Burkard R. E. \& Fincke U. 1985. Probabilistic Asymptotic Properties of Some Combinatorial Optimization Problems. Discrete Applied Mathematics, 12:21-29.

Caers J. 2011; Modeling Uncertainty in Earth Sciences. Wiley-Blackwell, Oxford, UK, 249 p.

Chilès J. \& Delfiner P. 1999. Geostatistics: Modeling Spatial Uncertainty. Wiley-Interscience, Canada, $695 \mathrm{p}$.

Deutsch D. V. 2002. Geostatistical Resevoir Modeling. Oxford University Press, New York, 376 p.

Deutsch D. V. \& Journel A. G. 1998. GSLIB - Geostatistical Software Library and User's Guide. Oxford University Press, New York, 369 p.

Gall J. 2014. Simulated Annealing; in Computer Vision: A Reference Guide. Springer, New York, P. 737-741.

Kennedy J. \& Eberhart R. 1995. Particle swarm optimization. Proceedings of IEEE international conference on neural networks. 4:1942-1948.

Kennedy J., Eberhart R. C. \& Shi Y. 2001. Swarm Inteligence. Morgan Kaufmann Publishers, San Francisco, $512 \mathrm{p}$.

Kennedy J. 2010. Particle Swarm Optimization; in Encyclopedia of Machine Learning. Springer, New York, p. 760-766. 
Kizilkale A. C. \& Dimitrakopoulos R. 2013. Optimizing Mining Rates under Financial Uncertainty in Global Mining Complexes. McGill, COSMO - Stochastic Mine Planing Laboratory, Research Report No.7, Vol.1, Montreal, Canadá, p. 202-223.

Lamghari A. \& Dimitrakopoulos R. 2013. Progressive Hedging Applied as a Metaheuristic to Schedule Production in Open-pit Mines Accounting for Reserve Uncertainty. McGill, COSMO - Stochastic Mine Planing Laboratory, Research Report No.7, Vol.1, Montreal, Canada, p. 110-137

Olea, R. A. 2003. Geostatistics for Engineers and Earth Scientists. Kluwer Academic Publishers, United States of America, 303 p.

Pannatier Y. 1994. MS-WINDOWS Programs for Exploratory Variography and Variogram Modeling in 2D. In Statistics of Spatial Processes: Theory and Applications. Bary, Italy

Pearl J. 1984. Heuristics: Inteligent Search Strategies for Computer Problem Solving. Addison-Wesley, Massachusetts, $401 \mathrm{p}$.

Rocha M. M. da. 1999. Estudo comparativo entre os métodos computacionais de avaliação de reservas e controles de teores da Mina de Capanema, Santa Bárbara, MG. Dissertação de Mestrado, Instituto de Geociências, Universidade de São Paulo, 78 p.

Romeijn H. E. 2009. Random Search Methods; in Encyclopedia of Optimization. Springer, New York, p. $3245-3251$.

Schoen F. 2009. Stochastic Global Optimization: Stopping Rules; in Encyclopedia of Optimization. Springer, New York, p. 3746-3743.

Shaw R.\& Srivastava S. 2007. Particle Swarm Optimization: A New Tool to Invert Geophysical Data. Geophysics, vol.72, p.75-83.

Silva D. S. F. \& Boisvert J. B. 2013. Infill Drilling Optimization for Maximizing Resource Tonnage. CGC Annual Report, 15:314/1-314/14.

Snyman J. A. 2005. Pratical Mathematical Optimization: An Introduction to Basic-Optimization Theory and Classical and New Gradient-Based Algorithms. Springer, New York, 276 p.

Takafuji E. H. de M. da. 2015. Estudo comparativo entre a simulação sequencial gaussiana e a simulação baseada em wavelets aplicado a quantificação de minério de CU em um depósito sintético. Dissertação de Mestrado, Instituto de Geociências, Universidade de São Paulo, 97 p.

Voss S. 2009. Metaheuristics; in in Encyclopedia of Optimization. Springer, New York, p. 2061-2075.

Wakernagel H. 2003. Multivariate Geoestatistics - An Introduction with Applications. Springer, Germany, 387 p. 

$226 \mathrm{p}$.

Yamamoto J. K. 2001. Avaliação e Classificação de Reservas Minerais. EDUSP, FAPESP, São Paulo, 
ANEXO 
A1

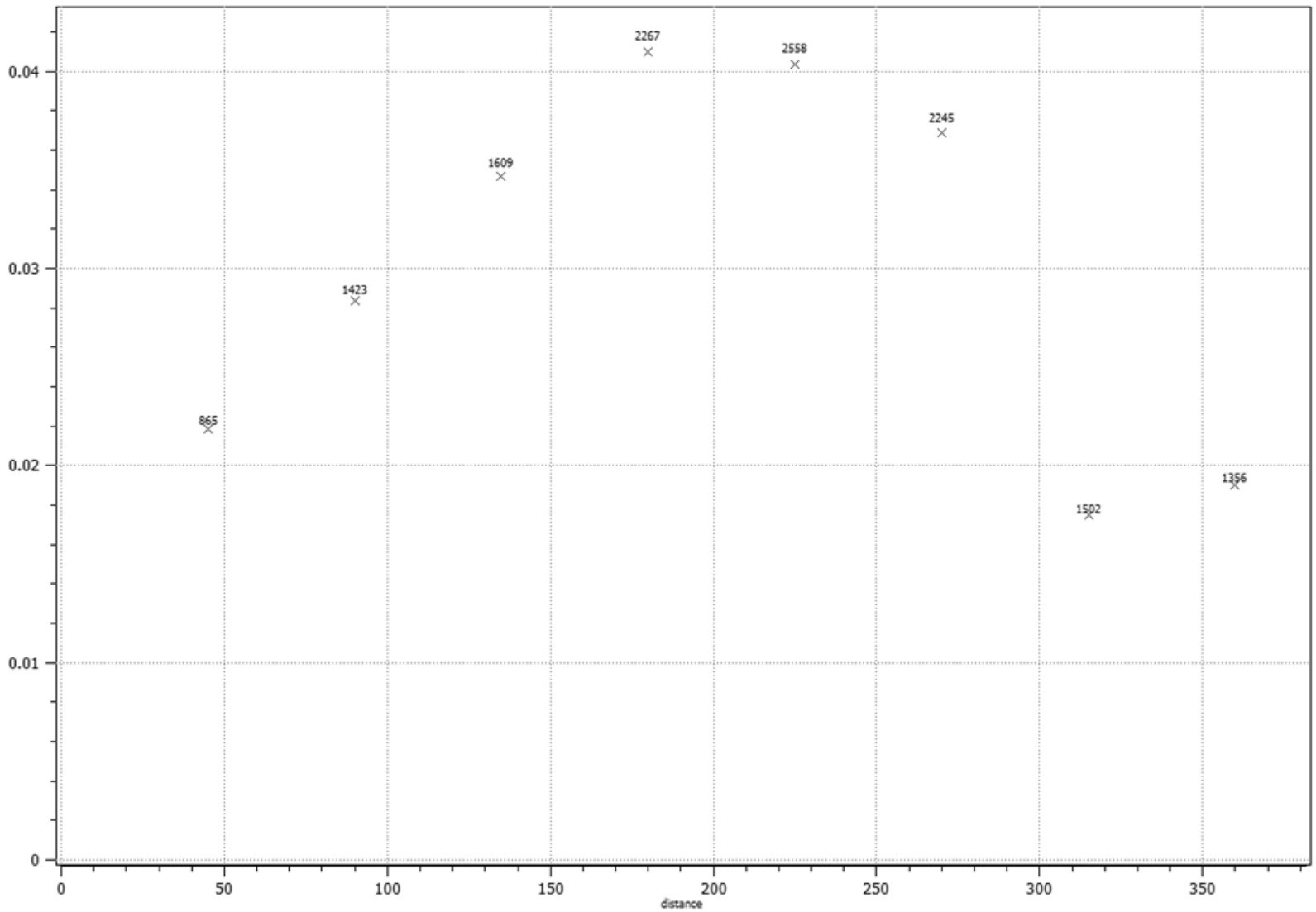

Figura A1 - Variograma experimental da análise exploratória na direção $0^{\circ}$ de azimute. 


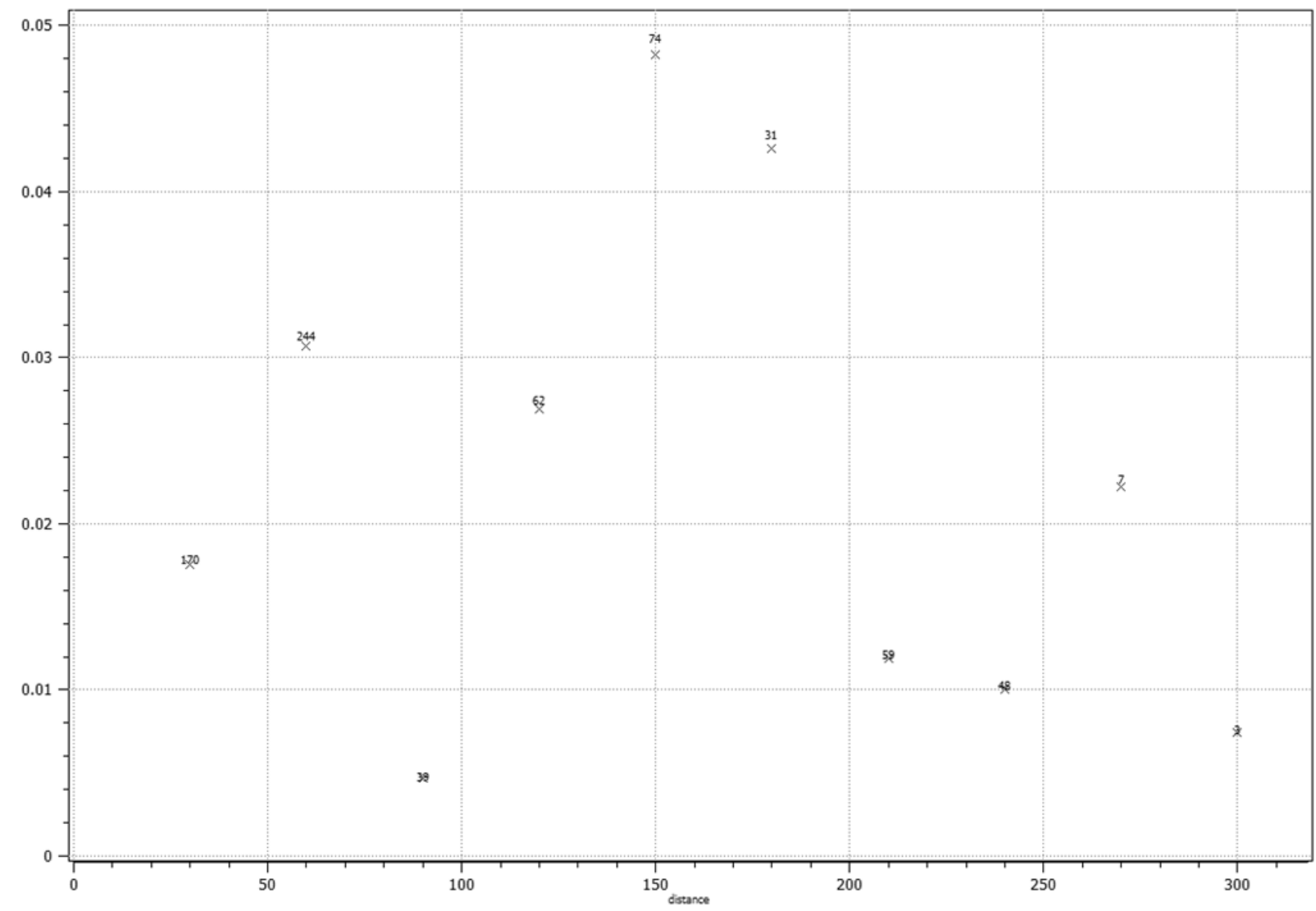

Figura A2 - Variograma experimental da análise exploratória na direção $45^{\circ}$ de azimute. 


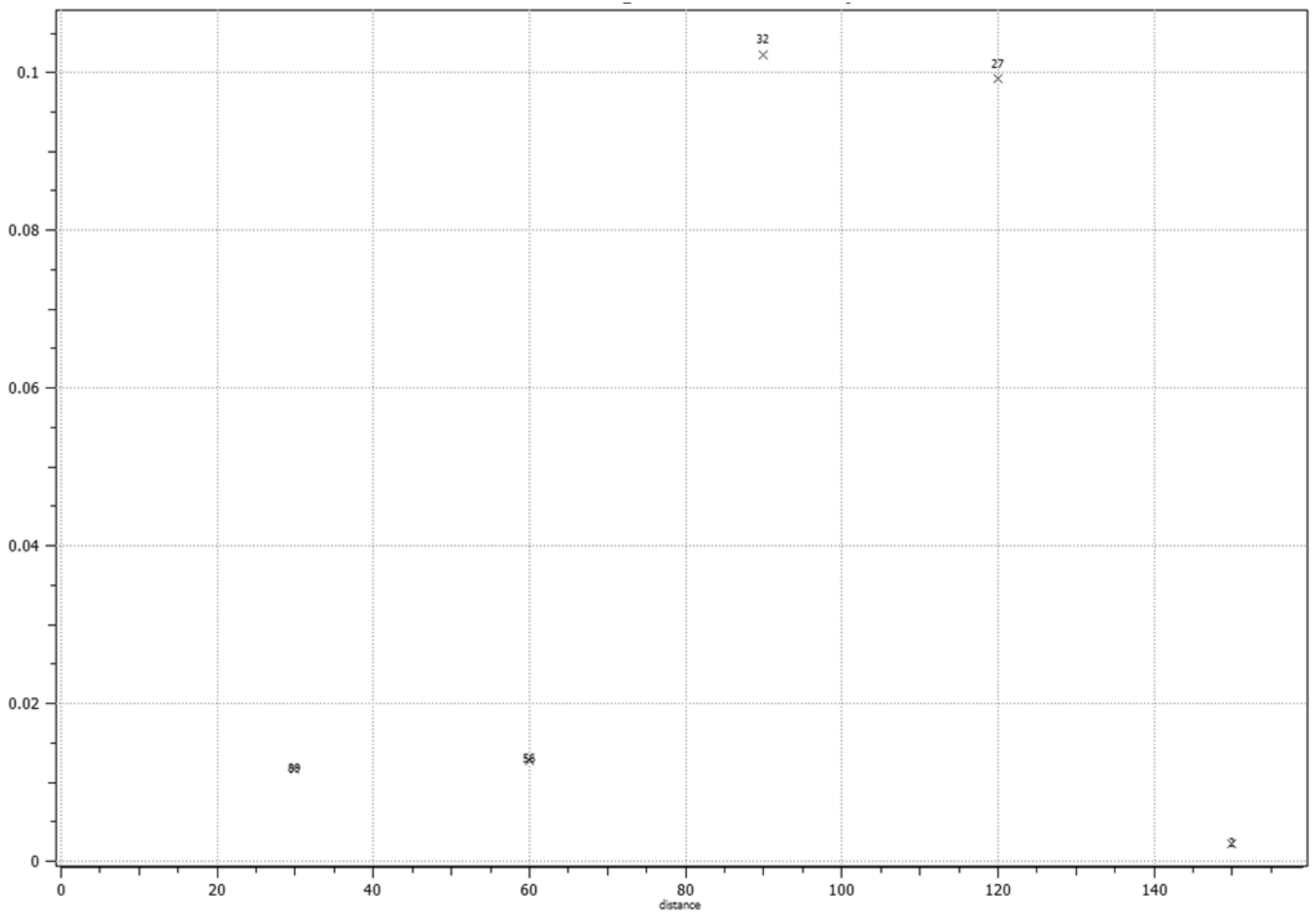

Figura A3 - Variograma experimental da análise exploratória na direção $90^{\circ}$ de azimute. 


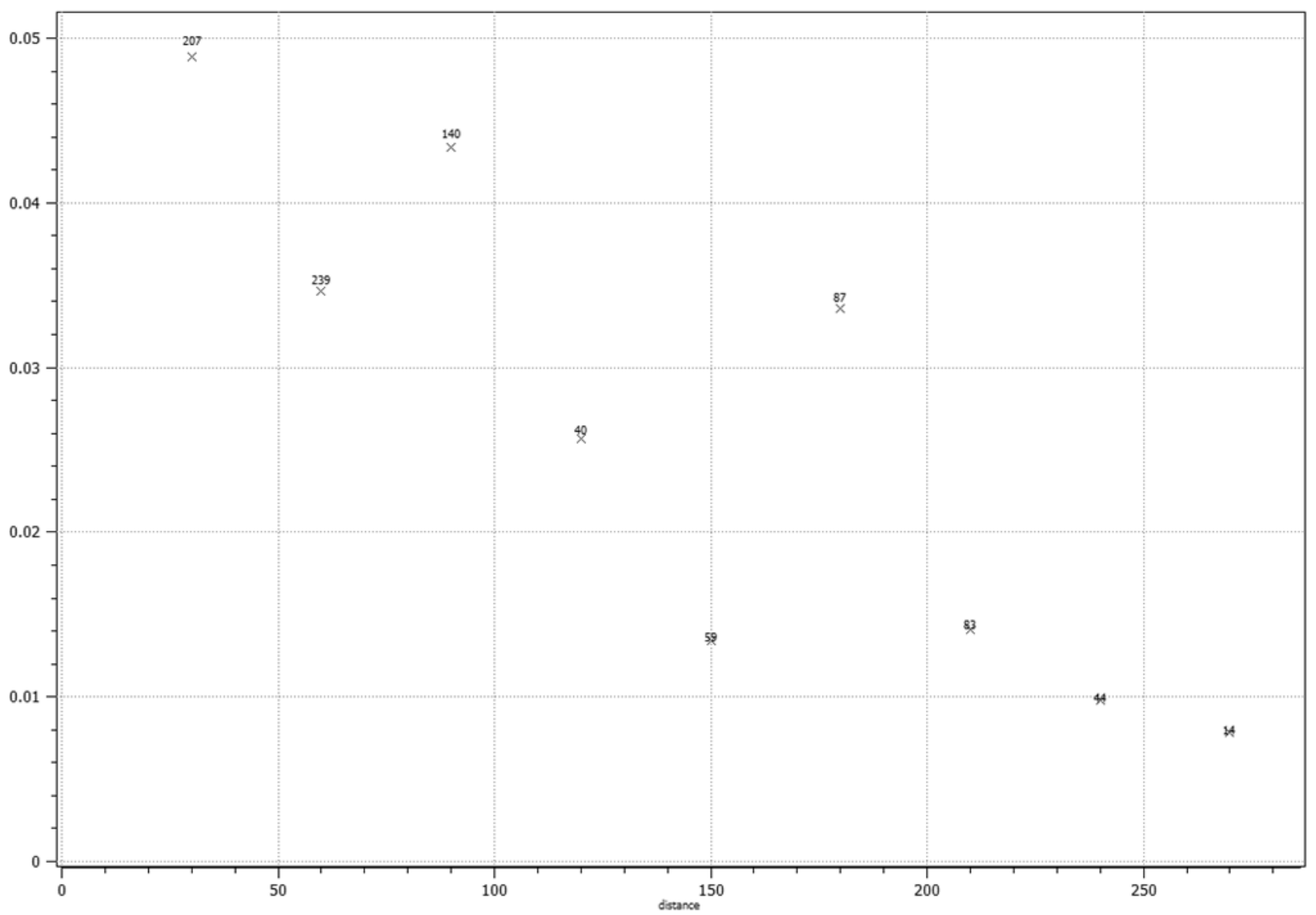

Figura A4 - Variograma experimental da análise exploratória na direção $135^{\circ}$ de azimute. 


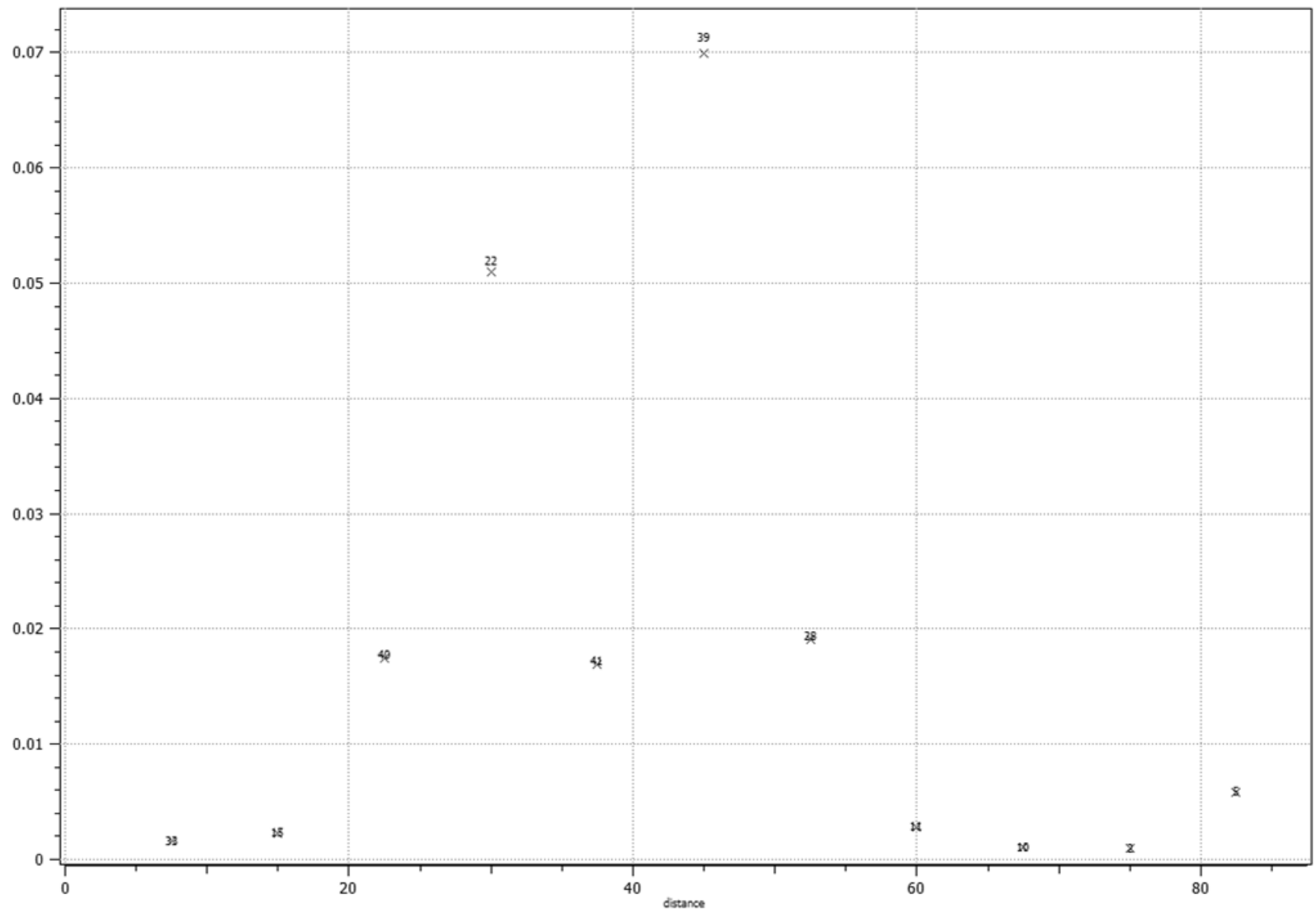

Figura A5 - Variograma experimental da análise exploratória na direção $0^{\circ}$ de azimute e mergulho $90^{\circ}$. 


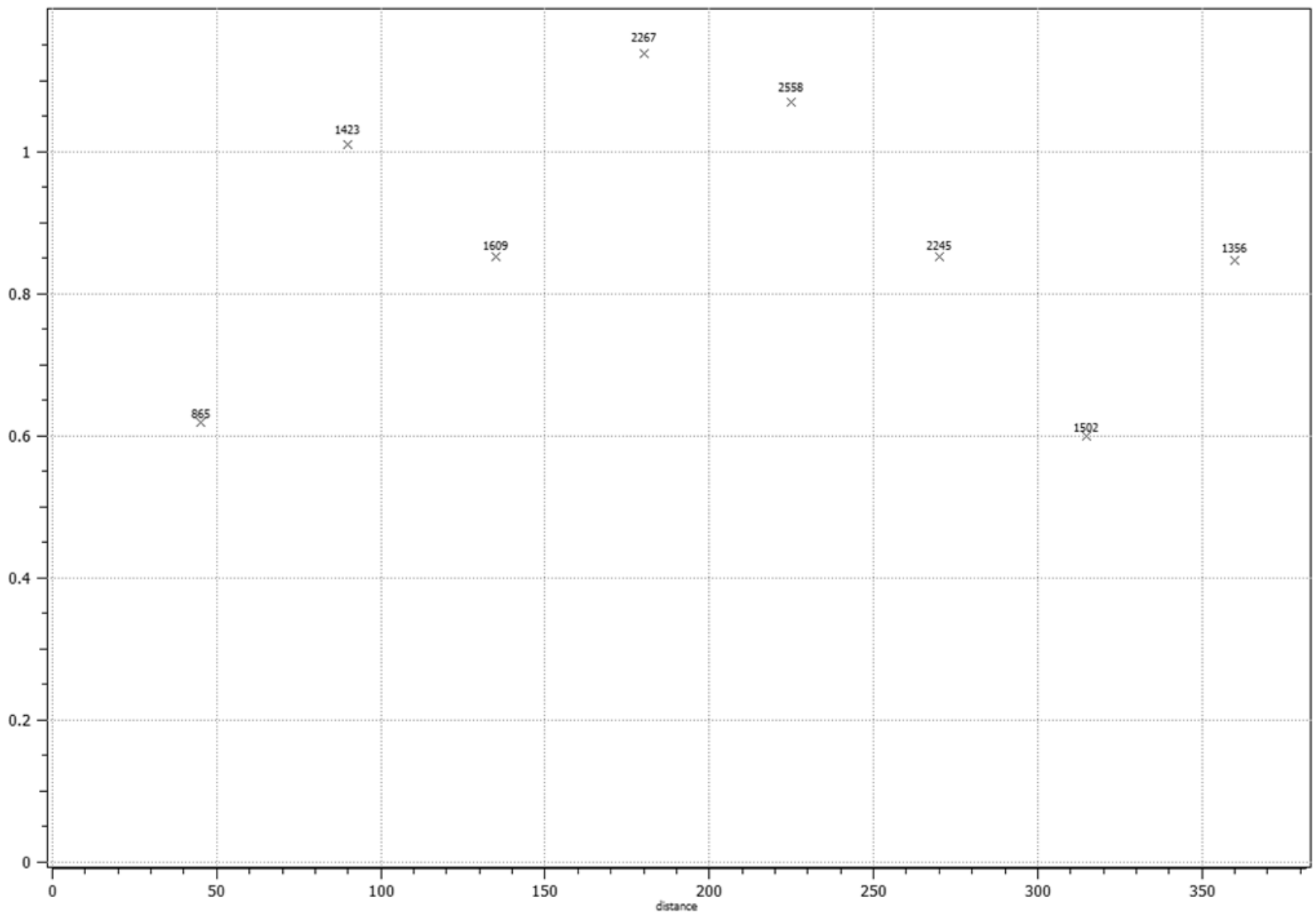

Figura A6 - Variograma experimental da análise exploratória dos dados transformados na direção $0^{\circ}$ de azimute. 


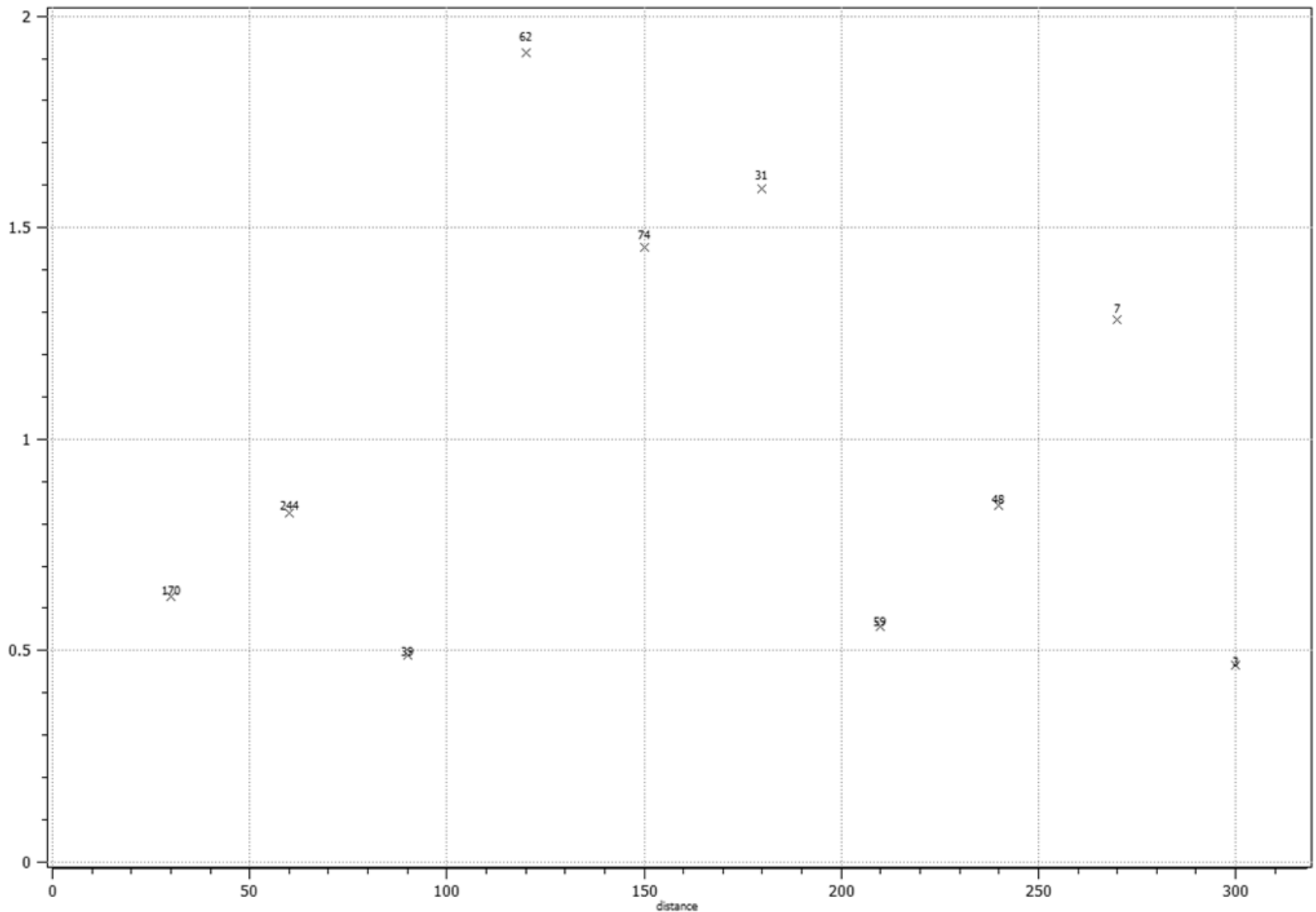

Figura A7 - Variograma experimental da análise exploratória dos dados transformados na direção $45^{\circ}$ de azimute. 


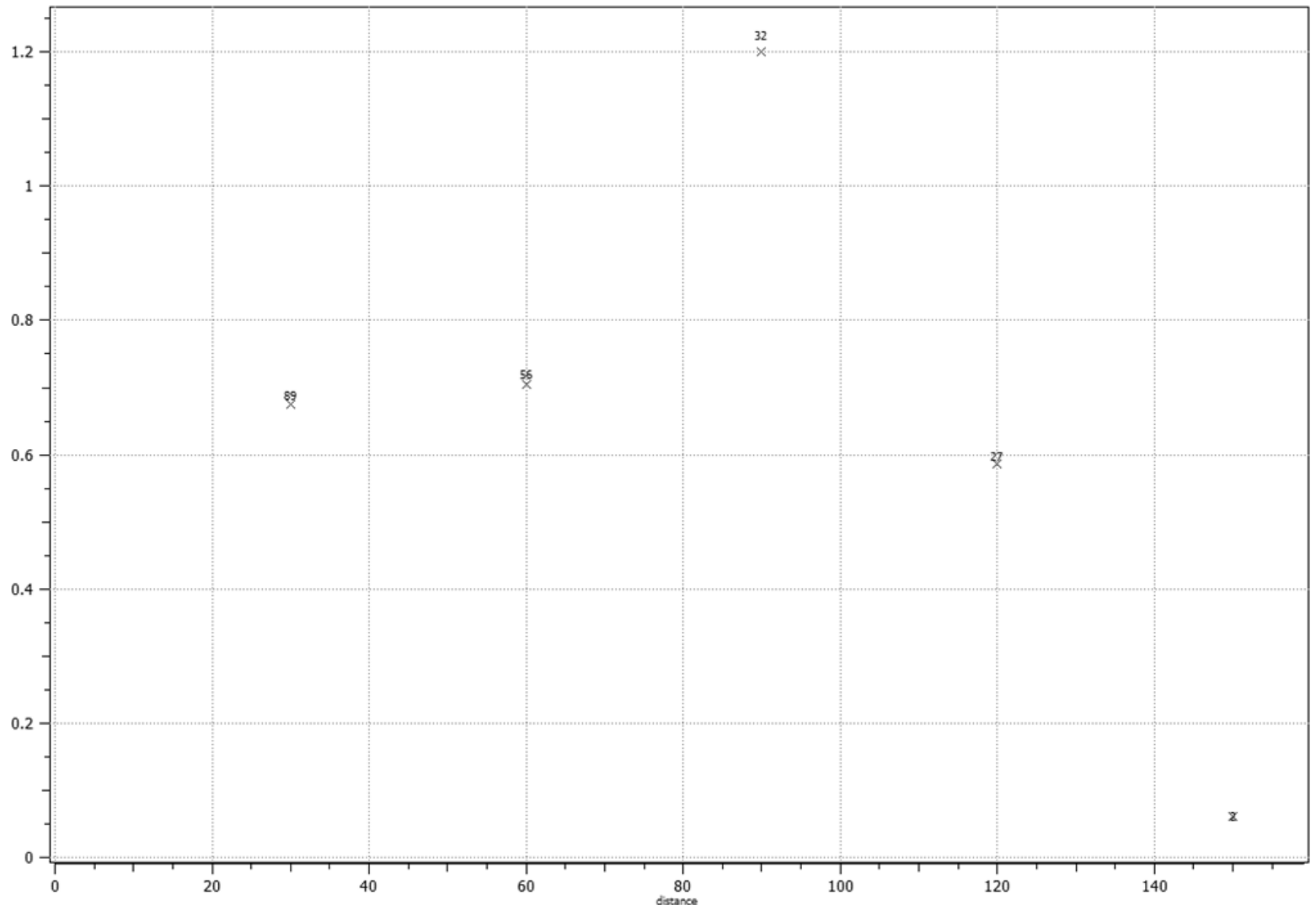

Figura A8 - Variograma experimental da análise exploratória dos dados transformados na direção $90^{\circ}$ de azimute. 


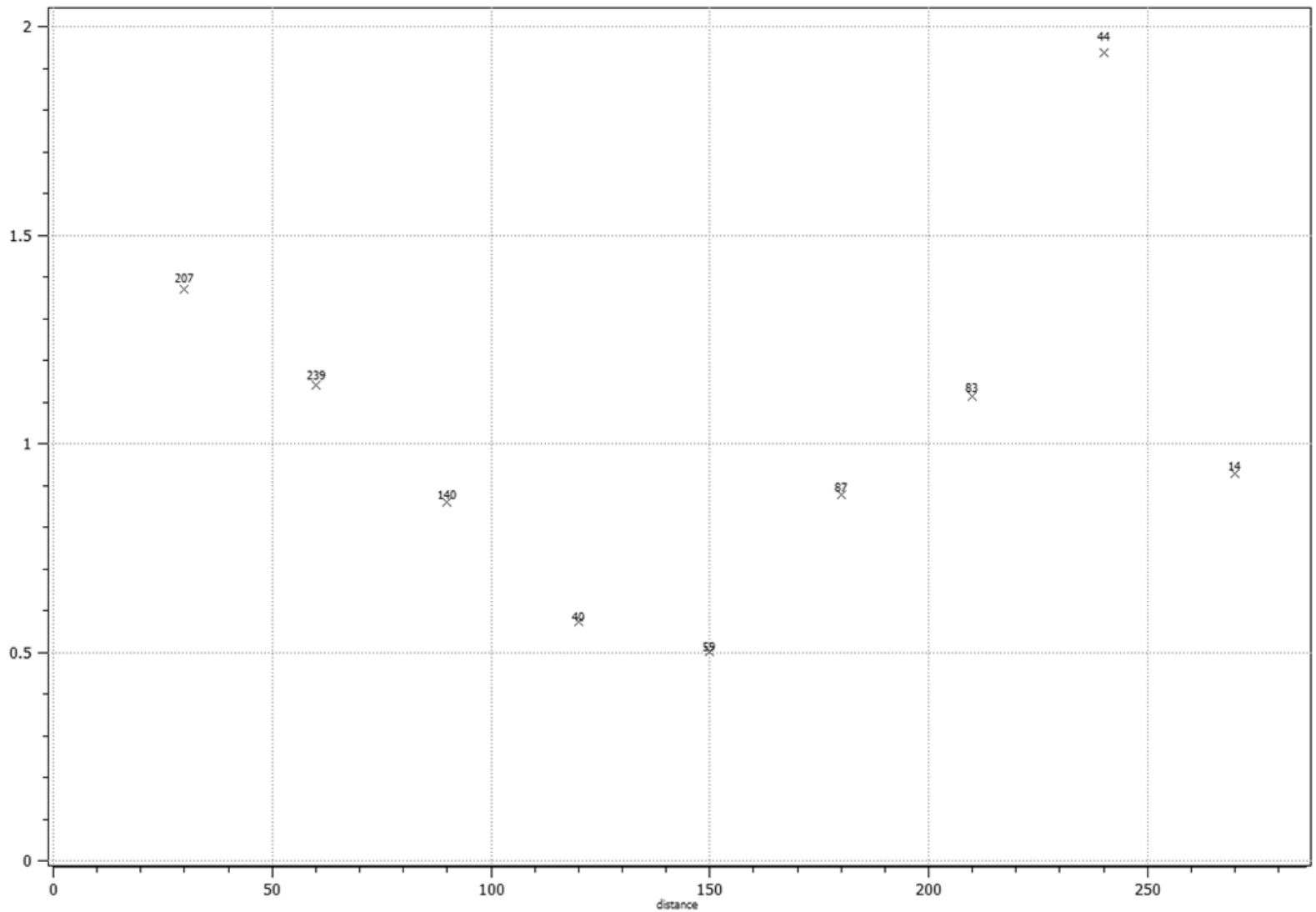

Figura A9 - Variograma experimental da análise exploratória dos dados transformados na direção $135^{\circ}$ de azimute. 


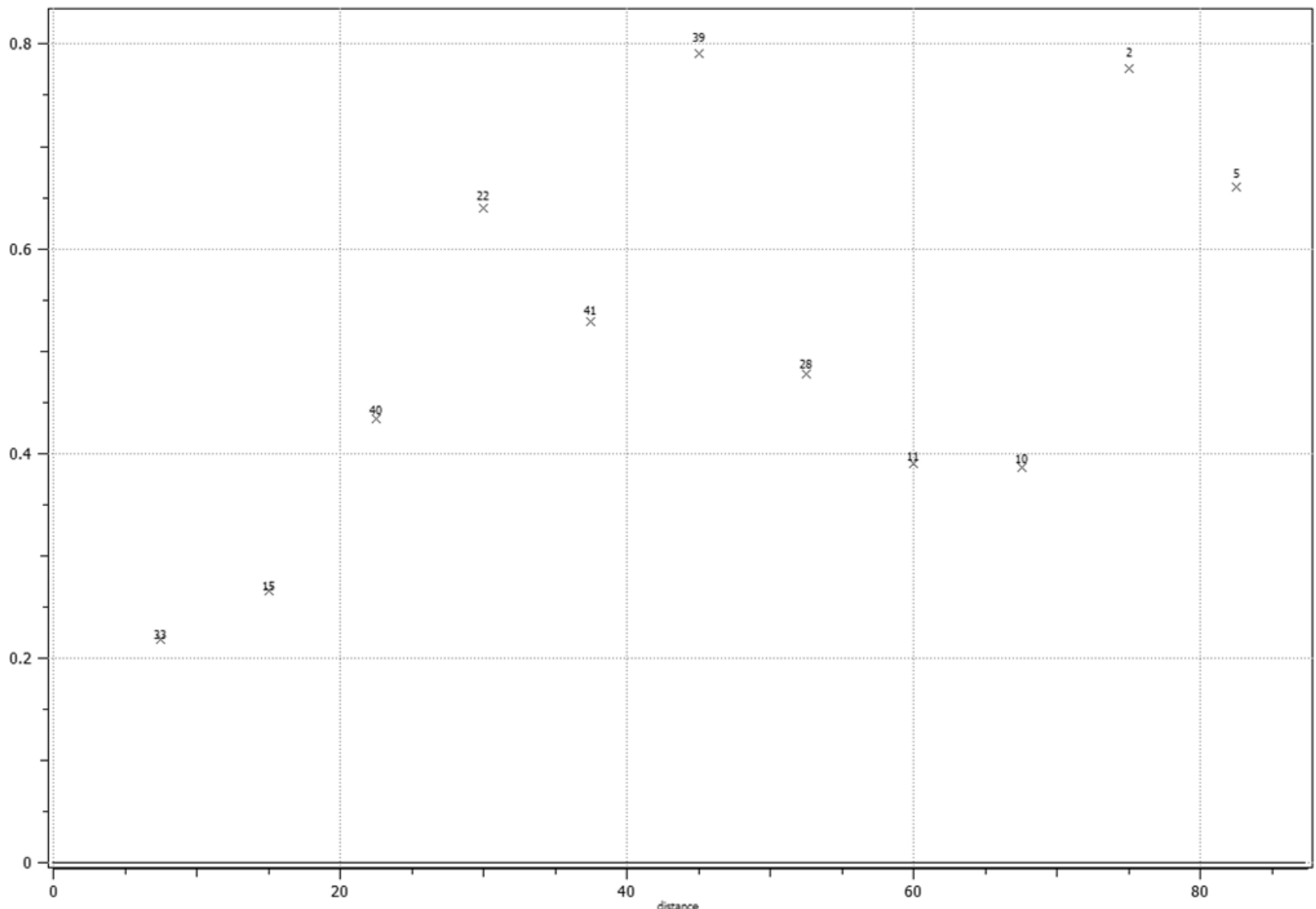

Figura A10 - Variograma experimental da análise exploratória dos dados transformados na direção $0^{\circ}$ de azimute e $90^{\circ}$ de mergulho. 


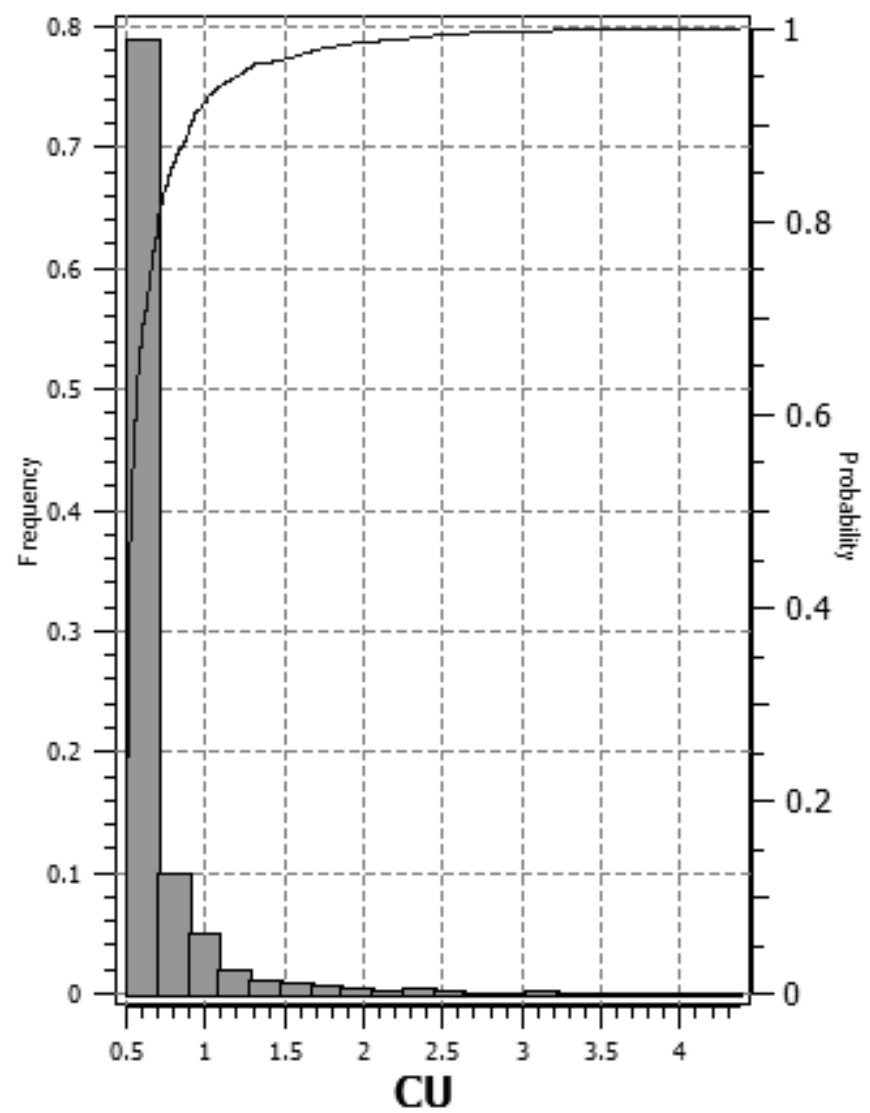

Figura A11 - Histograma e distribuição acumulada da amostragem otimizada não regularizada, locada utilizando a variância como função objetivo. 


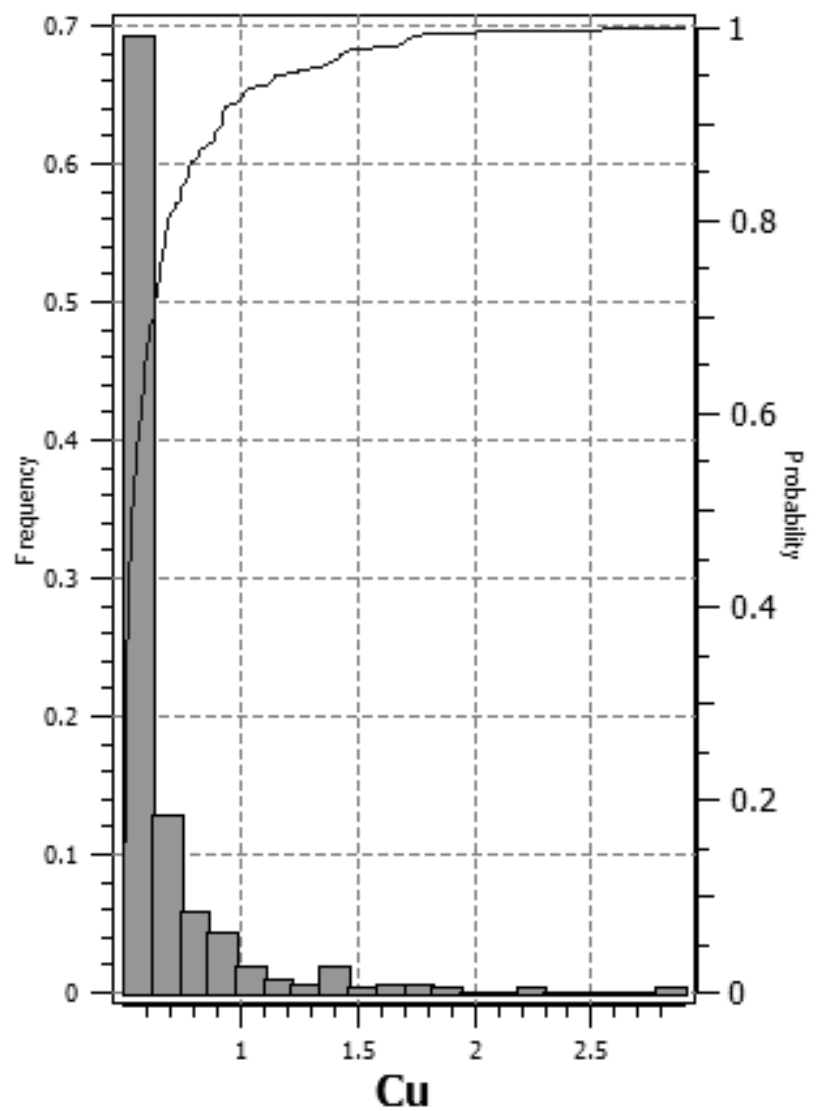

Figura A12 - Histograma e distribuição acumulada da amostragem otimizada regularizada, locada utilizando a variância como função objetivo. 


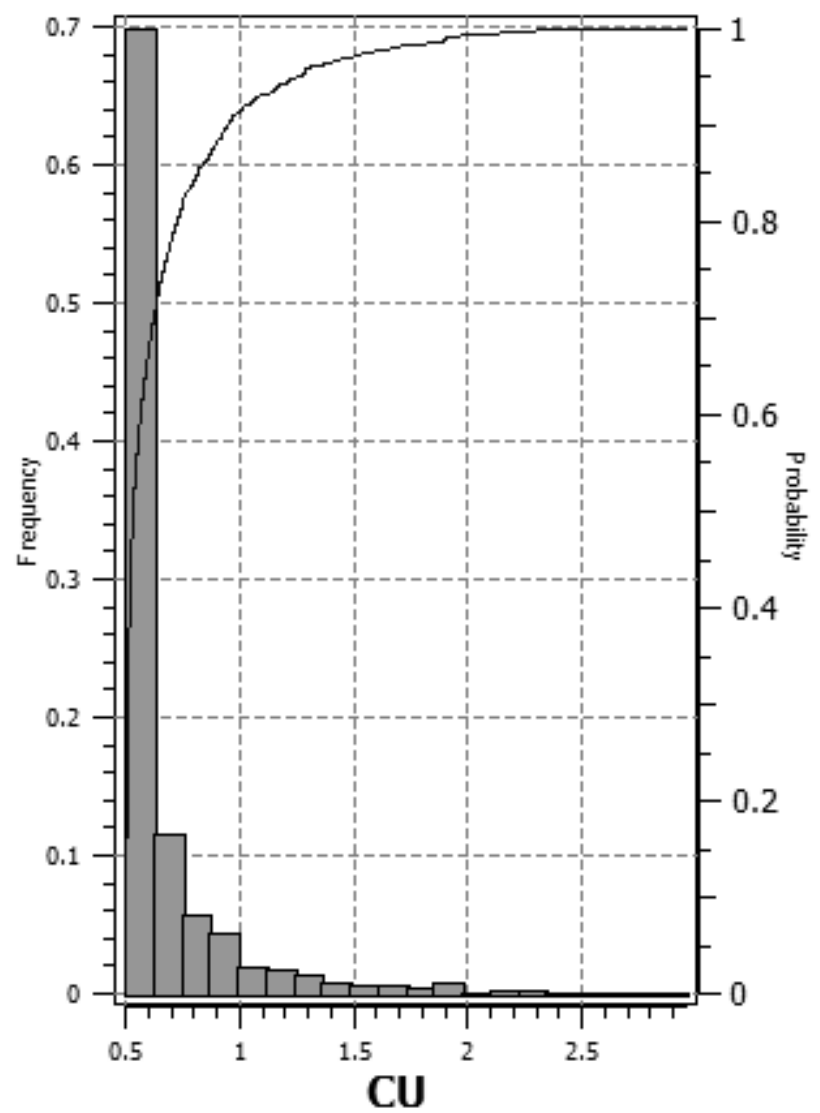

Figura A13 - Histograma e distribuição acumulada da amostragem otimizada não regularizada, locada utilizando o coeficiente de variação como função objetivo. 


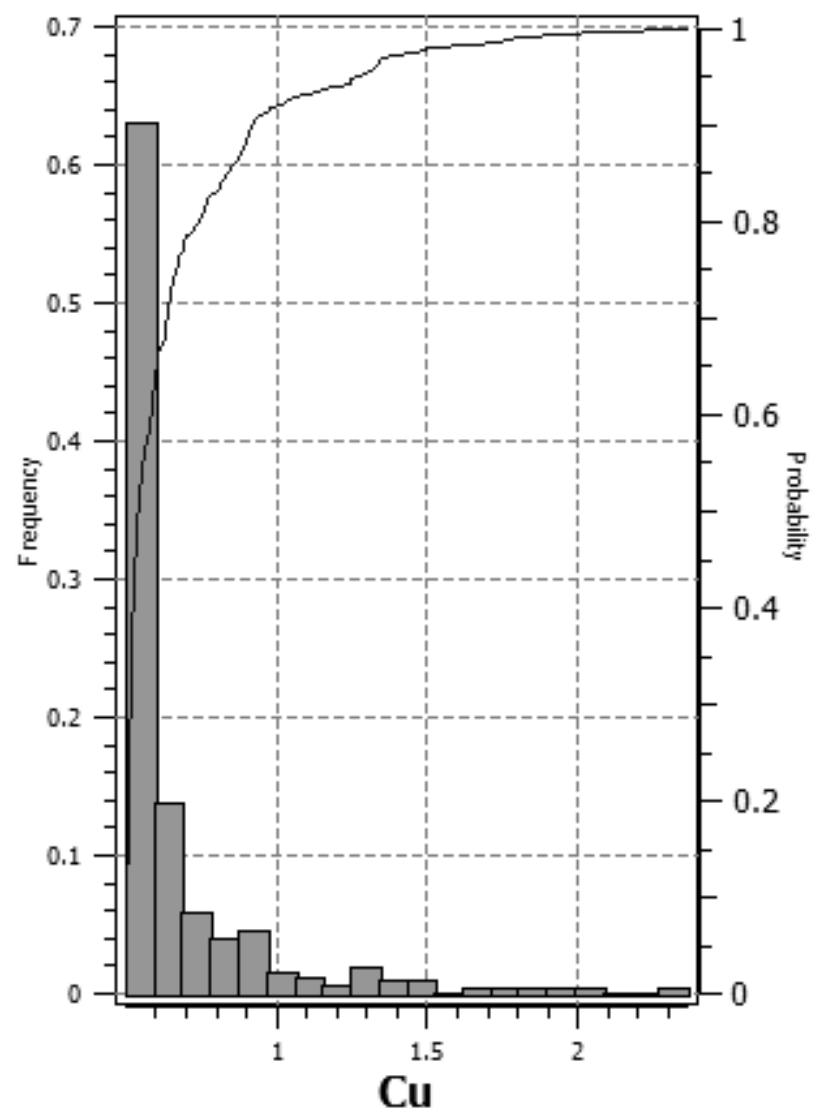

Figura A14 - Histograma e distribuição acumulada da amostragem otimizada regularizada, locada utilizando o coeficiente de variação como função objetivo. 


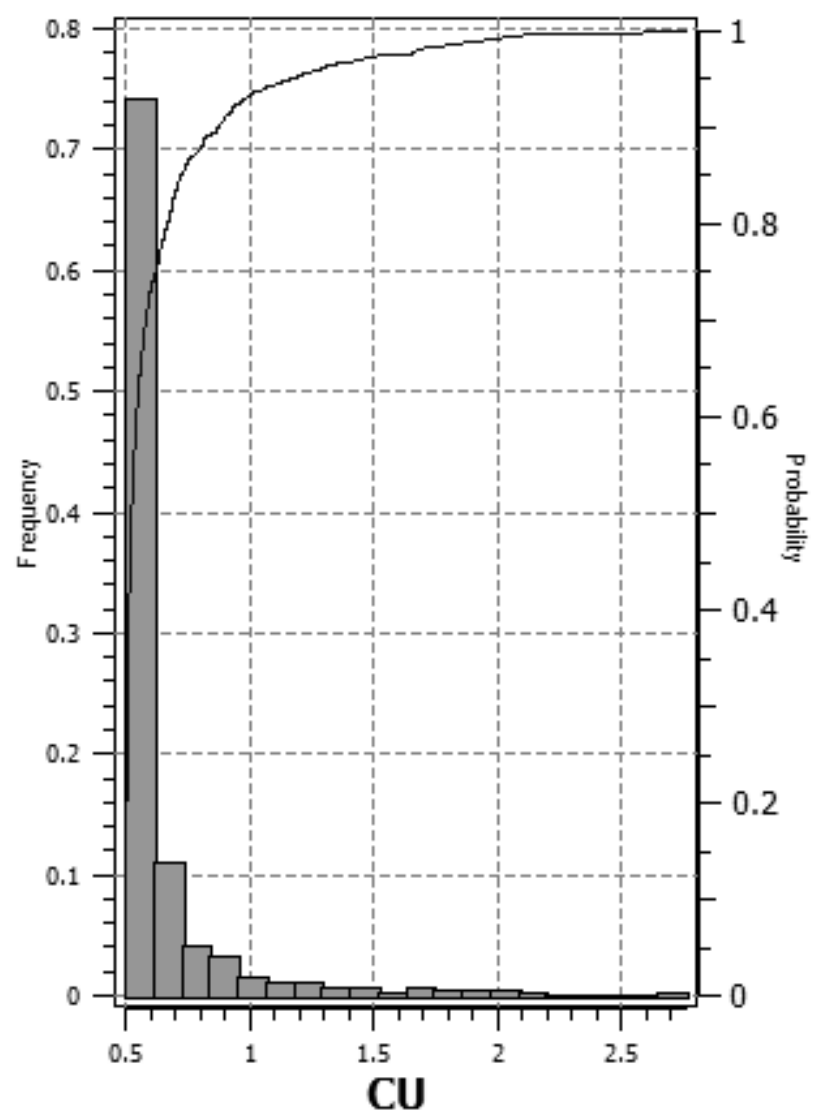

Figura A15 - Histograma e distribuição acumulada da amostragem otimizada não regularizada, locada aleatoriamente. 


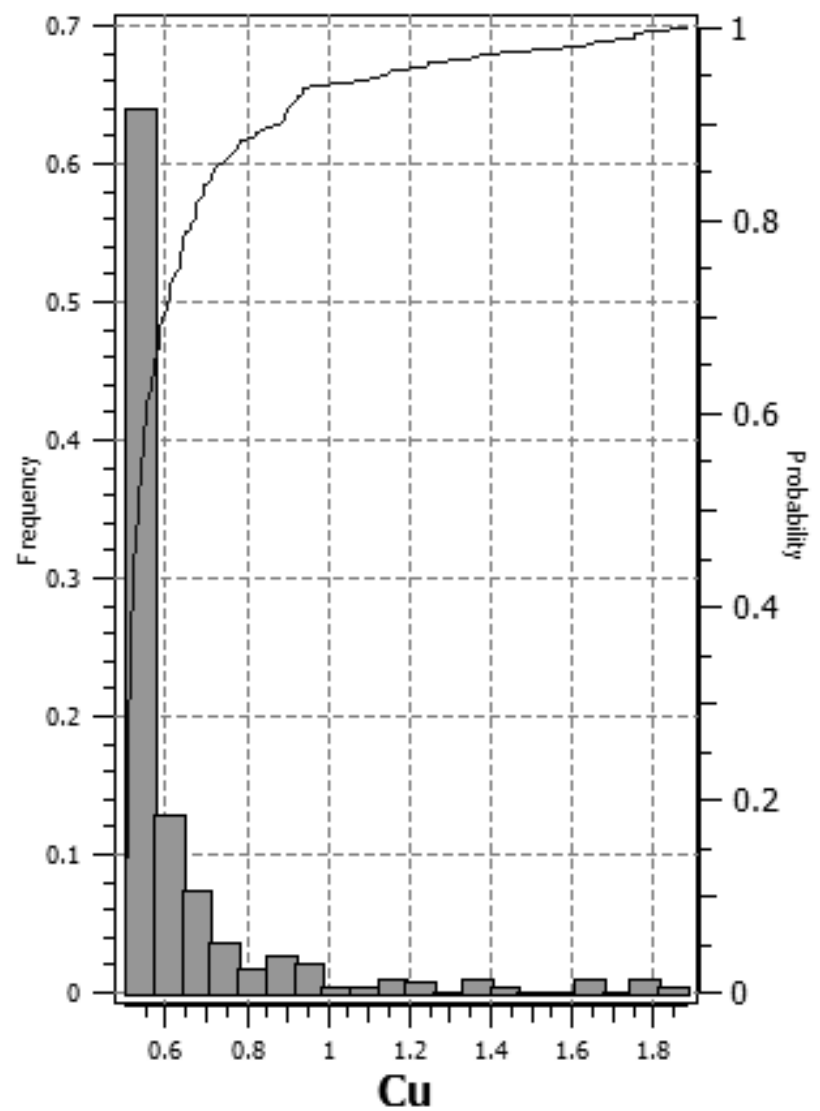

Figura A16 - Histograma e distribuição acumulada da amostragem otimizada regularizada, locada aleatoriamente. 


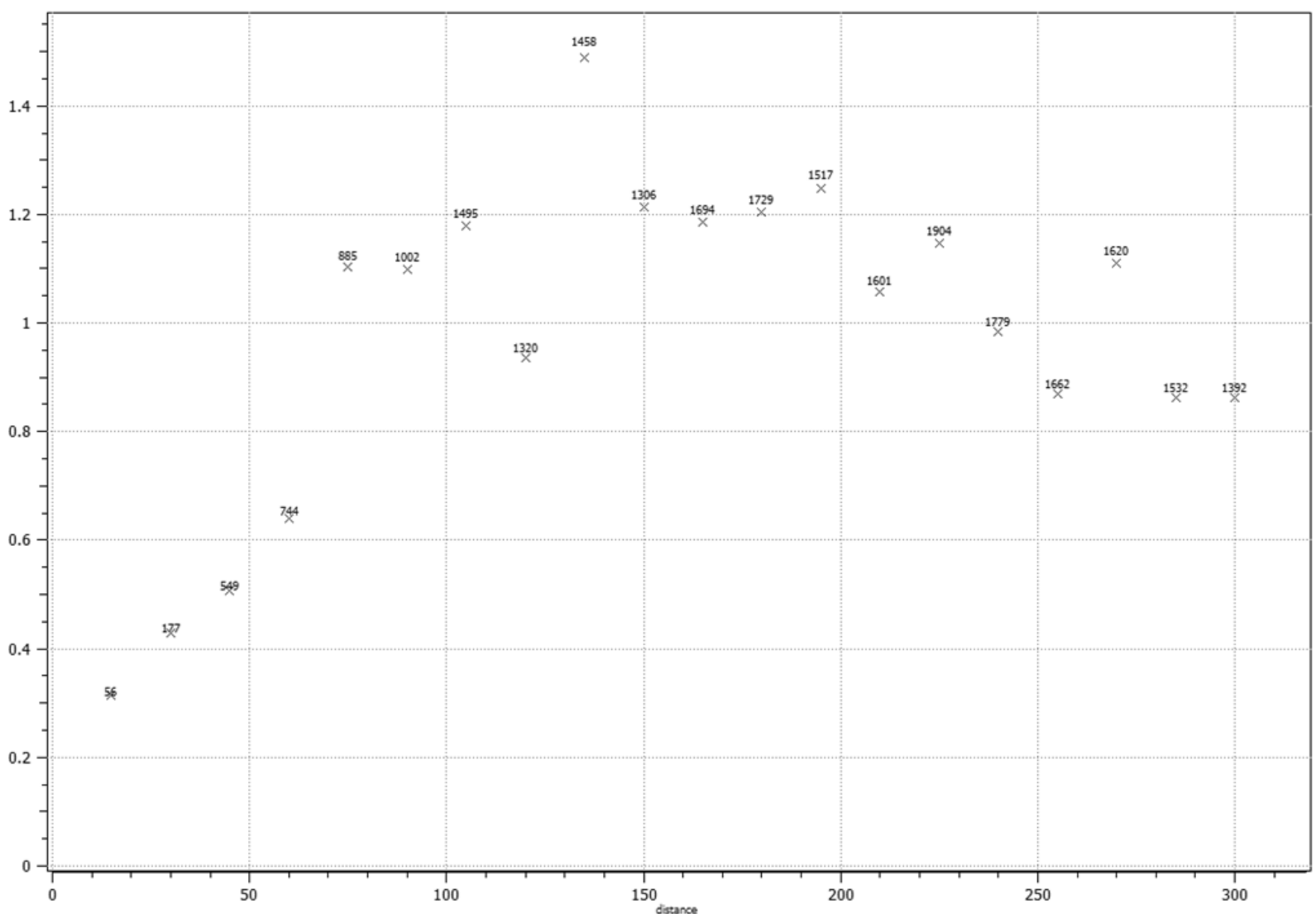

Figura A17 - Variograma experimental da análise exploratória dos dados atualizados com a amostragem baseada na otimização da soma da variância de blocos transformados em distribuição gaussiana. Cálculo realizado na direção $0^{\circ}$ de azimute. 


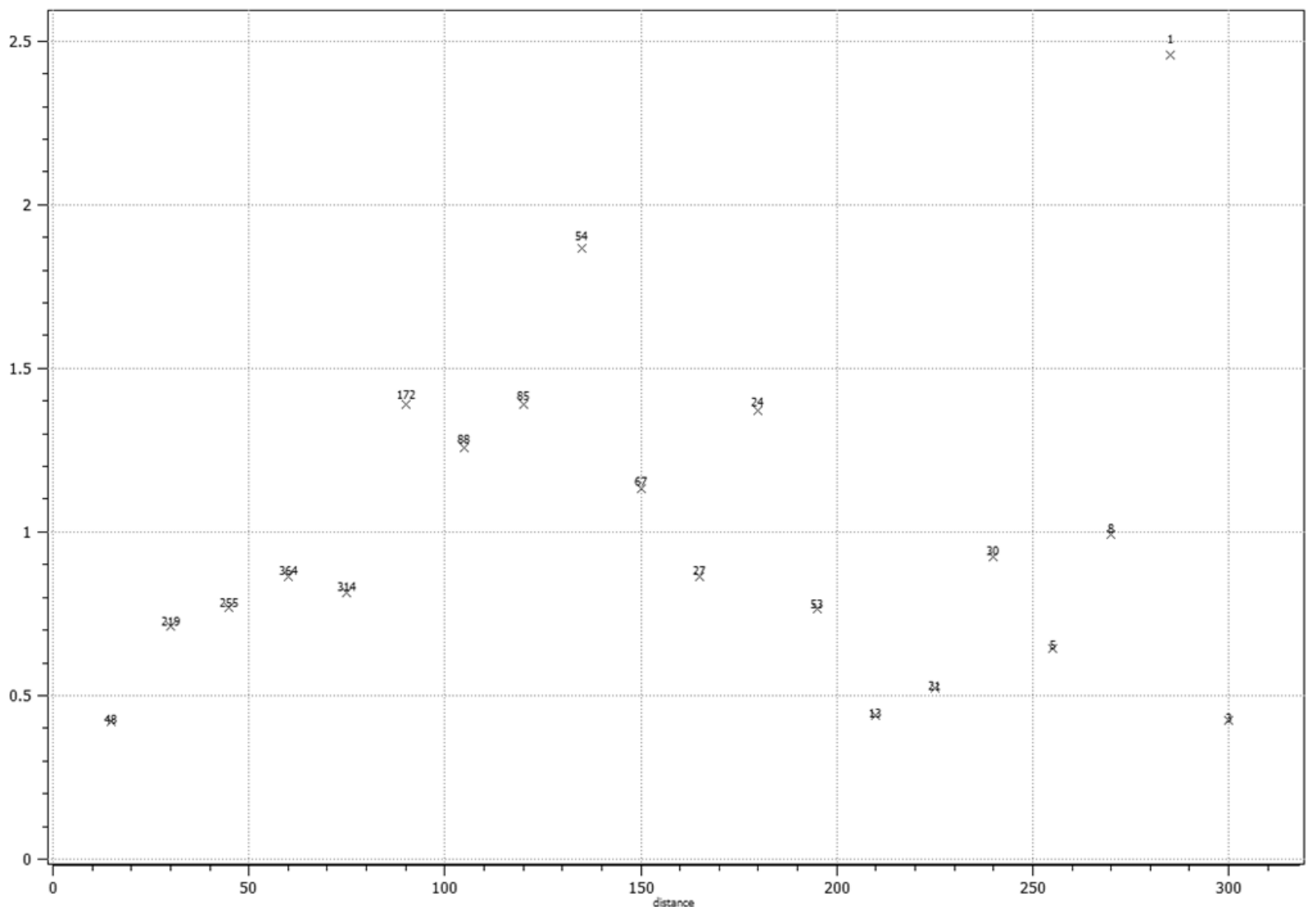

Figura A18 - Variograma experimental da análise exploratória dos dados atualizados com a amostragem baseada na otimização da soma da variância de blocos transformados em distribuição gaussiana. Cálculo realizado na direção $45^{\circ}$ de azimute. 


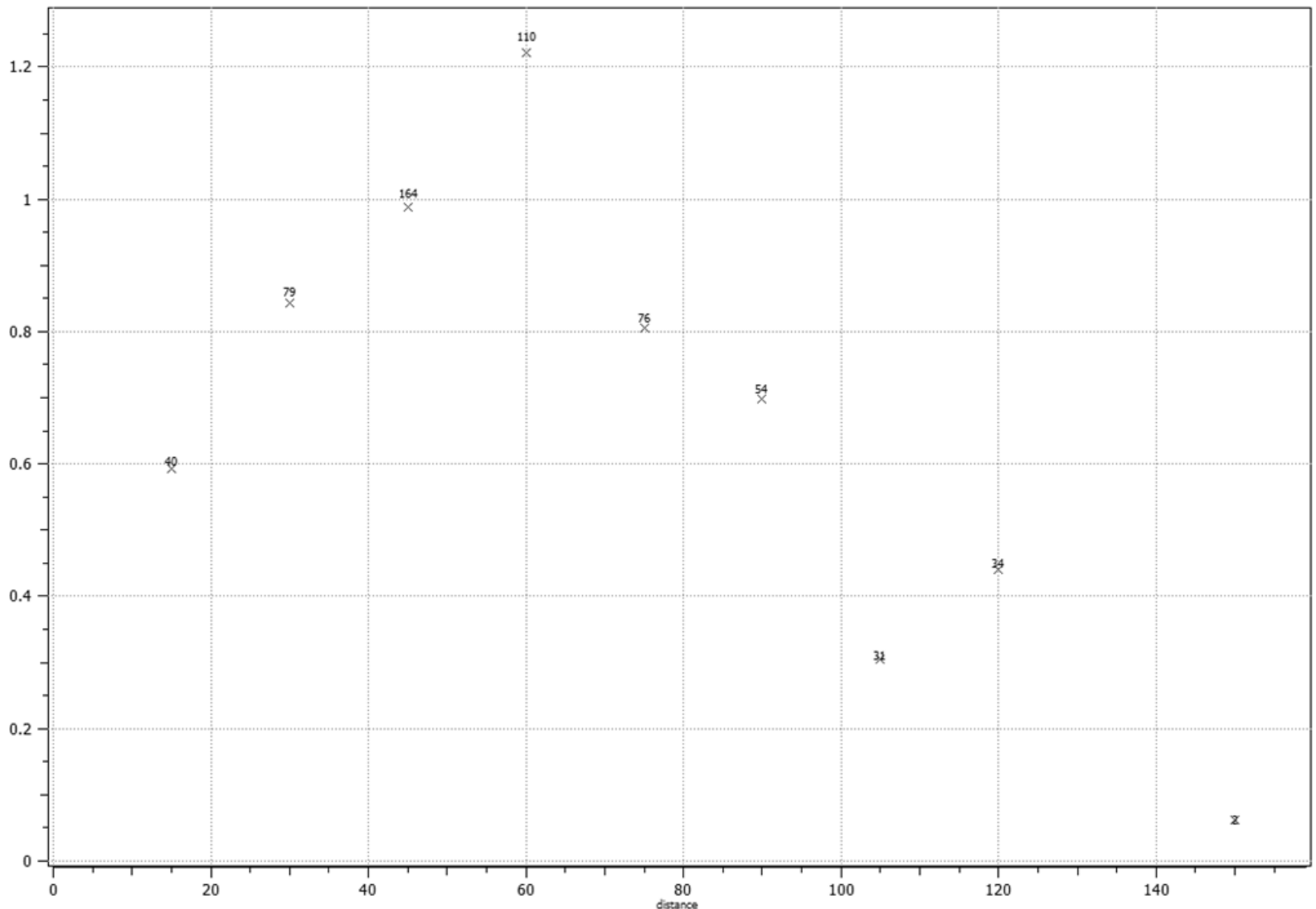

Figura A19 - Variograma experimental da análise exploratória dos dados atualizados com a amostragem baseada na otimização da soma da variância de blocos transformados em distribuição gaussiana. Cálculo realizado na direção $90^{\circ}$ de azimute. 


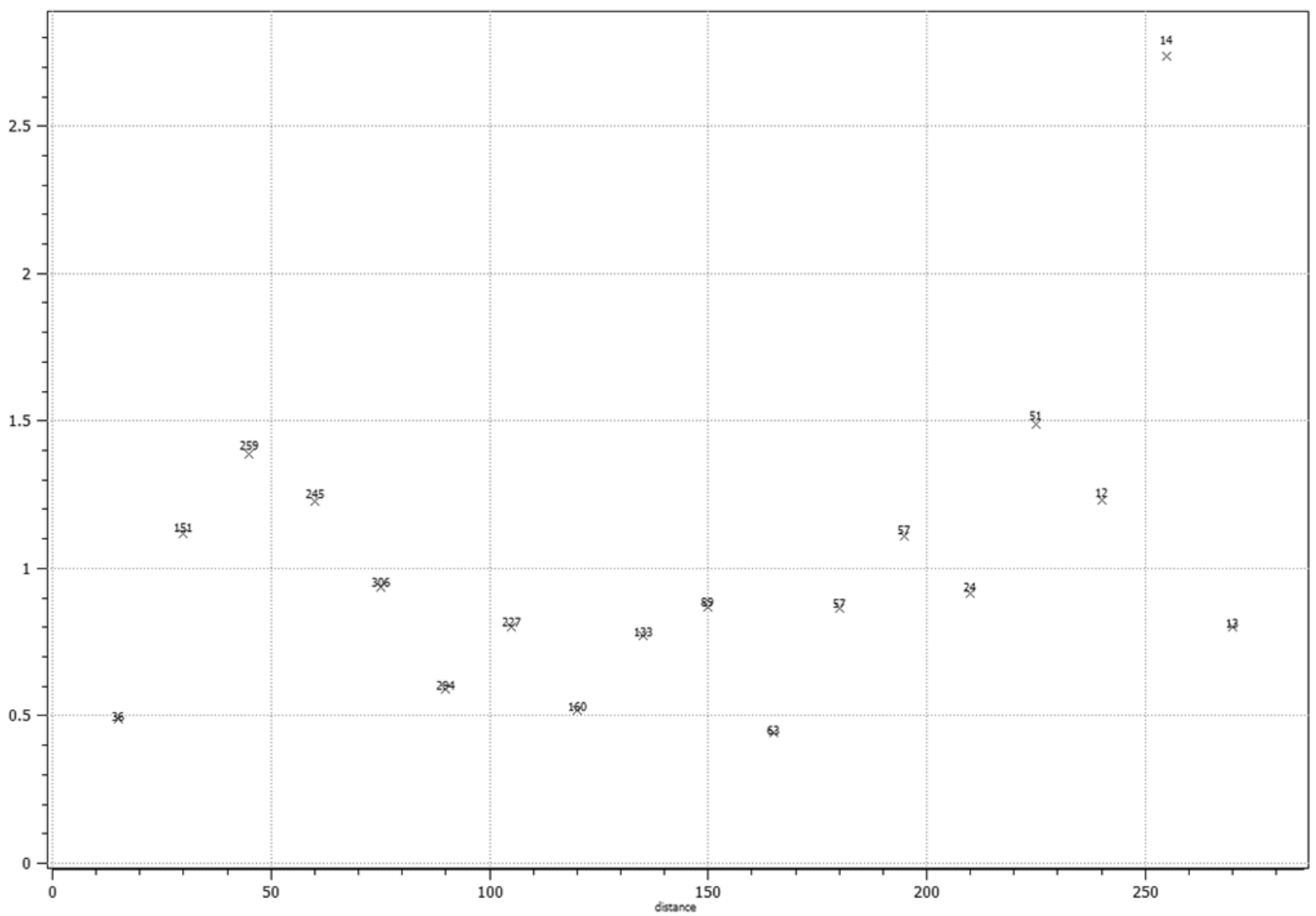

Figura A20 - Variograma experimental da análise exploratória dos dados atualizados com a amostragem baseada na otimização da soma da variância de blocos transformados em distribuição gaussiana. Cálculo realizado na direção $135^{\circ}$ de azimute. 


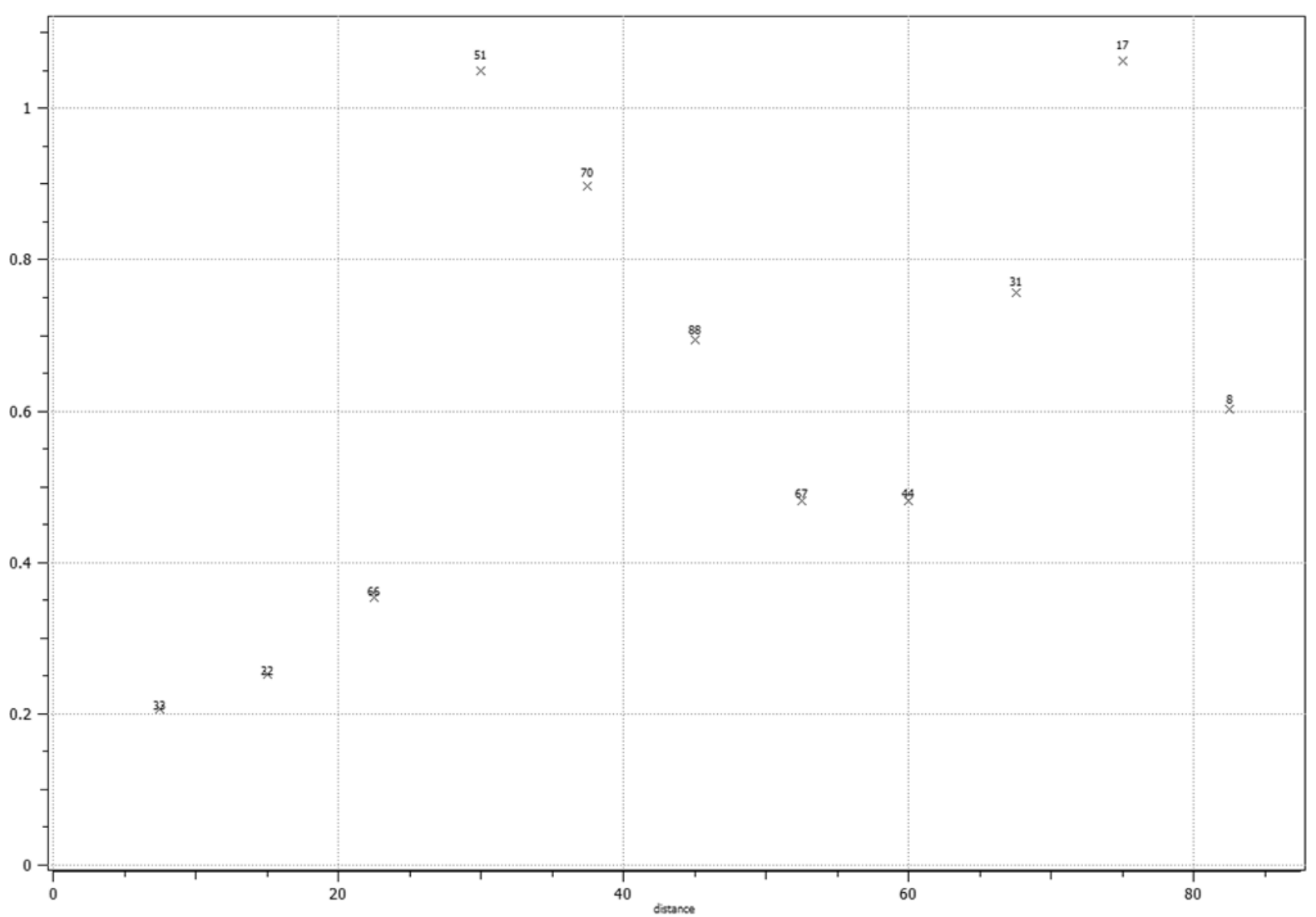

Figura A21 - Variograma experimental da análise exploratória dos dados atualizados com a amostragem baseada na otimização da soma da variância de blocos transformados em distribuição gaussiana. Cálculo realizado na direção $0^{\circ}$ de azimute com $90^{\circ}$ de mergulho. 


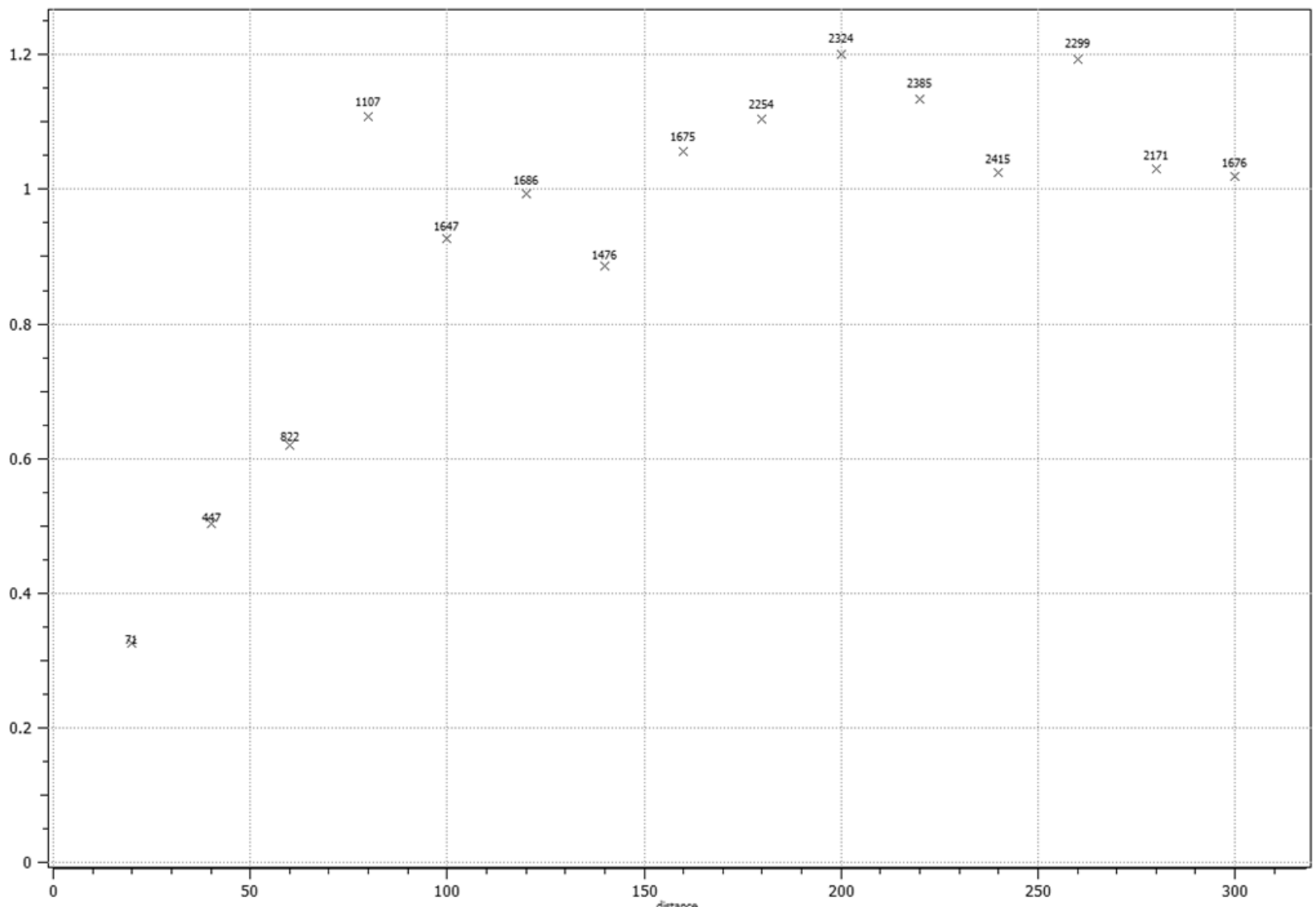

Figura A22 - Variograma experimental da análise exploratória dos dados atualizados com a amostragem baseada na otimização da soma dos coeficientes de variação dos blocos transformados em distribuição gaussiana. Cálculo realizado na direção $0^{\circ}$ de azimute. 


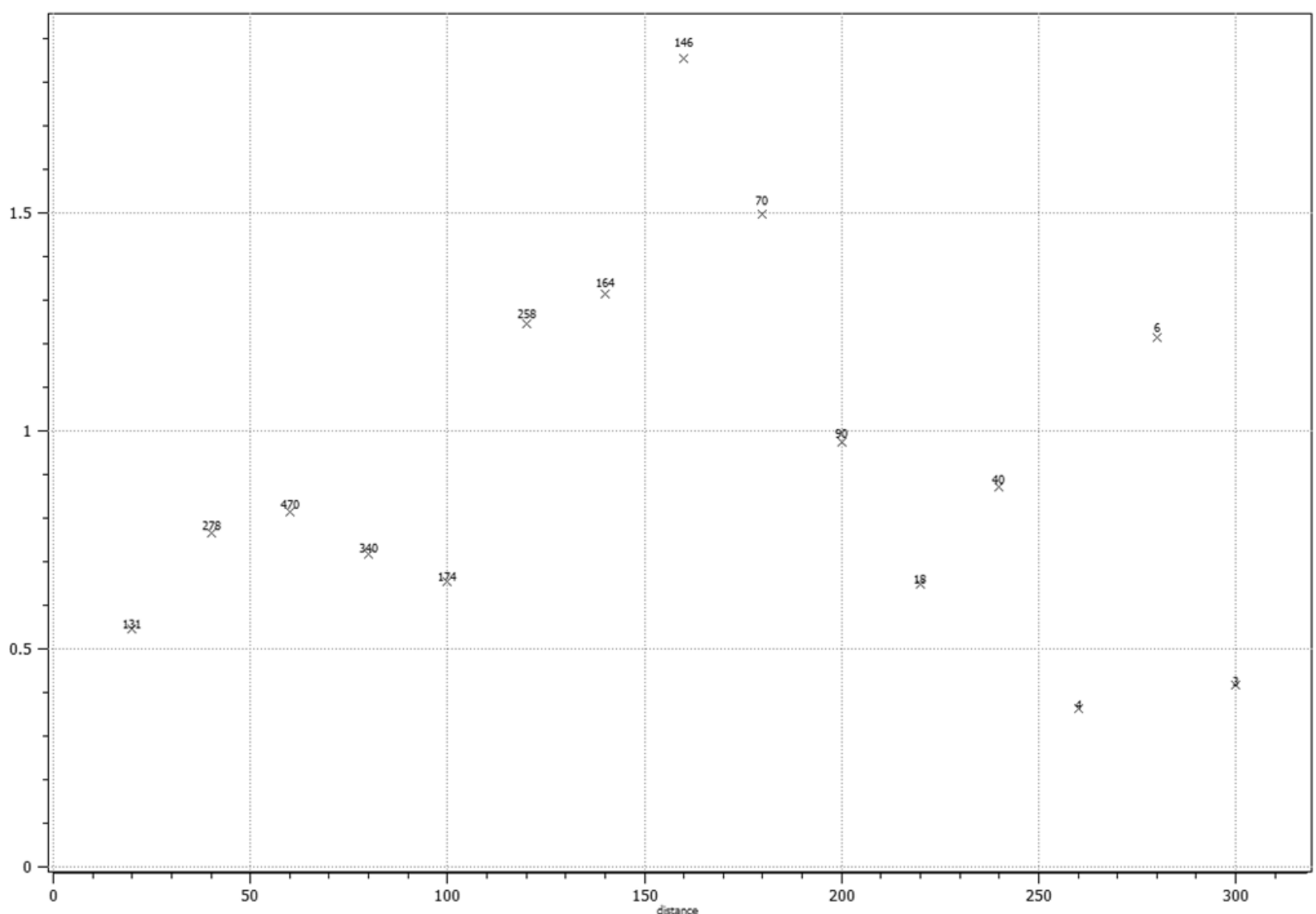

Figura A23 - Variograma experimental da análise exploratória dos dados atualizados com a amostragem baseada na otimização da soma dos coeficientes de variação dos blocos transformados em distribuição gaussiana. Cálculo realizado na direção $45^{\circ}$ de azimute. 


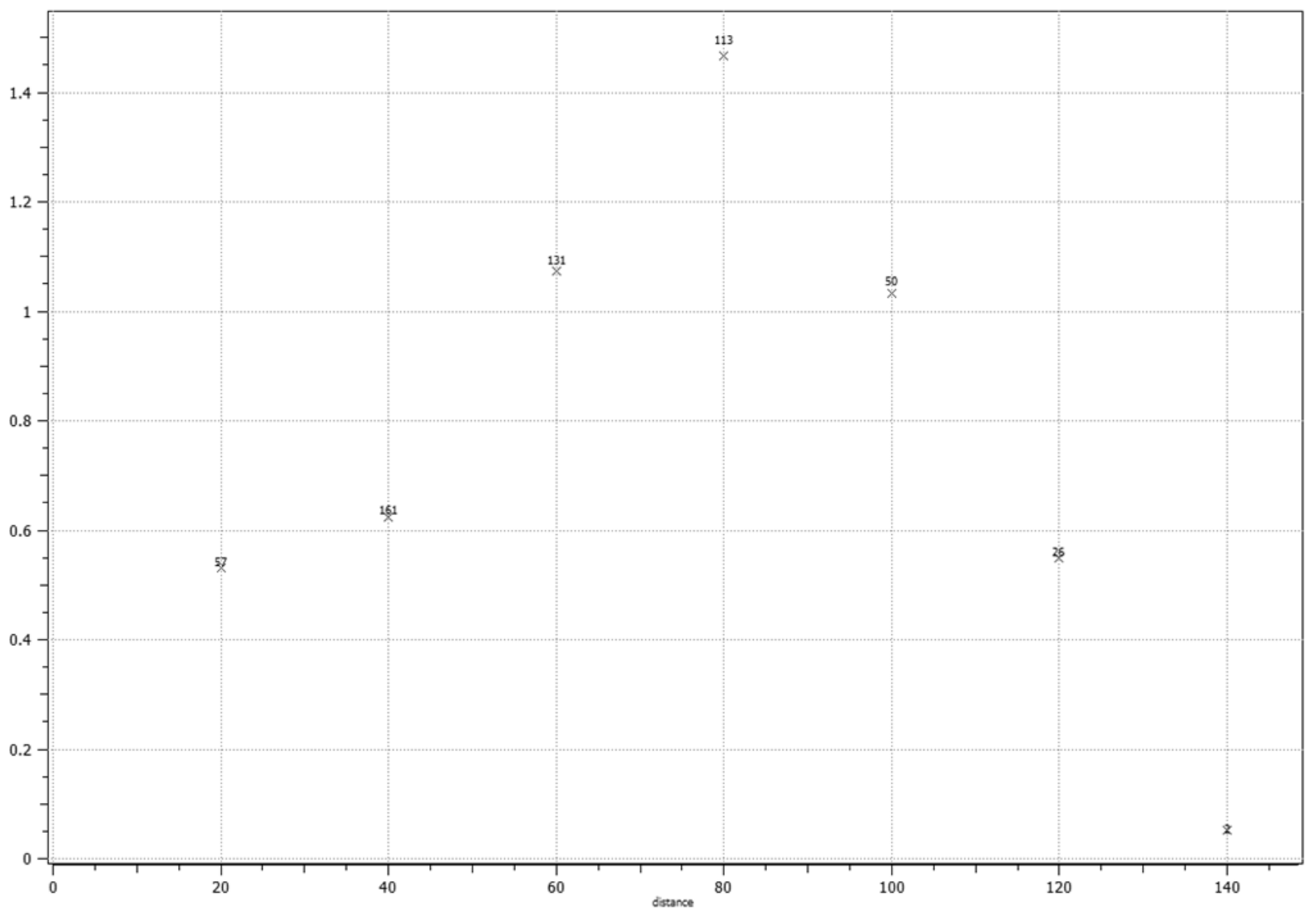

Figura A24 - Variograma experimental da análise exploratória dos dados atualizados com a amostragem baseada na otimização da soma dos coeficientes de variação dos blocos transformados em distribuição gaussiana. Cálculo realizado na direção $90^{\circ}$ de azimute. 


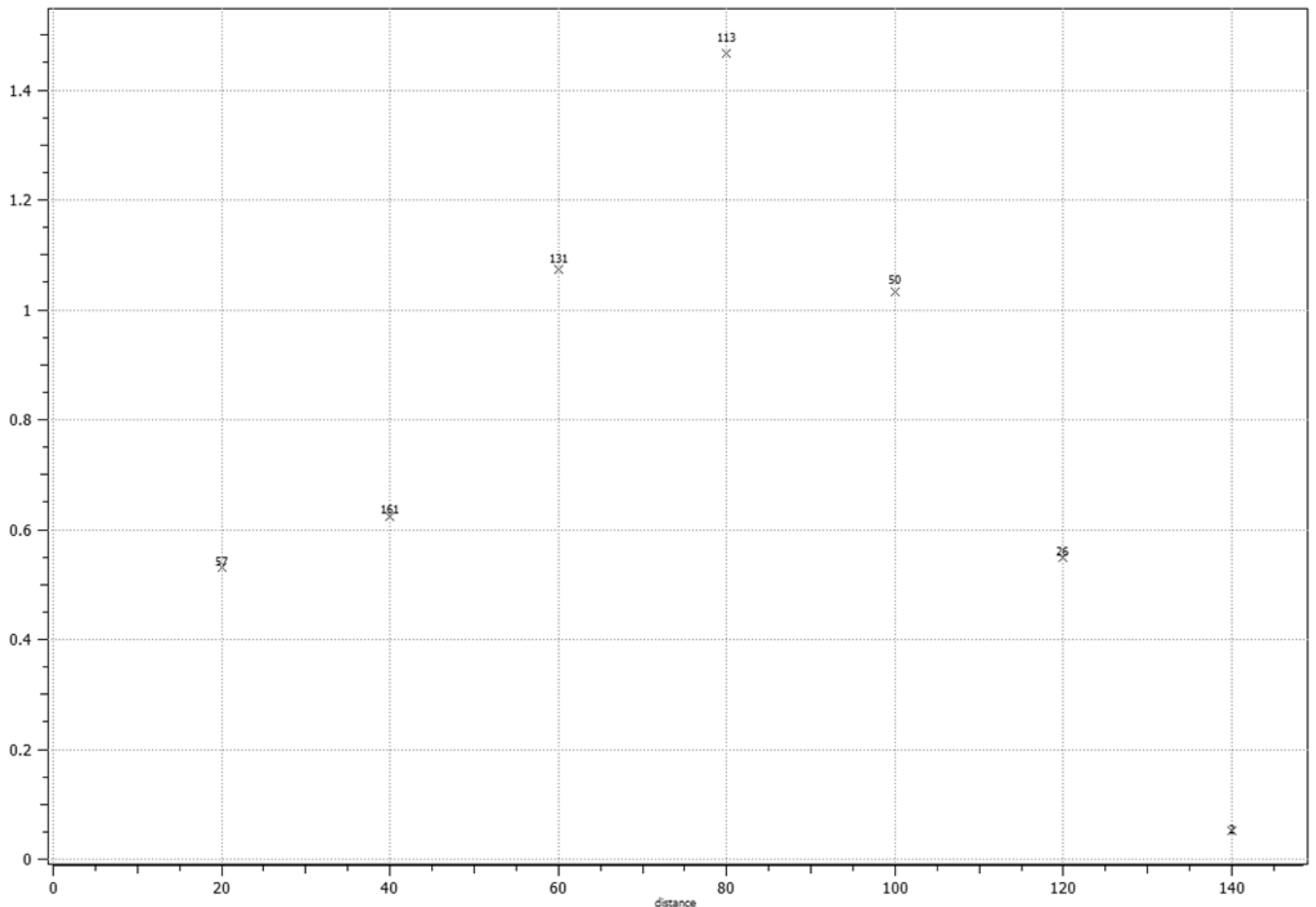

Figura A25 - Variograma experimental da análise exploratória dos dados atualizados com a amostragem baseada na otimização da soma dos coeficientes de variação dos blocos transformados em distribuição gaussiana. Cálculo realizado na direção $90^{\circ}$ de azimute. 


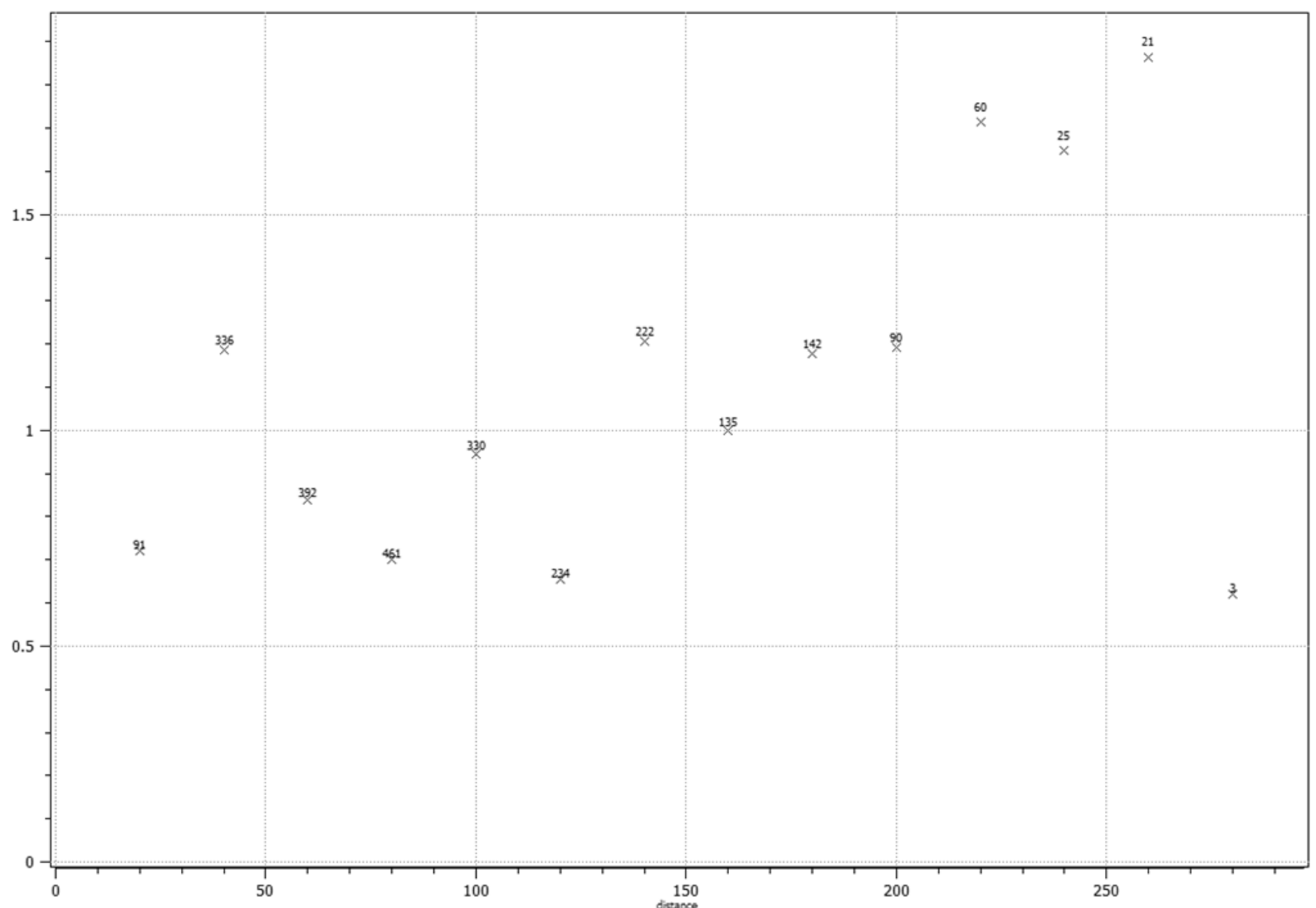

Figura A26 - Variograma experimental da análise exploratória dos dados atualizados com a amostragem baseada na otimização da soma dos coeficientes de variação dos blocos transformados em distribuição gaussiana. Cálculo realizado na direção $135^{\circ}$ de azimute. 


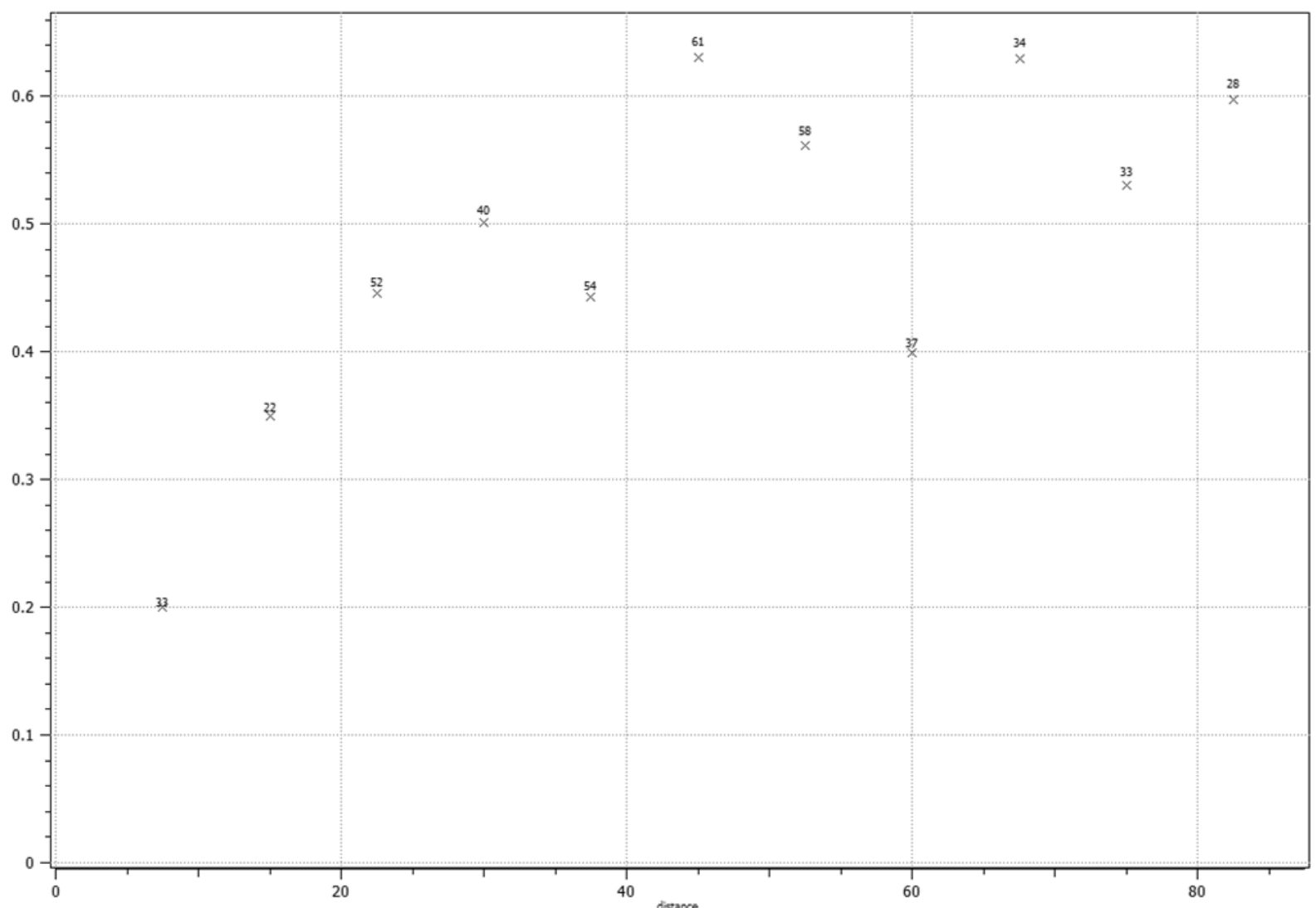

Figura A27- Variograma experimental da análise exploratória dos dados atualizados com a amostragem baseada na otimização da soma dos coeficientes de variação dos blocos transformados em distribuição gaussiana. Cálculo realizado na direção $0^{\circ}$ de azimute e $90^{\circ}$ de mergulho. 